\title{
Mice with gene alterations in the GH and IGF family
}

\author{
Yanrong Qian ${ }^{1} \cdot$ Darlene E. Berryman ${ }^{1,2} \cdot$ Reetobrata Basu $^{1} \cdot$ Edward O. List $^{1} \cdot$ Shigeru Okada ${ }^{1,3}$. \\ Jonathan A. Young ${ }^{1,2}$. Elizabeth A. Jensen ${ }^{1,2,4}$. Stephen R. C. Bell ${ }^{1,2}$. Prateek Kulkarni ${ }^{1,5,6}$. Silvana Duran-Ortiz ${ }^{1}$. \\ Patricia Mora-Criollo ${ }^{1,4}$. Samuel C. Mathes ${ }^{1}$. Alison L. Brittain ${ }^{1,2,6}$. Mat Buchman ${ }^{1,2}$. Emily Davis ${ }^{1,5,6}$. \\ Kevin R. Funk ${ }^{1,5,6}$. Jolie Bogart ${ }^{1,5}$. Diego Ibarra ${ }^{1,7}$. Isaac Mendez-Gibson ${ }^{1,8}$ • Julie Slyby ${ }^{1,5}$. Joseph Terry ${ }^{1,5}$. \\ John J. Kopchick ${ }^{1,2}$ (1)
}

Accepted: 21 October 2021 / Published online: 19 November 2021

(c) The Author(s), under exclusive licence to Springer Science+Business Media, LLC, part of Springer Nature 2021

\begin{abstract}
Much of our understanding of GH's action stems from animal models and the generation and characterization of genetically altered or modified mice. Manipulation of genes in the GH/IGF1 family in animals started in 1982 when the first GH transgenic mice were produced. Since then, multiple laboratories have altered mouse DNA to globally disrupt $G h, G h r$, and other genes upstream or downstream of GH or its receptor. The ability to stay current with the various genetically manipulated mouse lines within the realm of GH/IGF1 research has been daunting. As such, this review attempts to consolidate and summarize the literature related to the initial characterization of many of the known gene-manipulated mice relating to the actions of GH, PRL and IGF1. We have organized the mouse lines by modifications made to constituents of the GH/IGF1 family either upstream or downstream of GHR or to the GHR itself. Available data on the effect of altered gene expression on growth, GH/IGF1 levels, body composition, reproduction, diabetes, metabolism, cancer, and aging are summarized. For the ease of finding this information, key words are highlighted in bold throughout the main text for each mouse line and this information is summarized in Tables 1, 2, 3 and 4. Most importantly, the collective data derived from and reported for these mice have enhanced our understanding of GH action.
\end{abstract}

Keywords Growth hormone $\cdot$ Prolactin $\cdot$ Insulin-like growth factor $1 \cdot$ Transgenic mice $\cdot$ Knockout mice $\cdot$ Metabolism . Cancer · Aging

John J. Kopchick

kopchick@ohio.edu

1 Edison Biotechnology Institute, Ohio University, Athens, $\mathrm{OH}, \mathrm{USA}$

2 Department of Biomedical Sciences, Heritage College of Osteopathic Medicine, Ohio University, Athens, OH, USA

3 Department of Pediatrics, Heritage College of Osteopathic Medicine, Ohio University, Athens, OH, USA

4 Translational Biomedical Sciences Doctoral Program, Ohio University, Athens, OH, USA

5 Department of Biological Sciences, College of Arts and Sciences, Ohio University, Athens, OH, USA

6 Molecular and Cellular Biology Program, Ohio University, Athens, OH, USA

7 Department of Chemistry and Biochemistry, College of Arts and Sciences, Ohio University, Athens, OH, USA

8 College of Health Sciences and Professions, Ohio University, Athens, OH, USA

\section{Introduction}

Growth hormone (GH) helps regulate and coordinate growth and other physiological processes, including metabolism, fluid balance, immunity, and aging. The investigation of GH's actions has an extensive history. The growth-promoting activity of GH was recognized in 1921 when chronic administration of extracts from bovine pituitary glands resulted in enhanced weight gain when injected into rats $[1,2]$. Then in 1936, Houssay demonstrated both the diabetogenic activity of anterior pituitary extracts and the decreased severity of diabetes in anterior-hypophysectomized dogs [3]. The protein responsible, GH, was first purified from bovine (b) pituitary extracts in 1944 [4]. Human (h) $\mathrm{GH}$ was purified in 1956 from cadaver pituitary glands [5], and its efficacy was established in the treatment of pediatric GH-deficient patients [6]. Purified hGH was approved for use in the US in 1958 and became the standard treatment 


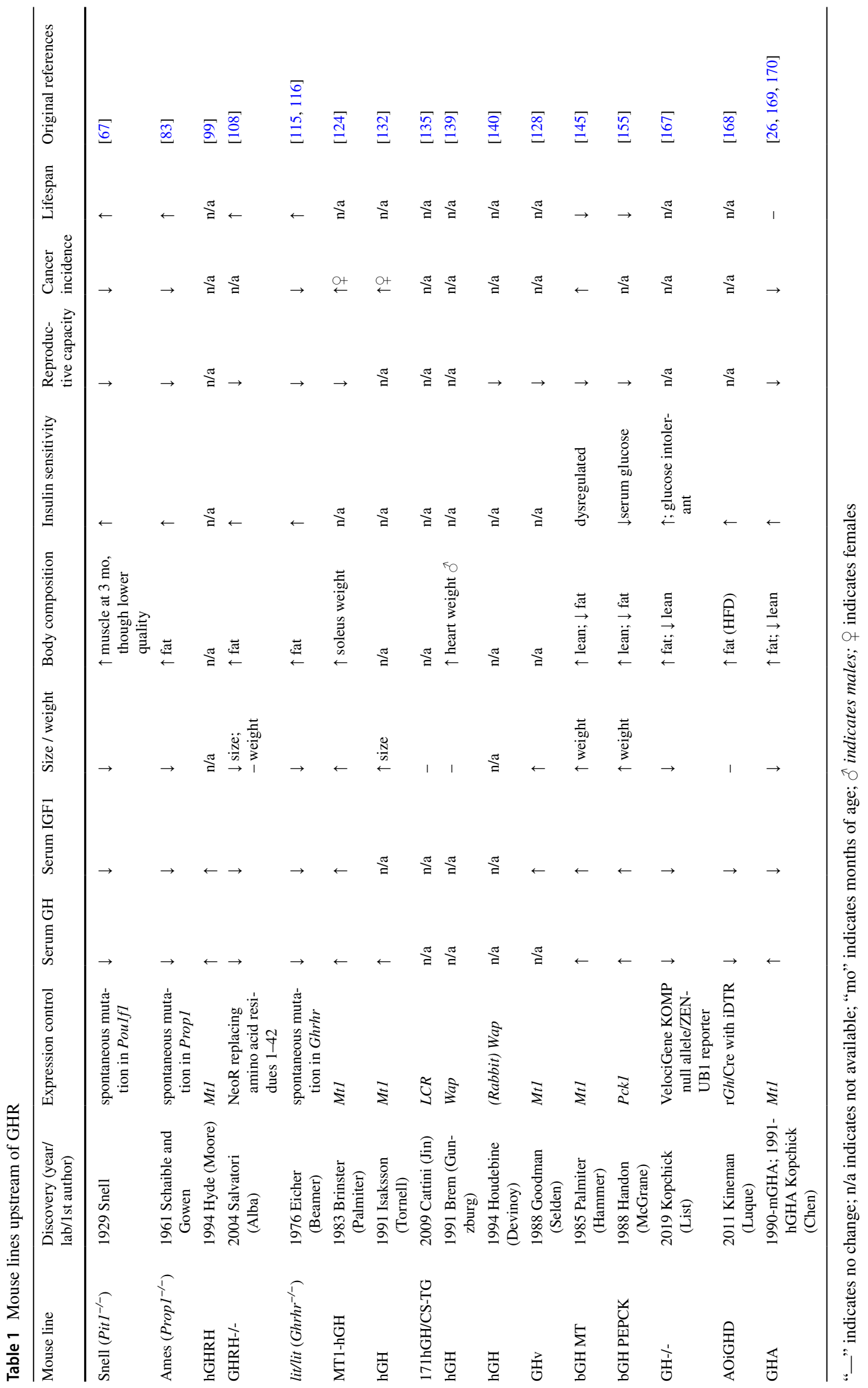


until recombinant human GH was approved for use in 1986 [7-9]. The interesting history of GH discoveries, both basic and clinical, has been recently reviewed $[2,10]$.

In humans, a GH-related gene cluster is located in a $78 \mathrm{k}$ base pair portion of chromosome 17 [11] and contains five tandemly linked GH-related genes, in which one $(G H I)$ present at the 5' end of the cluster is expressed in the anterior pituitary. Three of the other genes are expressed in the placenta, and one is a non-expressed pseudogene. $G H 1$ encodes a $22 \mathrm{kDa}$ protein consisting of 191 amino acids following cleavage of the 26-amino acid secretory signal peptide. It contains four antiparallel $\alpha$ helices and has significant structural homology with prolactin (PRL) and placental lactogen [12].

GH exerts its actions by binding to a specific cell surface receptor (R). The hGH receptor (GHR) gene is located on chromosome 5, encodes a single-chain transmembrane glycoprotein composed of 638 amino acids, and is a member of the type I cytokine receptor family. After removal of its 18-amino acid secretory signal peptide, hGHR is composed of a N-terminal, 246-amino acid extracellular domain; a 24-amino acid transmembrane domain; and a C-terminal, 350 -amino acid intracellular domain [13, 14]. The extracellular domain contains three disulfide bonds; two of which are essential for ligand binding [15]. The cytoplasmic domain contains two highly conserved sequences among cytokine receptors, Box 1 and Box 2. Box 1 contains nine amino acids with proline-rich and hydrophobic residues and acts as a binding site for a signal-transducing Janus kinase 2 (JAK2). The elegant work of Waters et al. provided a mechanistic model for this initiation of GH-GHR-induced intracellular signal transduction via JAK2 activation $[14,16]$. That is, GHRs exist as preformed dimers in the absence of ligands [17]. Two JAK2 molecules, each bound to a GHR, are closely located; however, trans-interaction of the kinase domain of one JAK2 molecule and the pseudokinase domain of the other JAK2 inhibit each other, and the JAK2 stays inactive. Upon GH binding, the relative position of GHRs changes, resulting in JAK2 activation [16]. Activated JAK2 further phosphorylates multiple tyrosine residues on the intracellular domain of the GHR [18-20], which serves as binding sites for proteins possessing $\mathrm{SH} 2$ domains. The most common and best described of the GH induced intracellular signaling pathways involves signal transducer and activator of transcription (STAT) 5a and 5b molecules. STAT5 molecules are recruited to the phosphotyrosine residues on the GHR and become activated through tyrosine-phosphorylation by JAK2. Tyrosine phosphorylation of STAT molecules results in the dissociation of the STAT molecules from the receptor followed by homo- or heterodimerization and translocation to the nucleus, where they regulate the expression of GH target genes [21].
One of the negative regulators of the JAK-STAT signaling pathway is the suppressor of the cytokine signaling (SOCS) protein family. SOCS1-3 and cytokine-inducible $\mathrm{SH} 2$-containing protein (CISH) are implicated in the negative regulation of GH action, of which SOCS2 appears to play a major role [22]. All SOCS proteins are able to direct the ubiquitination of $\mathrm{SH} 2$ and $\mathrm{N}$-terminal bound substrates for degradation [23]. Additionally, SOCS3 has been shown to directly inhibit the enzyme activity of JAK2 by its kinaseinhibitory region [24].

Manipulation of GH genes in animals started in 1982 when the first GH transgenic mouse was produced by Palmiter et al. using a fusion gene consisting of the promoter/ enhancer of the mouse metallothionein-1 (Mt1) gene and the rat (r) $G$ gene [25]. The fusion gene was microinjected into the pronuclei of fertilized mouse eggs and gave rise to giant mice, featured on the cover of a 1982 issue of Nature [25]. Usually, mice generated in this manner (microinjection of cloned DNA in fertilized mouse eggs) are termed hemizygous, signifying random incorporation of the injected DNA into the mouse genome. Breeding of hemizygous mice can result in new mouse strains containing two or more copies/ alleles of the injected DNA.

Our group has employed a structure/function experimental design using transgenic mice for the past three decades. During this time, we discovered that substitution of one amino acid, Gly119 in bGH (Gly120 in hGH), by several amino acids (except Ala) resulted in a competitive antagonist of the GHR [26-28]. Expression of this GHR antagonist in vivo resulted in dwarf mice [26]. At that time, we predicted that GH interacted with a secondary target protein to explain the mechanism of GHR antagonism [26]. Later, Cunningham et al. demonstrated that, indeed, one GH molecule interacted with two GHR molecules to initiate signal transduction [29].

We and others have also employed gene disruption, or 'knockout' (KO) technology, to globally disrupt $G h, G h r$, or other genes upstream or downstream of GH or its receptor. Our group has focused on Ghr gene disruptions. Ghr-/- (also called GHRKO or GHR-/-) mice are dwarf and obese, with low insulin-like growth factor 1 (IGF1) and high GH levels [30]. Importantly, since the mice lack functional GHRs, they are GH insensitive or resistant and, thus, more insulin sensitive than wild-type (WT) littermates [31]. They are also resistant to high-fat diet (HFD)-induced type 2 diabetes (T2D) [32] and cancer [33-36]. Surprisingly, GHR-/- mice have a longer lifespan than WT mice [37]. One GHR-/mouse lived a week short of five years and set the standard for the Methuselah Mouse Prize as the world's longest-lived laboratory mouse (http://reason.com/archives/2004/08/18/ methuselah-mouse). Since then, our group, as well as others, have developed many tissue-specific GHRKO mice, which will be described below [38-65]. 


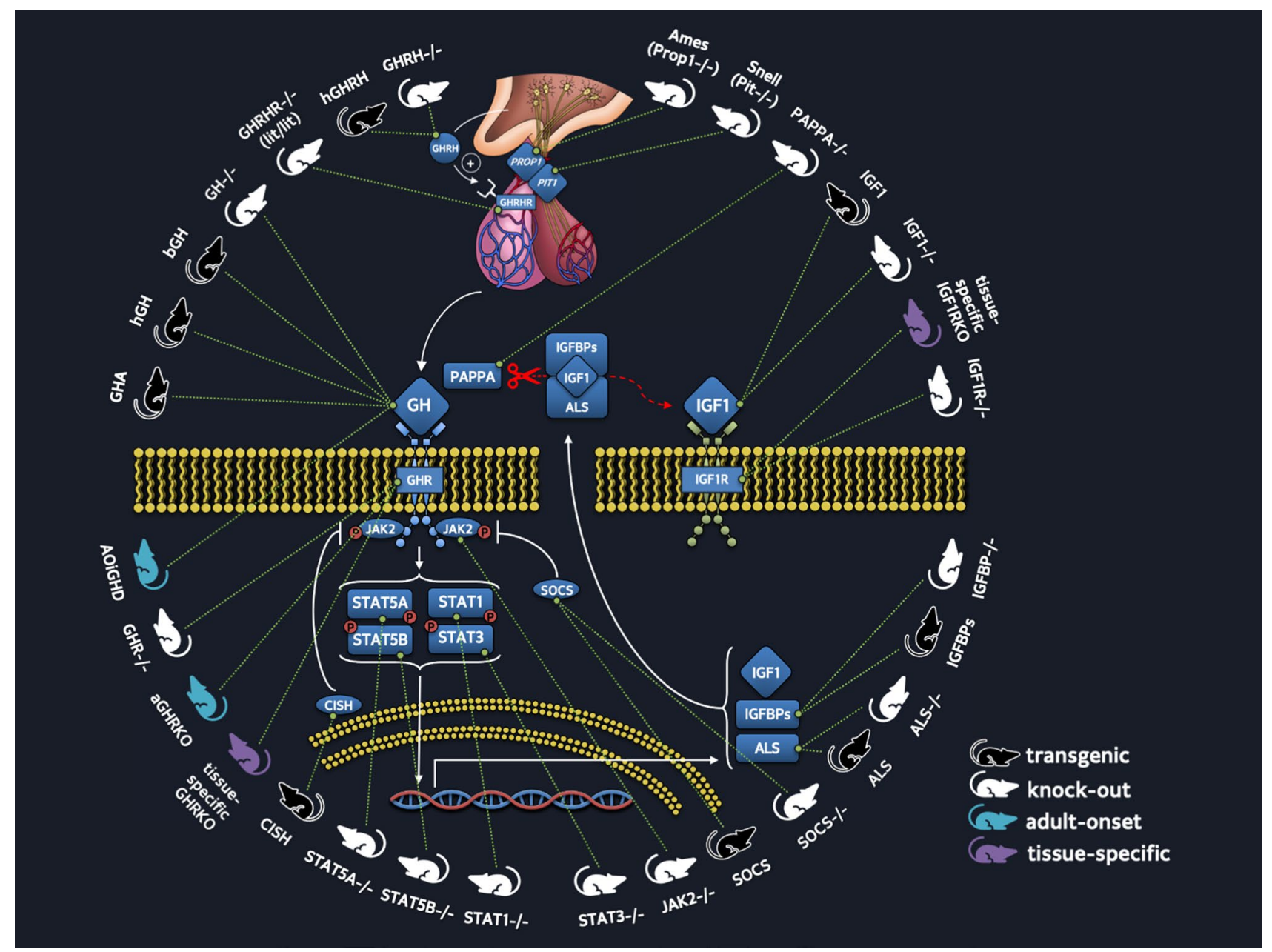

Fig. 1 Summary of transgenic and knockout mouse lines with altered GH/IGF action. The diagram shows proteins involved in the regulation of $\mathrm{GH}$ secretion, $\mathrm{GH}$ induced intracellular signaling, and the production of IGF1, ALS, IGFBP3. The different mouse colors

Internally, the task of 'keeping up' with the various genetically manipulated mouse lines within the GH/IGF1 family has been daunting. Thus, in this review, we have critically reviewed the literature related to the initial characterization of many natural and gene-manipulated mice related to the actions of GH, prolactin (PRL), and IGF1. We acknowledge that additional phenotypic/biochemical/endocrine data may exist for these mouse lines but consider this beyond the scope of this review.

Below, we have organized the mouse lines by modifications made to constituents of the GH/IGF family either upstream or downstream of GHR or to the GHR itself. Throughout this review, we define global homozygous null (-/-) mice as knockouts (KOs) and heterozygotes as +/- . For all mouse lines discussed, we recognize the individual(s) who generated the mice along with the date and laboratory name. Mice with 'upstream' modifications include represent mice with a transgene overexpressed (black), mice with genes that have been knocked out globally (white), adult-onset knockouts (blue) or tissue-specific knockouts (purple) (Color figurre online)

$\mathrm{GH}$ transgenic, GH-/-, GH releasing hormone (GHRH) transgenic, GHRH-/-, GHRHR-/-, GHR antagonist, PRL/-, PRLR-/-, and PRLR antagonist transgenic mouse lines. GHR modifications include global GHRKO (GHR-/-), various tissue-specific GHRKOs, and temporal GHRKOs. Modifications downstream of GHR include those made to several signal transduction molecules including JAK2 and STAT5, IGF1 and IGF1R, IGF binding proteins (BPs), ALS and PAPP-A transgenic, and KOs. Importantly, available data on the effect of altered gene expression on growth, GH/IGF1 levels, body composition, reproduction, diabetes, metabolism, cancer, and aging are summarized for each mouse line and in Tables 1, 2, 3, and 4. For ease of finding this information, key words are shown in bold throughout the main text. Also, to aid the reader, we have divided each section into "origin" and "phenotype". To provide additional context, Fig. 1 illustrates the mouse lines with alteration in 
the GH/IGF family and relevant upstream and downstream constituents referred to in this review. Figure 2 compares several transgenic and null mouse lines related to $\mathrm{GH}$ action for adiposity, metabolism, cancer incidence, and longevity. Figure 3 provides a timeline of when the mouse lines were generated. Overall, we hope this review will provide a comprehensive reference to investigators by collating numerous results and references relating to specific mouse lines within the GH/IGF1 family. Importantly, the collective data derived and reported for these mice have enhanced our understanding of GH action.

\section{Mouse lines upstream of GHR}

Circulating GH is produced by the acidophilic somatotroph cells of the anterior pituitary gland. The transcription factors Prophet of Pit-1 (PROP1, gene product of Prop1), pituitary-specific transcription factor 1 (PIT1; gene product of Poulf1), and GH releasing hormone receptor (Ghrhr) are sequentially expressed in the developing pituitary and are together responsible for the regulation of GH production. PROP1 is critical for both the development of anterior pituitary cell types (somatotrophs, gonadotrophs, lactotrophs, thyrotropes) and in inducing PIT1 expression. PIT1 regulates further differentiation of the pituitary cell lineages, as well as the expression of the Ghrhr gene, which in turn, promotes the clonal expansion of these cells [66]. Pituitary GH production is positively regulated by hypothalamic GHRH and gastric ghrelin, and negatively by hypothalamic somatostatin
(SRIF) and endocrine IGF1. Each of these proteins binds to its cognate receptors - GHRH receptor (GHRHR), ghrelin receptor / GH secretagogue receptor (GHS-R), SRIF receptor subtypes, and IGF1R, in order to elicit their actions [66]. Mouse lines discovered or engineered to focus on each of these regulatory nodes of $\mathrm{GH}$ production have allowed us to understand developmental regulation and downstream physiological effects in a new light. Each will be discussed briefly below and is summarized in Table 1.

\section{Snell (Pit1-/-) and Ames (Prop1-/-)}

The earliest mouse lines discovered to have a somatotrophic deficiency in GH production resulting in distinctive phenotypes were Snell and Ames mice. These mice have been at the center of hundreds of published research reports since their discovery and are essential in the current understanding of the action of GH.

\section{Snell dwarf mice (dw/dw; Pit1-/-; Pou1f1-/-)}

Origin In 1921, George Snell (Nobel Prize, 1980) observed a new recessive Mendelian genotype of dwarfism in his mouse stock [67]. This Snell dwarf mouse (also termed $d w /$ $d w$ or Pit1-/- or Poulf1-/-) represented the second case of hereditary dwarfism in rodents, following a previous report in guinea pigs [67].

Phenotype Snell reported the length of this mature dwarf mouse reaches that of a 16-17-day-old 'normal' mouse. The Snell dwarf mice also weigh only one fourth of their

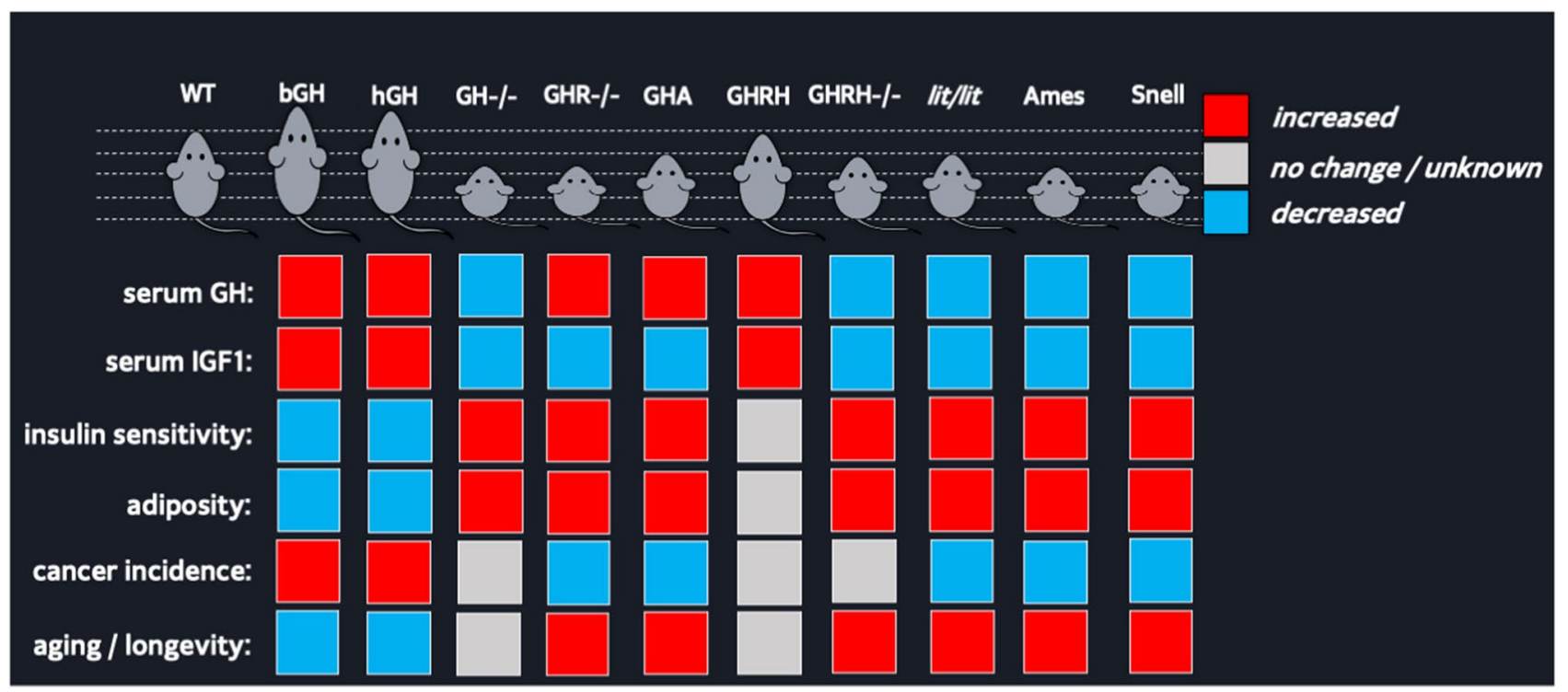

Fig. 2 Phenotypic comparison among several transgenic and knockout mouse lines with altered GH action. The mice compared are depicted at the top of the figure along with their relative size and the altered genes. The red box indicates increased growth, the blue box indicates decreased growth, and the grey box indicates no change in growth relative to WT controls (Color figure online) 
Fig. 3 Production timeline of GH/IGF1 mouse lines. Before 1980 , only three mouse lines related to the GH/IGF family had been discovered (Snell,

Ames and lit/lit mice). Through transgenic and 'knock-out' technology, generation of different mouse lines with altered GH/ IGF family signaling increased. The 1990 s were mainly dedicated to transgenic and global knockouts associated with altered GHR, IGF1, PRL and JAK/STAT. The first tissuespecific mouse line was generated in 1999, foretelling more than two decades of additional conditional GHR and IGF1 knockouts. To date, there are 137 mouse lines dedicated to exploring the effects of the $\mathrm{GH} /$ IGF family; all these mouse lines contribute to a deeper understanding of the impact of GH and IGF1 on health and disease. $T g$ transgenic mouse lines, $K O$ knockout mouse lines

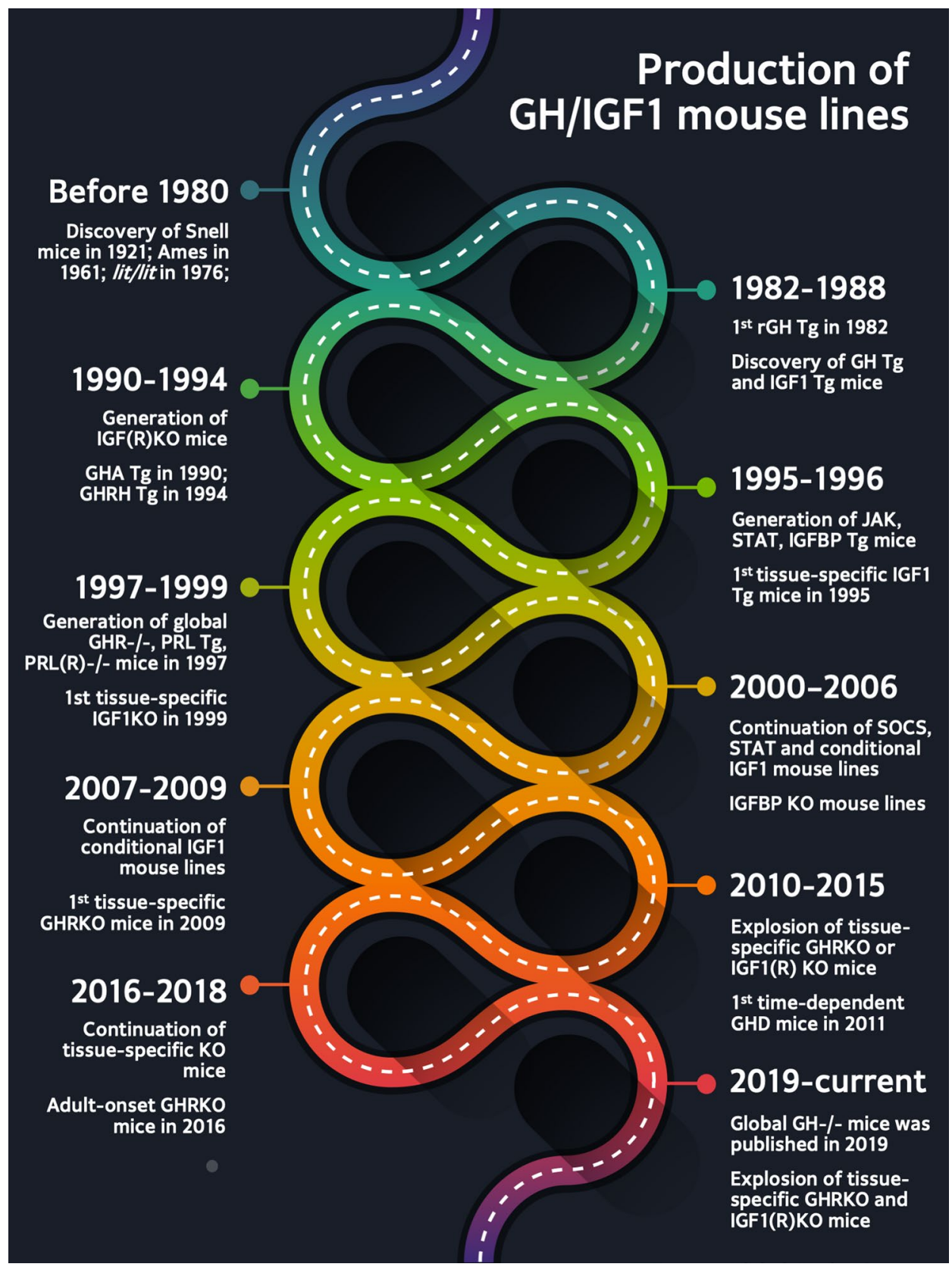

wild-type counterparts [67]. Snell mice have since been part of numerous studies worldwide and are characterized by pituitary hypoplasia, with a combined deficiency of $\mathbf{G H}$, PRL, and thyroid-stimulating hormone (TSH), which later was found to be due to a spontaneous point mutation in the Poulf1 gene [68]. This mutation abrogates the interaction of the PIT1, a POU family transcription factor, with its target transcriptional regulatory sequence. This, in turn, leads to improper formation and dysfunction of the pituitary somatotrophs, lactotrophs, and thyrotrophs [68], as well as nearly undetectable levels of serum IGF1 [69]. The severely suppressed growth of Snell dwarf mice [70] is partially restored following thyroxine and GH replacement therapy [71].
A 'diabetogenic' effect of $\mathrm{GH}$ has been known since 1930s [72]. Subsequent studies have revealed that GH induces insulin resistance primarily in peripheral tissues [73] via (i) elevated free fatty acid (FFA) from increased lipolysis leading to increase of diacylglycerol and ceramides and suppression of IRS1 activation in liver and skeletal muscle; (ii) elevated FFA induced increase of acetyl-CoA, leading to increased gluconeogenesis in liver and kidney; (iii) upregulation of PI3K regulatory p85a subunit in mouse white adipose tissues (AT); and (iv) upregulated SOCS expression [74]. Insulin resistance is an important metabolic hallmark in patients with acromegaly [75] while congenital GH insensitivity in Laron Syndrome (LS) individuals is associated 


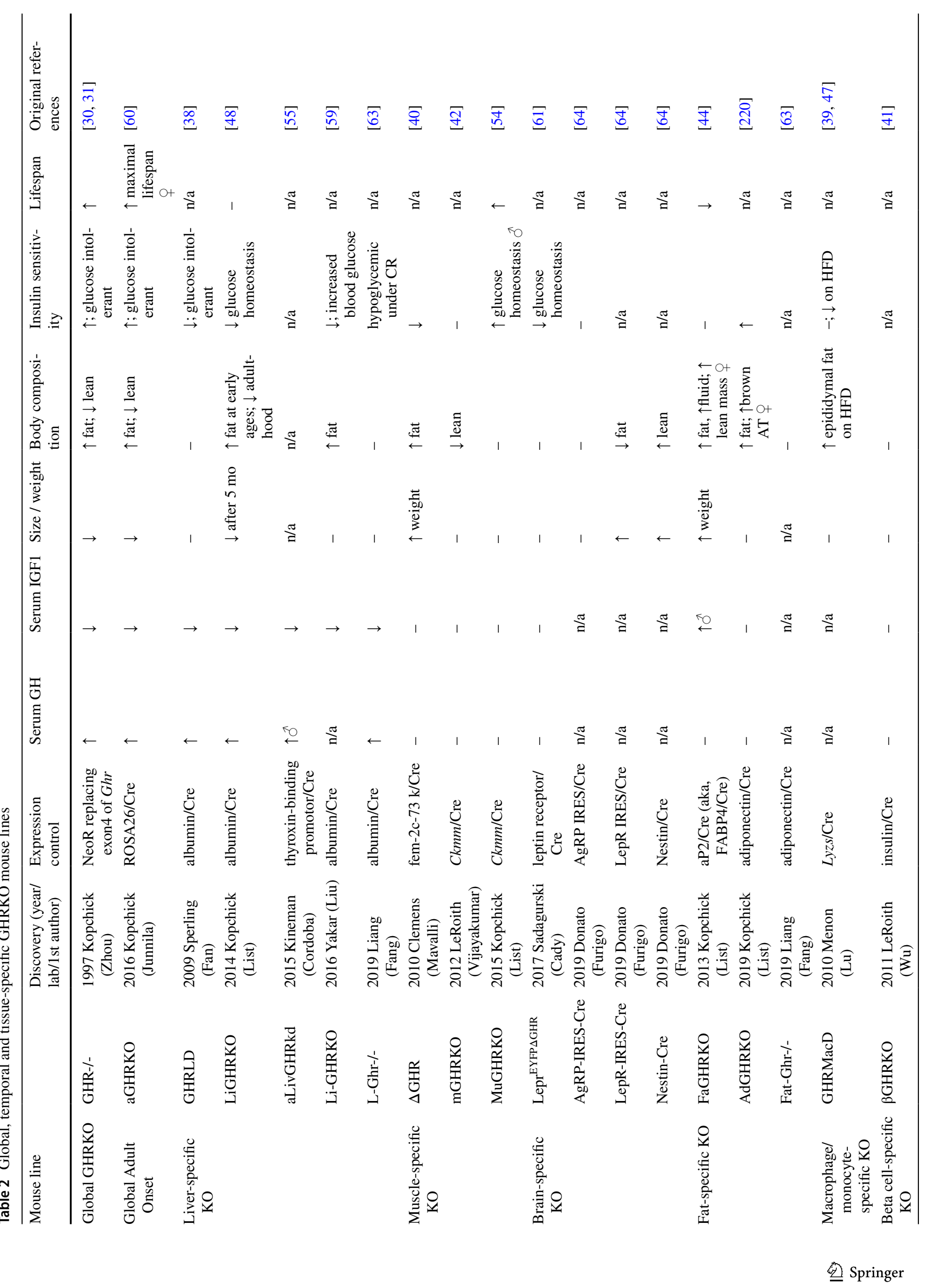




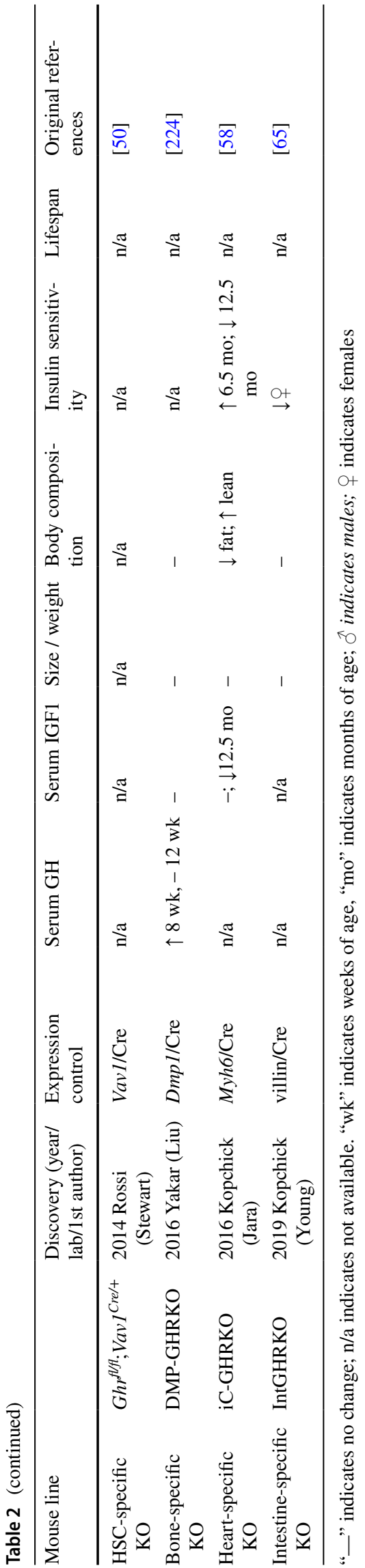

with improved insulin sensitivity [76]. In agreement, GHdeficient Snell mice display a low utilization of circulating glucose, reduced serum insulin levels, and increased insulin sensitivity, as well as decreased free radical-induced damage (lower protein carbonyl content) [77].

Snell mice show an increase in lifespan compared to WT mice, with a $50 \%$ and $29 \%$ increase in males and females, respectively $[52,70]$ and are protected from a number of age-related pathophysiologies, including neurological decline [78], collagen denaturation [70], cataract development, glomerular damage and cancer [79]. However, these dwarf mice have defects in hearing, musculature, immunity, and reproduction. At three months of age, Snell mice have more muscle mass as compared to WT but also a compromised muscle quality and poor fatigue recovery [80]. Defects in reproductive capacity of Snell mice include sterility and delayed testicular growth [81]. Hormone replacement $(\mathrm{GH}+$ thyroxine $+\mathrm{TSH})$ restores fertility in male mice but not in females [71]. Congenital deafness due to a lack of TSH is partially rescued in these mice by thyroid hormone treatment [82]. Overall, results from the Snell mouse were the first to strongly implicate GH in lifespan determination.

\section{Ames mice (Prop1-/-)}

Origin The Ames mouse was first reported in 1961 by Schaible and Gowen [83]. These mice have a spontaneous recessive mutation in the Propl gene, necessary for expression of PIT1, which results in the lack of somatotrophs, lactotrophs, and thyrotrophs similar to that seen in Snell mice.

Phenotype Ames mice have a severe lack of GH, PRL, and TSH, and very low circulating IGF1 [84]. Ames mice are small with a low body weight [85] and are one-third the body size of WT mice. Although Ames mice have increased adiposity, they exhibit lower circulating blood glucose and enhanced insulin sensitivity due to the lack of GH's diabetogenic effect [86, 87]. These dwarf mice are protected from HFD-induced insulin resistance unlike agematched WT mice [88]. Additional distinct physiological characteristics of Ames mice include significantly higher brown AT [89], lower resting core body temperature [90], and a reduced senescent cell burden in white AT [91]. Similar to Snell mice, Ames mice are also markedly resistant to standard oxidative stress inducers like paraquat and diaquat, even at older ages [92]. Moreover, Ames dwarf mice have a significantly lower incidence of fatal neoplasms, including lung adenocarcinoma [93]. Similar to Snell mice, Ames mice also exhibit a markedly increased lifespan, with males living an average of $\sim 50 \%$ longer and females living $>60 \%$ longer than their WT littermates [94, 95]. Interestingly, a further extension of lifespan is observed in these mice when subjected to caloric restriction (CR), which indicates that the anti-aging effects exhibited via CR and the Propl gene 


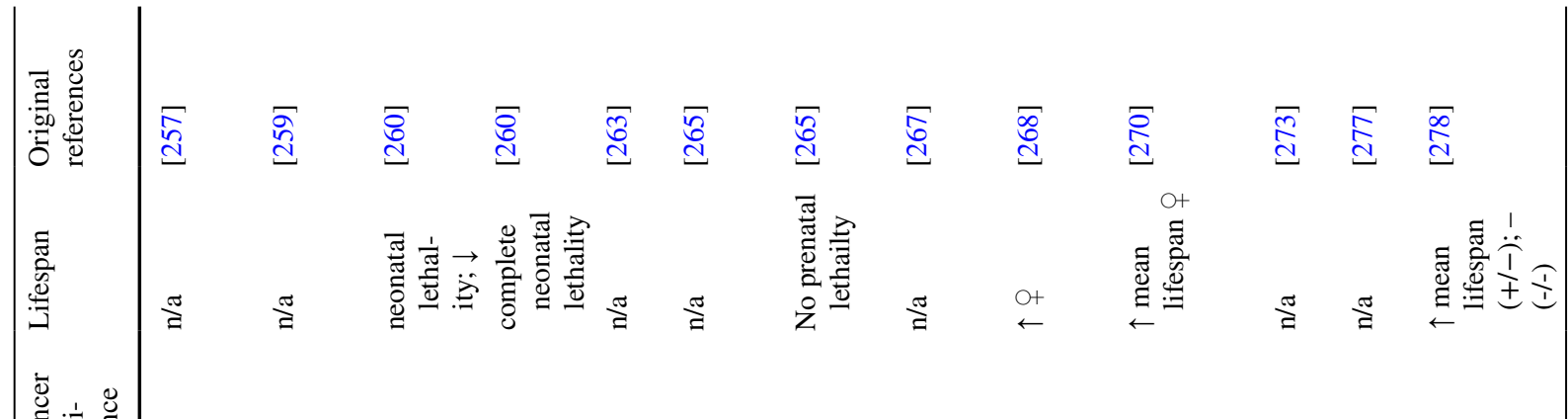

$$
\begin{aligned}
& \text { U. }
\end{aligned}
$$

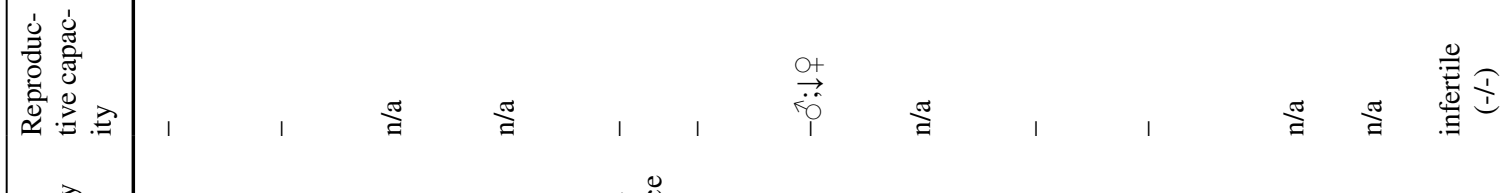

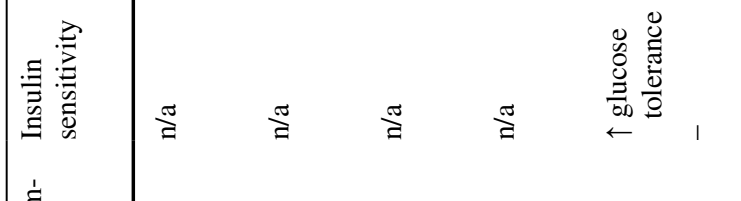

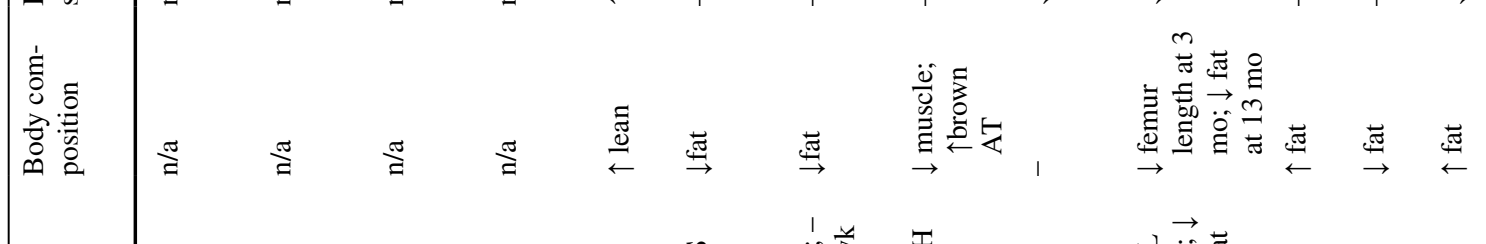

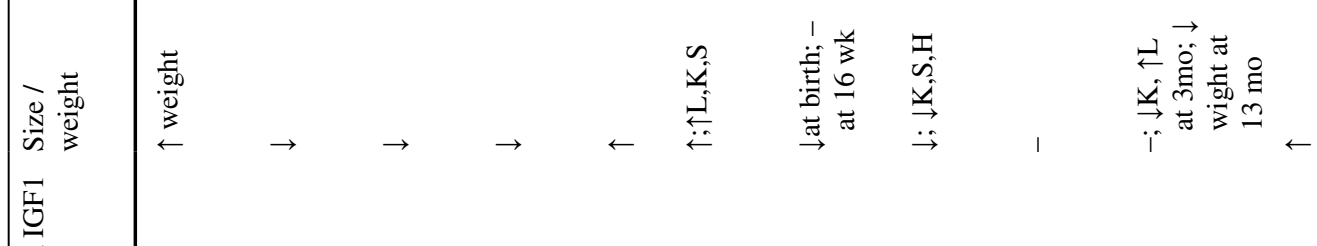

$$
\begin{aligned}
& \stackrel{\Xi}{\Xi}
\end{aligned}
$$

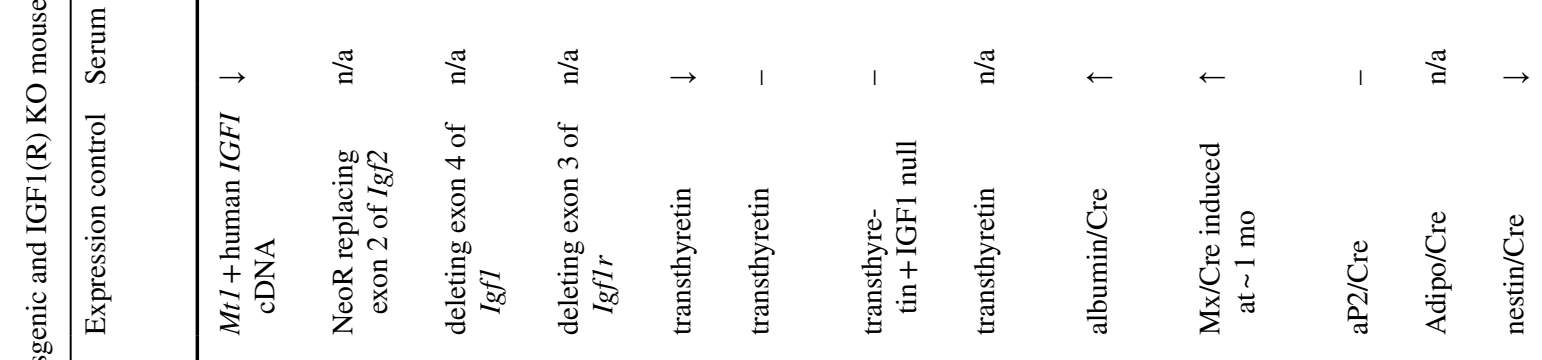

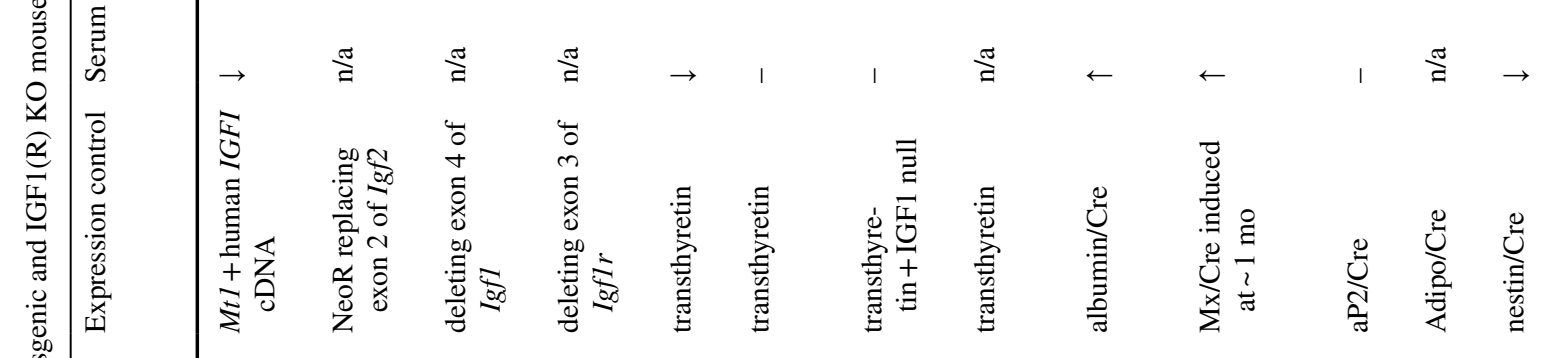

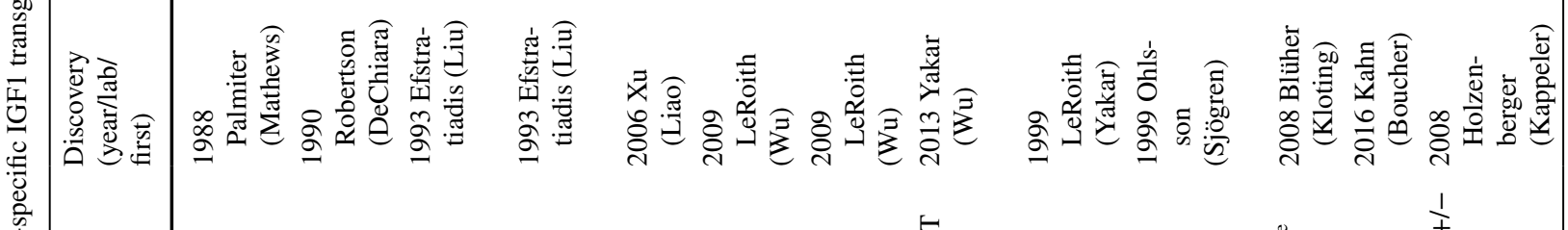

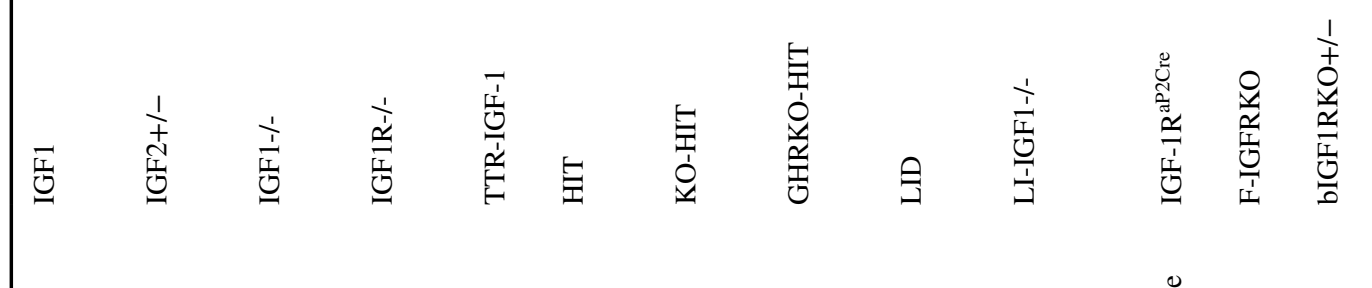

$$
\begin{aligned}
& \stackrel{\breve{.}}{.}
\end{aligned}
$$

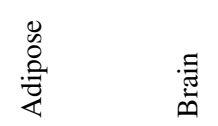

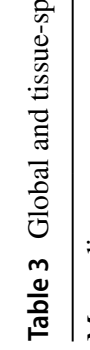




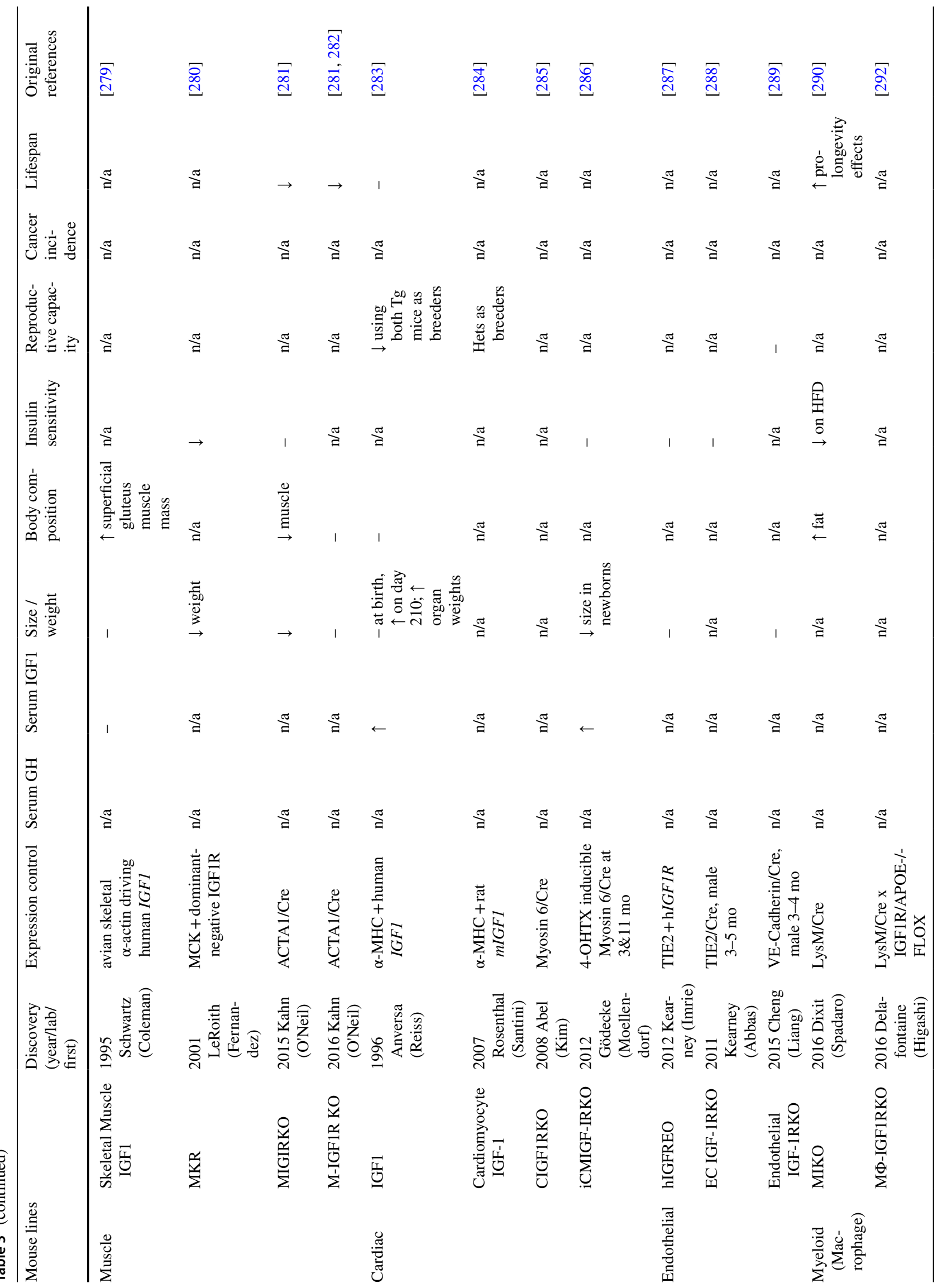




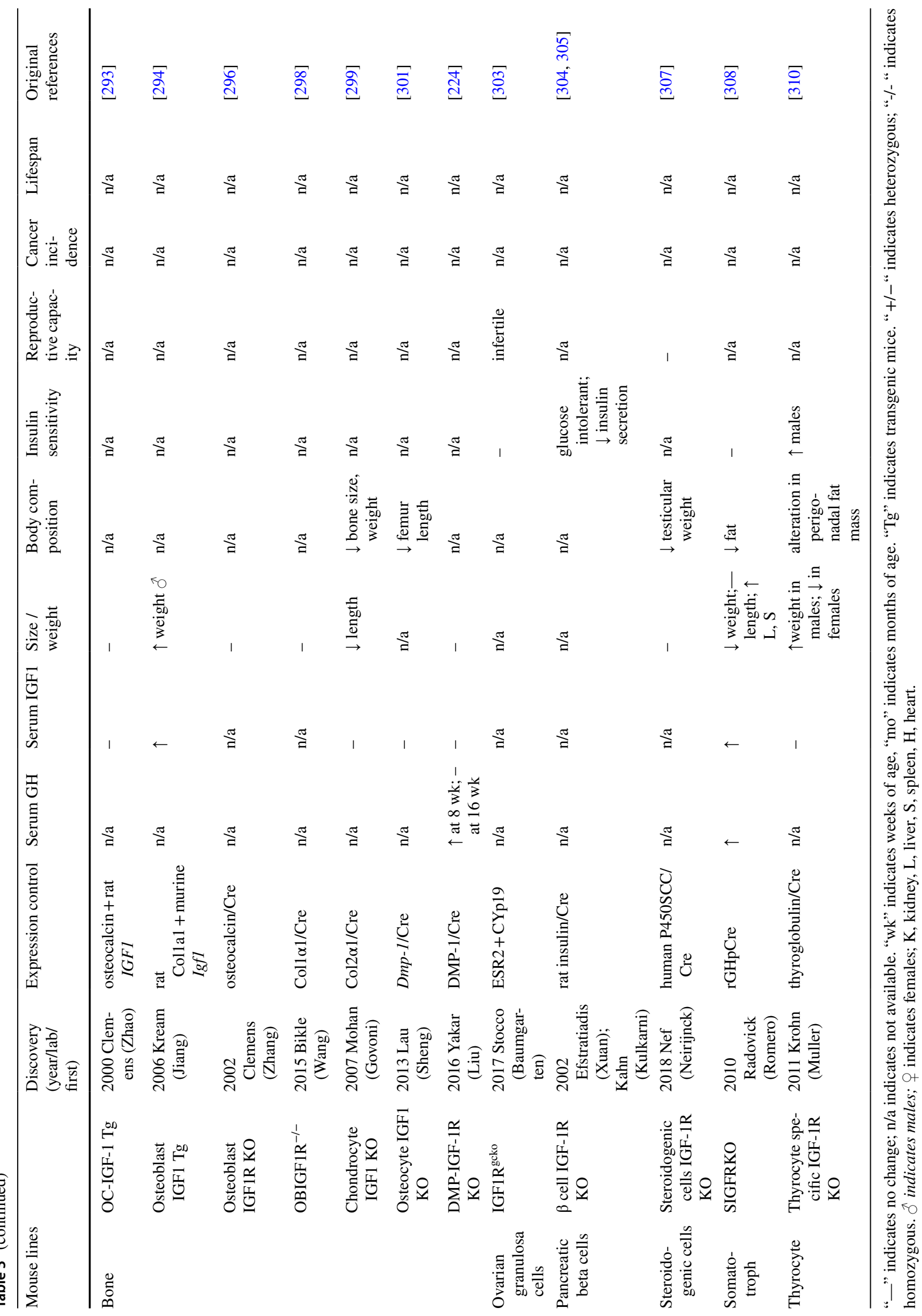




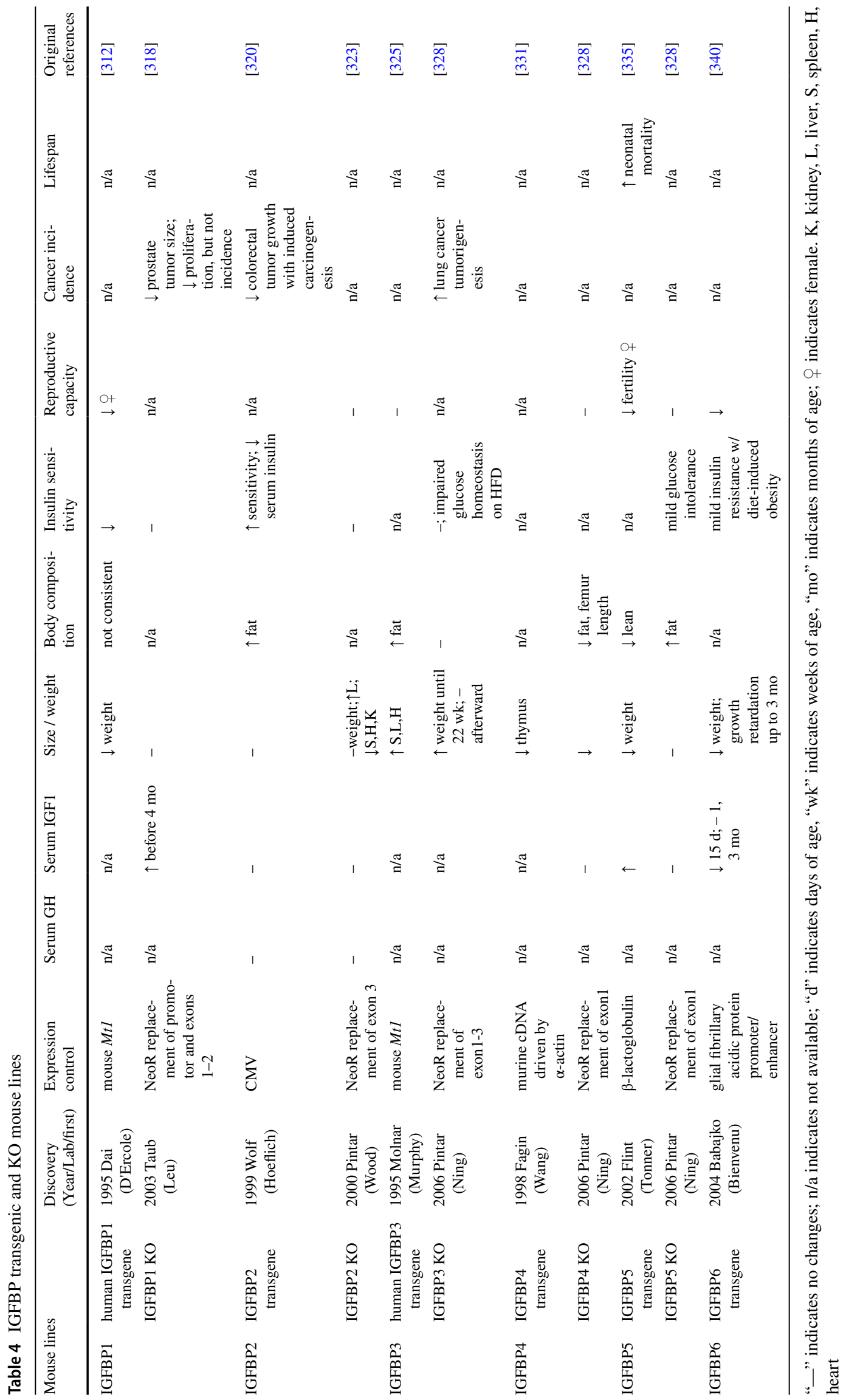


mutation occur through independent mechanisms [96, 97]. Despite these positive attributes, Ames mice suffer from a number of reproductive deficiencies. They are hypogonadal with decreased levels of gonadotropin and testosterone [98]. Although some male Ames mice remain fertile, all females are sterile. Further, Ames mice suffer from auditory deficits but, unlike in the Snell mice, are almost completely rescued by early life thyroid hormone treatment [82].

Overall, Ames and Snell mice present similar deficiencies in three pituitary hormones (GH, PRL, TSH), resulting in similar phenotypes of extended lifespan, improved oxidative stress response, improved insulin sensitivity, and reduced incidence of cancer. Numerous studies surrounding them have deepened our understanding of the endocrine control of specific aspects of health, disease, and lifespan.

\section{Growth hormone releasing hormone (GHRH) and its receptor (GHRHR)}

GHRH and its cognate receptor, GHRH receptor (GHRHR), promote GH release primarily along the hypothalamuspituitary axis. Human patients with isolated GH deficiency (IGHD) are often found to have inactivating mutations in the GHRHR or GHRHR gene locus. Therefore, a better understanding of this ligand-receptor pair in modulating the physiological effects of GH has clinical relevance. Below we discuss three mouse lines associated with the GHRHGHRHR pair.

\section{Human GHRH transgenic mice}

Origin In order to study the effects of GHRH in modulating the GH/IGF axis, Hyde and colleagues developed a human GHRH transgenic mouse (hGHRH) in 1994 using the Mtl gene promoter/enhancer to drive expression of the $h G H R H$ gene [99].

Phenotype GHRH transgenic mice have increased serum concentrations of mouse GH, PRL and IGF1 and are significantly larger in body size than WT mice [99]. As such, they are a mouse model of pituitary associated acromegaly. Also, endogenous hypothalamic GHRH levels are significantly suppressed, while levels of somatostatin (SST or SRIF) and SST receptor subtypes are elevated compared to littermate controls [100]. The upregulation of GHRH action in mice leads to massive hyperplasia of mammosomatotrophs observable at 8-months of age [101]. In adulthood (16-24-months age), pituitary adenomas immunoreactive for GH and PRL are often observed [102-104]. Transgenic GHRH mice were employed to study the effect of GH in regulating the production of neuropeptides from the anterior pituitary. In the anterior pituitary of GHRH transgenic mice, the tachykinins (substance-P and neurokinin A) are markedly increased in males and females [105]. Tachykinins, found in nearly all vertebrates, are one of the largest family of neuropeptides involved in neuronal excitation, behavioral response, vasodilation, and regulation of smooth muscle contraction. Also, the hyperpolarizing neuropeptide galanin, found in human central nervous system (CNS) and gut, are known to be produced by pituitary cells following $\mathrm{GH}$ stimulation in vitro [106]. In the pituitaries of male GHRH transgenic mice, galanin mRNA and peptide contents are also highly upregulated [99]. However, the levels of the neuropeptide, vasoactive intestinal polypeptide, in the anterior pituitary of male hGHRH transgenic mice are half of that of nontransgenic animals [107]. No data on the lifespan of these hGHRH transgenic mice are available.

\section{GHRHKO mice (Ghrh-/- or GHRH-/-)}

Origin The GHRHKO mouse (Ghrh-/- or GHRH-/-) was generated as a new mouse line of congenital GH deficiency in 2004 by Alba and Salvatori. Amino acid residues 1-42 of the Ghrh gene were replaced by a neomycin resistance (NeoR) gene [108].

Phenotype GHRH-/- (Ghrh-/-) mutant mice exhibit highly reduced levels of pituitary $G h$ mRNA and protein and reduced liver Igfl $\mathrm{mRNA}$ and serum IGF1 [108]. Growth retardation in the null animals is first detected at 3 weeks of age, and null mice are $60 \%$ the body size of either Ghrh+/+or Ghrh+/- littermates by 12-weeks [108]. GHRH analogs, acting as agonists of the cognate receptor, improve body length and body weight [109]. GHRH-/- mice have increased intra-abdominal and subcutaneous fat depots, concomitant with an increase in food intake $[110,111]$. Increased body temperature, intrascapular brown AT, and thermogenesis is observed in GHRH-/- mice, which could be a function of the increased metabolic rate of a smaller sized mouse to maintain body-temperature [111, 112]. Adiponectin levels are suppressed in both intra-abdominal and subcutaneous white AT depots, while it is elevated in the serum of these animals [110]. Despite an increased adiposity, insulin sensitivity is markedly improved in null mice and is found to be associated with decreased TOR signaling in white AT [113]. These GHRH-/- dwarf mice are longlived with median lifespan increased in males and females by $50 \%$ and $43 \%$, respectively. Maximal lifespan is increased by $18 \%$ in males and $33 \%$ in females [113]. CR also significantly increases overall survival along with both relative and maximal lifespan, indicating an additive effect especially in females [113]. Microarray analysis reveals several differentially regulated genes in the liver of GHRH-/- mice compared to WT littermates, wherein expression of multiple xenobiotic detoxification genes are dramatically increased [113]. The reported reproductive deficiencies in these null mice include suppressed rates of apoptosis and lipid peroxidation in testes of adult GHRH-/- mice compared to controls 
[114]. As another model of congenital GH/IGF1 deficiency, GHRH-/- mice share multiple phenotypes of the Snell and Ames mice.

\section{GHRHRKO mice (little; lit/lit; Ghrhr-/- or GHRHR-/-)}

Origin In 1976, Beamer and Eicher first reported the 'little' (or lit/lit) mouse, a new dwarf mouse deficient in GH and PRL due to a homozygous missense mutation in the Ghrhr gene $[115,116]$.

Phenotype This dwarf had very low levels of GH and, consequently, IGF1 [117]. The serum GH levels in these mice are only $1 \%$ of those of WT controls [118], and serum IGF1 and IGFBP3 are also highly reduced [118, 119], while IGFBP1, 2, and 4 remain unaffected [119]. Low serum leptin [70] and reduced PRL levels are observed in the lit/lit mice [115]. The body weight of these mice is about $2 / 3$ rd that of WT mice [70, 118], along with reduced levels of body fluid, protein and minerals. The lit/lit mice exhibit abnormally larger AT, especially in males [119]. Numerous results show that the growth of several cancers, including sarcoma and prostate tumor implants $[120,121]$, is reduced in this GH deficient mouse. Also, MCF7 breast cancer xenograft growth is reduced by almost half in lit/lit mice compared to WT controls [122]. The femoral lengths, periosteal circumference, and bone mineral density (BMD) are reduced in the lit/lit mice [123], and these mice have an extension in lifespan by $23 \%$ in males and $25 \%$ in females[70]. Thus, both GHRH-/- and GHRHR-/- mice have significantly suppressed GH/IGF action, resulting in considerably smaller body size, increased adiposity, reduced cancer growth, and extended lifespan.

\section{Growth Hormone (GH)}

The clinical relevance of GH treatment for GH deficient children and adults, as well as the extended lifespans of both Ames and Snell mice, fueled interest in the study of GH action in genetically altered mice. The first GH transgenic mouse with the rat $G h$ gene expressed under the mouse $M t 1$ promoter/enhancer developed by Palmiter et al. in 1982, grew almost twice as large as the littermate controls [25] and opened up a transformative scope of studying human conditions in laboratory mice. Beginning there, several mouse lines, transgenic for both human (h) and mouse (m) GH have been produced, which partially recapitulated several features of the human condition of GH excess found in patients with acromegaly.

\section{Human GH transgenic mice (hGH)}

MT1-hGH transgenic mice Origin The first hGH transgenic mouse was generated by Palmiter and Brinster in 1983 using the $M t l$ promoter/enhancer driving hGH expression [124].

Phenotype $\mathrm{Zn}$ or Cd treatment of the MT1-bGH mice further increase the $M t 1$-promoter/enhancer activity by up to tenfold [124]. The serum hGH levels in these mice are reported to be as high as $3000-900,000 \mathrm{ng} / \mathrm{mL}$ [125]. Expectedly, serum IGF1 levels in hGH mice are also significantly higher than those of WT mice [124]. In addition, the serum PRL level is reduced [126] while hypothalamic somatostatin expression is twofold higher than normal [127]. These MT1-hGH transgenic mice are larger in body size the wild type (WT) littermates [128] with markedly increased body weight and greater muscle mass with more and larger type-1 and type-2 fibers [129]. However, hGH transgenic mice suffer from reproductive defects, including a dramatic decrease in ability of males to impregnate females possibly due to the lactogenic effects of ectopically expressed hGH. This occurs despite enlarged testes and seminal vesicles [130]. Likewise, female mice are sterile, possibly due to a dysregulated PRL axis. Daily progesterone injections as well as PRL-secreting ectopic pituitary transplants from WT female mice reverses this reproductive defect [126]. Other abnormalities include severe kidney lesions, glomerular hypertrophy with sclerosis, and hyalinosis associated with tubule-interstitial changes [125]. Transgenic female mice also have a markedly higher incidence of malignant mammary tumors at 27-43 weeks of age [131]. No reports on the lifespan of hGH mice are available.

MT1-hGH transgenic mice Origin A second transgenic mouse line expressing hGH under the mouse $\mathrm{Mtl}$ promoter/ enhancer was produced in 1991 by Tornell and Isaksson [132].

Phenotype These transgenic mice resemble those produced by Palmiter and Brinster with larger body size and higher levels of circulating hGH than WT mice. Female transgenic mice also have markedly higher levels of spontaneous mammary carcinomas similar to those described above [131, 132]. This high frequency of spontaneous mammary carcinomas is probably due to hGH-mediated activation of the mouse PRLRs rather than GHRs $[133,134]$. This finding is later clarified by the same group via generation of bovine (b) GH transgenic mice in the same genetic background as the hGH mice, which did not exhibit spontaneous mammary carcinomas, as only hGH binds and activates both the GHR and PRLR [133].

$171 \mathrm{hGH} / \mathrm{CS}$ mice Origin Cattini and colleagues in 2009 generated a third hGH transgenic mouse line named $171 \mathrm{hGH} /$ CS [135] to analyze the pituitary regulation of human GH 
production. These $171 \mathrm{hGH} / \mathrm{CS}-\mathrm{TG}$ mice contain a 171 $\mathrm{kb}$ DNA fragment containing the intact $\mathrm{h} G H$ / chorionic somatomammotropin $(G H / C S)$ gene locus, along with the locus control region (LCR) from chromosome-17, including sequences required for pituitary specific expression [135].

Phenotype Both pituitary and placental expression of hCS-A, hCS-B, and placental hGH-variant are detected in these transgenic mice during gestation, in proportions comparable to that in the human placenta, along with high hGH levels [135, 136]. Corticosteroid treatments increase both human and mouse GH levels as well as the Ghrhr mRNA in primary pituitary cells from $171 \mathrm{hGH} / \mathrm{CS}-\mathrm{TG}$ mice [136]. Studies using these mice reveal that hGH production is impacted by the circadian rhythm via direct binding of circadian transcription factors at an enhancer motif in the hGH promoter locus. GH production is suppressed in these mice by acute sleep deprivation [137] and by HFD feeding only during the light (inactive) stage of daily cycle [138].

Wap-hGH mice Origin In a fourth transgenic mouse line expressing human GH generated by Gunzburg et al. in 1991, the mammary specific whey acidic protein (Wap) promoter/ enhancer was used to drive ectopic expression of hGH in mouse milk [139]. Another attempt at producing hGH in the milk of transgenic mice driven by a $6.3 \mathrm{~kb}$ long 5 '-flanking region of the rabbit WAP promoter/enhancer was undertaken in 1994 by Houdebine and colleagues [140]. These models highlight the important lactogenic effect of human $\mathrm{GH}$, given its unique ability to bind to and activate both $\mathrm{GH}$ and PRL receptors [141].

Phenotype Male transgenic mice from Gunzburg have higher plasma LDL-cholesterol and lipid peroxides and increased heart weights and lipid accumulation in liver compared to WT counterparts [142], suggesting a potential cardiac risk for male mice chronically exposed to hGH via the mammary gland. The body size of these mice does not differ from controls. The second Wap-hGH mouse from Houdebine produce up to $22 \mathrm{mg} / \mathrm{ml}$ of hGH in the milk but the lactogenic activity of hGH induces multiple dysfunctions including sterility in some of the transgenic females [140]. The same group generated another mouse line using the same transcriptional regulatory system, which express up to $16 \mathrm{mg} / \mathrm{mL}$ of bGH in the milk [143].

MT1-GHv mice Origin A fifth transgenic mouse line, expressing the human placental GH-variant (GH2, or $G H-V$; $G H v$ ) under the mouse $M t 1$ promoter/enhancer was created by Selden and colleagues in 1988 [128].

Phenotype These mice, similar to the MT1-hGH animals, have a larger body size than normal with elevated IGF1 levels and present a range of reproductive defects including small litter size (significantly lower than the expected at $50 \%$ ), reduced fetal growth, increased pre- and post-natal mortality, as well as a $20 \%$ infertility rate in females[144]. Male MT1-hGHv mice are unable to impregnate the females in most cases and have increased testes and seminal vesicle weights like the MT1-hGH mice [130]. In both the MT1hGH and MT1-GHv mice, spermatogenesis is unaffected [130].

\section{Bovine GH transgenic mice (MT1-bGH and PEPCK-bGH)}

MT1-bGH mice Origin The first mouse overexpressing bGH (bGH) driven by the $\mathrm{Mtl}$ promoter/enhancer was generated by Hammer et al. in 1985 [145].

Phenotype In the MT1-bGH mice, bGH concentrations are 40- to 400-fold those of WT mice (m) GH, and the transgene is expressed in almost all tissues [145, 146]. Serum IGF1 as well as somatostatin levels are markedly upregulated [127, 147]. The MT1-bGH mice weigh significantly more than controls with increased organ weights and higher lean mass and reduced fat mass [146, 148, 149]. They have larger body size and also model the human condition of acromegaly. These transgenic mice exhibit dysregulated insulin sensitivity as they are hyperinsulinemic at young ages but hypoinsulinemic and hypoglycemic at older ages [150]. Interestingly, both male and female mice also have increased adiposity in early life but switch to a leaner than normal phenotype at four (males) to six (females) months of age [146]. While GH is known to increase gluconeogenesis, MT1-bGH mice surprisingly exhibit suppressed glucose production following a pyruvate challenge, which could be confounded by higher insulin levels [151]. On HFDs, they are resistant to diet-induced obesity but develop dyslipidemia and diabetes [152]. Further, a dysregulated adipokine profile with decreased adiponectin and increased inflammatory IL-6, TNF $\alpha$, and increased serum cholesterol have been reported [153, 154].

PEPCK-bGH mice Origin McGrane et al. developed a second bGH mouse line in 1988, employing the phosphoenolpyruvate carboxykinase (PEPCK; Pckl) transcriptional regulatory region ligated upstream to the $\mathrm{b} G H$ gene [155].

Phenotype PEPCK-bGH mice have serum bGH levels higher than that of MT1-bGH mice [127], reaching up to $2300 \mathrm{ng} / \mathrm{mL}$, and cAMP administration causes a further twofold increase in bGH levels. As the bGH transgene in these mice is driven by the PEPCK promoter/enhancer, interventions such as a high carbohydrate diet that can suppress PEPCK mRNA, might also suppress the bGH transgene expression. Accordingly, a carbohydrate-rich diet intake by these mice does result in suppressed gluconeogenesis and hence PEPCK expression and in turn, suppresses GH expression by $90 \%$, while increasing serum insulin levels. The PEPCK-bGH animals have a twofold higher growth rate despite the transgene being expressed in the liver and 
kidney, indicating an endocrine effect of the bGH transgene. The pituitary weight of PEPCK-bGH mice is elevated, with smaller Golgi in pituitary somatotrophs. Serum IGF1 concentrations of these transgenic mice range between 2-threefold higher than those of WT mice [156] along with upregulated somatostatin levels similar to the MT1-bGH transgenic animals [127]. PEPCK-bGH mice weigh approximately 1.5-times more than WT mice [156], with increased lean mass[146, 148] and increased weights of internal organs, including kidney, liver, and heart [149]. In addition, sevenmonth-old PEPCK-bGH mice display improved glucose clearance, and lower blood glucose and HbAlc levels, while glucose and insulin sensitivities are comparable to WT mice [156]. These mice also develop inflammatory arthritis with production of autoantibodies [157].

Similar to hGH transgenic mice, a range of reproductive disorders are observed in the females of both MT1- and PEPCK-bGH mice, including an increased interval between pairing with a male and conception, increased interval between litters, reduced number of litters, reduced fetal growth, increased pre- and postnatal mortality and alterations in sex ratio [144]. More than $60 \%$ of the PEPCK-bGH and $20 \%$ of the MT1-bGH female mice are infertile, concomitant with the higher level of circulating bGH in PEPCK compared to MT1 animals [144]. Male bGH transgenic mice (both MT1 and PEPCK) have significantly higher weight of the testes and seminal vesicles but spermatogenesis or fertility is unaffected [130].

There is a significant decrease in the lifespan of both MT1- and PEPCK- driven bGH transgenic, giant mice. MT1-bGH mice have a maximal lifespan of 24-months and a 1-year survival-rate of $44 \%$, while PEPCK-bGH mice have a maximal lifespan of only 18 -months and a 1 -year survivalrate of $25 \%[158,159]$. The early morbidity of bGH mice recapitulates several factors underlying the shortened lifespan observed in untreated human patients with acromegaly. MT1-bGH mice suffer from renal and cardiac defects [160]. These mice exhibit renal disorders like hypercellular glomeruli early in life, advancing to increased glomerular size and progressive glomerulosclerosis at adulthood [160]. A significantly increased heart mass concomitant with impaired systolic function and a decreased energy reserve in the myocardium is also observed [149]. An increased mitogenic action of excess $\mathrm{GH}$ on its main target organ - the liver - leads to a number of hepatic abnormalities in both bGH transgenic mouse lines. For example, in both MT1- and PEPCK-bGH mice, hepatomegaly is observed as early as 2 weeks of age and progresses maximally into young adulthood, with an enhanced expression of proto-oncogenes and activation of multiple mitogenic signaling intermediates like c-SRC, mTOR, STAT3, GSK3, NFkB, c-fos, c-jun, and c-myc $[153,154,161]$. Additionally, pro-tumorigenic hepatocellular events, including upregulation of tumorigenic galectin-1 [162], and elevated oncogenic signaling pathways, are observed in the livers of both male and female PEPCKbGH mice [163]. Both MT1- and PEPCK-bGH mice are known to develop spontaneous liver tumors [164]. In both mouse lines, a sustained hepatic hypertrophy and inflammation lead to a significantly higher rate of spontaneous hepatocellular carcinogenesis compared to WT controls [164-166].

In summary, human and bovine $\mathrm{GH}$ transgenic mice have a decreased fat mass, with increased body size and lean mass. However, these mice have fertility defects, exhibit kidney and cardiovascular dysfunction, and have elevated neoplasm incidence along with a decreased lifespan.

\section{GH-/- mice (Gh-/- or GHKO)}

Origin In order to investigate the effects of GH absence and $\mathrm{GH}$ replacement on phenotypic variables, GH-/- mice were generated in the Kopchick laboratory in 2019, using a VelociGene KOMP definitive null allele that replaces the $G h$ gene with a ZEN-UB1 selectable reporter [167].

Phenotype Circulating GH in GH-/- mice is reduced to an undetectable level compared with that of WT controls [167]. Serum IGF1 levels are also significantly reduced ( $90 \%)$. Disruption of the $G h$ gene significantly reduces nasal-anal body length ( $>30 \%$ ), and body composition is significantly altered in both sexes, with body weight and lean mass significantly decreased and fat mass significantly increased relative to controls. GH-/- mice of both sexes demonstrate greatly enhanced insulin sensitivity probably due to the lack of GH's diabetogenic effect. However, GH-/mice are significantly glucose intolerant (although greater in males than females), which is attributed to their decreased pancreatic islet size. Liver, kidney, heart, spleen, gastrocnemius, soleus, and quadriceps masses are also significantly decreased, whereas AT mass and relative brain weight are significantly increased. Liver triglyceride content and adipocyte size in the subcutaneous depot are elevated in both male and female GH-/- mice. White AT fibrosis is significantly decreased in the subcutaneous white AT depot of both sexes compared to controls, suggesting depot-specific effects of GH. In summary, GH-/- mice show similar phenotypes as other mouse lines that lack GH action, although their cancer incidence and lifespan have not been reported at the time of this publication.

\section{Adult onset-isolated GH deficiency mice (AOiGHD)}

Origin To better understand the metabolic effects of somatopause - the progressive decline of hormones in the hypothalamic-pituitary-somatotrophic axis with age - a mouse line of adult onset-isolated GH deficiency (AOiGHD) was created by Kineman and colleagues in 2011 by breeding the inducible monkey diphtheria toxin receptor mice (iDTR) 
with mice having a rat $G h$ promoter/enhancer driven Cre recombinase [168].

Phenotype The adult $\mathrm{Cre}^{+-}{ }^{-} \mathrm{iDTR}^{+/-}$offspring are treated with diptheria toxin (DT) to selectively ablate somatotroph cells expressing diphtheria toxin receptor at 10-12 weeks of age, resulting in a 50\% decrease in circulating $\mathbf{G H}$ and IGF1 levels [168]. These mice also have lower fasting insulin levels and improved whole-body insulin sensitivity when fed either low-fat or HFD relative to WT littermates. Indirect calorimetry suggested that these mice utilize mainly carbohydrates for energy metabolism. Furthermore, detrimental physiological effects are seen only in HFD animals including increased fat mass, decreased hepatic lipids, and impaired glucose clearance and insulin output. The AOiGHD mice also have decreased liver weight accompanied with reduced liver triglyceride content. Overall, the mouse line shows that reduction in circulating GH and IGF1 levels with age improves insulin sensitivity and prevents metabolic dysfunction under moderated caloric intake.

\section{GHR antagonist transgenic mice (GHA)}

Origin To understand some of the effects of pharmacological perturbations to $\mathrm{GH}$ action, a transgenic mouse line that expresses a mutated-bovine GH gene that effectively antagonizes endogenous $\mathrm{GH}$ action was created. These transgenic GHR antagonist (GHA) mice were generated in a C57BL/6 J background in the Kopchick laboratory between 1990 and 1991 via the fusion of the mutated $G H$ transgene downstream of the mouse $M t 1$ promoter/enhancer [26, 169, 170]. The mutated bovine GH gene differs from its WT counterpart in that it encodes a single amino acid substitution at position 119 . The glycine that typically occupies this position, found in the third alpha-helix of bGH (G119 in bovine GH; G120 in human GH), is critical for the successful activation of the GHR [171]. When glycine 119 is substituted with arginine, the resulting molecule competitively inhibits the association of mouse GH with the GHR [172]. Similarly, when a lysine is substituted for the glycine at position 120 of the human $G H$ gene, an effective human GHR antagonist is produced. Following these discoveries, Kopchick and colleagues went on to develop the novel drug, SOMAVERT® (Pegvisomant for injection), which is a GHR antagonist that inhibits the interaction of endogenous GH with GHR and is now used world-wide for the treatment of patients with acromegaly [173].

Phenotype As a result of the overexpression of the GHR antagonist, GHA mice have smaller body size and show a $30 \%$ lower mean growth ratio $[26,170]$ with significantly reduced body weight [147], wherein lean mass is reduced, and body fat is increased compared to controls [174]. GHA mice have increased lipid storage in the inguinal subcutaneous white AT depot and a relative increase in extra-peritoneal to intra-peritoneal white AT [174]. Additionally, GHA mice have markedly lower serum IGF1 [26, 147, 170, 172], lower serum IGFBP3 [37], and higher pituitary mouse (m) GH levels than nontransgenic littermates $[26,170]$. The pituitary weight of GHA mice is about half that of controls, with moderate to sparsely granulated somatotrophs compared to those densely granulated in WT mice [147]. Despite increased obesity [175], GHA mice are more insulin sensitive than controls [174]. Increased brown AT mass accompanied by higher expression of thermogenic factors has also been reported [175]. On a HFD, although GHA mice gain more weight than WT controls (males $>$ females), they are protected from HFD-induced glucose intolerance and hyperinsulinemia [176]. Additionally, GHA mice are protected from streptozotocin-induced diabetic kidney lesions [175] and from cancer. For example, after treatment with the mammary carcinogen DMBA, $66 \%$ of GHA mice remain tumor-free compared to only $1 / 3^{\text {rd }}$ of the controls and have less tumors and a smaller tumor burden [172]. Although no significant difference in lifespan between GHA and WT mice has been reported [158], female GHA mice tend to live longer than controls.

In summary, the phenotypes observed in GH transgenic mice with elevated $\mathrm{GH}$ action contrast significantly to those seen in the GH-/- or GHA mice. All these observations strongly suggest that GH plays a critical role in promoting growth, body size, lean mass, glucose intolerance, and reproductive deficiency, while the absence or deficiency of GH improves glucose homeostasis, adiposity, cancer resistance, and longevity.

\section{Prolactin and prolactin receptor (PRL and PRLR)}

Prolactin (PRL) is a protein secreted from the lactotrophs of the anterior pituitary gland [177] and has a structure similar to that of GH. PRL secretion is stimulated by PRL releasing factors such as thyrotropin releasing hormone, oxytocin and neurotensin [178]. On the contrary, PRL secretion is inhibited by dopamine and somatostatin [179] and induced by gamma-aminobutyric acid [180]. PRL binds to PRL receptors (PRLR), which are a member of cytokine receptors that lack intrinsic kinase domains but possess JAK2 associating regions; thus, PRL resembles the GHR and transduces similar intracellular signals. Human PRLR can bind at least three ligands including PRL, placental lactogen and hGH. Like GHR, PRLR consists of an extracellular domain for ligand binding, a helical transmembrane portion and an intracellular region. However, alternative precursor mRNA splicing leads to different isoforms of the PRLR with identical extracellular domains while the intracellular domains differ in size (referred to as 'long' or 'short' PRLR) [177]. The receptor homodimer is constitutively expressed on cell surfaces in a ligand-independent manner in several tissues and 
peripheral organs including the breast, prostate, brain, pituitary gland, heart, uterus and skin [178]. Although hundreds of actions of PRL have been reported [181, 182], a main function of PRL is to promote both growth of the mammary gland and to induce and maintain lactation. In the following section, PRL transgenic, PRL-/-, PRLR-/-, PRLR variants, and PRLR antagonist mice will be discussed.

\section{MT1-PRL transgenic mice}

Origin To study prostate hyperplasia, Tornell and colleagues in 1997 generated MT1-PRL transgenic mouse lines which overexpressed PRL [183].

Phenotype These transgenic mice have ubiquitous expression of rat PRL ( $\mathrm{rPrl}$ ) under the control of $\mathrm{Mtl}$ promoter/ enhancer. Three mouse lines generated, L1, L2 and L3, have an increase in serum rat PRL by $\sim 250 \mathrm{ng} / \mathrm{ml}, 15 \mathrm{ng} / \mathrm{ml}$, and $100 \mathrm{ng} / \mathrm{ml}$ respectively [183]. The endogenous mouse PRL serum levels are not reported though mouse PRL mRNA is detected in all parts of the prostate glands. The three PRL transgenic mouse lines exhibit enlarged prostates due to increased PRL secretion along with increased prostate weight and hyperplasia compared to the controls. Interestingly, these mice also have elevated IGF1 levels close to that of bGH mice although the GH levels are not reported. L1 and L2 mice remain fertile, while L3 mice, with the highest PRL levels, are infertile [183].

\section{Local prostate specific prolactin expression: $\mathrm{Pb}-\mathrm{PRL}$ transgenic mice}

Origin To assess the role of PRL in abnormal prostate growth in transgenic animals that overexpress PRL, Kindblom et al. in 2003, developed a Pb-PRL transgenic mouse line, which locally produce PRL in the prostate [184].

Phenotype In this mouse line, the minimal probasin $(\mathrm{Pb})$ promoter/enhancer is used to direct $\mathrm{r} P r l$ expression in the epithelial cells of dorsolateral, ventral, and anterior of prostate lobes. Marked enlargement of prostate glands is observed in the transgenic males, which is also observed in the MT1-PRL mice. Though both MT1-PRL and Pb-PRL have marked ductal dilation and elongation, MT1-PRL mice have significantly elevated ductal branching points and tips while $\mathrm{Pb}$-PRL mice have normal branching points. The data suggest that PRL action can differentially impact a variety of prostate cells. The heterozygous Pb-PRL animals remain fertile [184].

\section{Mammary epithelial PRL overexpressing mice (NRL-PRL)}

Origin PRL is crucial in development and differentiation of the mammary gland. Many epidemiological studies have linked PRL with increased risk of estrogen receptor positive
$(\mathrm{ER} \alpha+)$ breast tumors [185]. To specifically study the role of PRL in breast cancer, Schuler and colleagues developed a PRL transgenic mouse line in 2003 [186]. This mouse line called NRL-PRL has locally overexpressed $\mathrm{r} P r l$ transgene in mammary epithelia driven by a hormonally nonresponsive promoter/enhancer - neu-related lipocalin (NRL).

Phenotype The NRL-PRL females develop mammary pathology and $\mathrm{ER} \alpha+$ and $\mathrm{ER} \alpha-$ carcinomas $[186,187]$. Overall, breast cancer development in NRL-PRL mice strongly implicates PRL in development of ER $\alpha+$ cancers.

\section{PRL knockout mice (Prl-/- or PRL-/-)}

Origin To determine the effects of a lack of PRL, Nelson Horseman et al. generated the PRL-/- mouse line in 1997 through a targeted insertion of a NeoR gene into the region of the PRL gene encoding the second $\alpha$ helix [188].

Phenotype Although no detectable effect on growth or adiposity at any age is observed [188], male PRL-/- mice exhibit impaired glucose tolerance at 4 weeks of age [189]. Also, higher leptin concentrations are found in PRL-/- mice on normal chow compared to WT mice [189]. Females are sterile, indicating that PRL is essential for female fertility, whereas males remain reproductively viable [188]. Since PRL has been found to influence the immune system, it was expected that these mice would be immunocompromised. However, no significant difference is reported in the number of B- and T-cells in PRL-/- mice compared to controls [188].

\section{PRLR knockout mice (Prlr-/- or PRLR-/-)}

Origin To determine the effects of a lack of PRL action, Ormandy et al. in the laboratory of Paul Kelly generated a prolactin receptor knockout mouse line (PRLR-/-) in 1997 [190].

Phenotype These mice present features like those noted in PRL-/- mice. Female PRLR-/- mice are sterile and show changes in estrous cyclicity when compared to WT mice [190]. Heterozygous female mice are fertile but display abnormal maternal behavior including decreased pup retrieval, leaving pups unattended or scattering them around the cage [190]. However, males are 'partially infertile' [190], with $20 \%$ of all tested males exhibiting delayed fertility [181]. Both male and female PRLR-/- mice experience a significant decrease in bone formation and a reduction in bone mineral density compared to controls [191]. In terms of glucose homeostasis, PRLR-/- mice have reduced pancreatic islet density and $\beta$-cell mass, as well as reduced pancreatic insulin mRNA levels in both sexes [192]. There is also a marked reduction in abdominal fat mass in both sexes. Importantly, PRLR-/- mice are protected from prostate carcinogenesis [193], suggesting that abrogated PRL action might be protective against prostate cancer. 


\section{PRLR variants}

PRLR is expressed ubiquitously with various proportions of long and short isoforms in different tissues. In mice, four PRLR variants have been classified as one long (LPRLR) and three short forms (S1PRLR, S2PRLR, S3PRLR). S1PRLR and S2PRLR forms are mouse specific while LPRLR and S3PRLR are homologous in other species [194]. Only LPRLR has been shown to induce transcription of milk producing genes while both LPRLR and S1PRLR have been shown to modulate cell proliferation. Similarly, rat PRLR has a long (LPRLR), a variant (Nb2), and a short (F3-SPRLR) form. Interestingly, F3-SPRLR results in formation of inactive heterodimer resulting in absence of downstream signaling in vitro. Several mouse lines have been generated to study the individual effects of each type of isoforms.

F3-SPRLR mice Origin To assess the dominant negative effects of SPRLR and role of PRL in normal mammary gland development, Saunier et al. developed a transgenic mouse line in which the F3-short form of the rat PRLR (F3-SPRLR) was expressed in mouse mammary epithelium driven by mouse mammary tumor virus-long terminal repeat (MMTV-LTR) in 2003 [194].

Phenotype Mice with low levels of transgene expression exhibit phenotypes similar to WT animals while mice expressing high levels of transgene show impaired mammary gland development and lactation although fertility is unaffected [194]. Hence, locally blocking PRL/PRLR at the mammary gland hinders mammary gland development indicating the crucial role of PRLR signaling in mammary tumors.

PR-1 mice Origin To assess the signal transduction of the short PRLR isoform, Binart et al. in the Kelly laboratory developed a mouse line with overexpression of the short isoform of the mouse PRLR (originally called PR-1, also known as S1PRLR) in 2003 [195]. The $\operatorname{Prl}$ gene is expressed in heterozygous $\mathrm{Prlr}+/-$ mice driven by the elongation factor $1 \alpha(\mathrm{EF} 1 \mathrm{~A})$ promoter/enhancer.

Phenotype Previous studies have shown that heterozygote Prlr+/- mice exhibit severe defects in lactation after the first pregnancy [190]. Interestingly, introducing the short form of the gene (Prl) in Prlr+/- mice results in normal mammary ductal development and the ability to lactate after the first pregnancy. The results from this study strongly indicate that the short form of PRLR is specifically involved in mammary stem cell formation.

Tg-RL and CL-RL mice Origin PRL is involved in corpus luteum (CL) formation and progesterone production crucial in embryo implantation and maintenance of pregnancy. To delineate the role of PRLR long form in CL function, Le et al. in 2012 developed two transgenic mouse lines expressing only PRLR long form - one ubiquitously expressed and named $\mathrm{Tg}$-RL driven by the EF1A promoter/enhancer, and the other in CL-specific manner and named CL-RL driven by the transcriptional regulatory region of the hydroxysteroid 17-beta dehydrogenase 7 ( $h s d 17 b 7$ ) CL-specific gene [196].

Phenotype Both mouse lines have normal follicular development and ovulation rates. An interesting malformation of vasculature is observed in both mouse lines, which can be attributed to lack of PRLRs (short form) function [196].

PRLR antagonist transgenic mice Origin The rational design for competitive PRLR antagonist where it competes with endogenous PRL and binds but does not activate the PRLR was based on the pioneering work on the GHR antagonist (Pegvisomant) by the Kopchick laboratory. Goffin and colleagues in 2003 generated the first PRLR antagonist by replacing the glycine in the 3rd PRL $\alpha$-helix. This glycine, when replaced with arginine at position 129 (G129R), resulted in a strong antagonist of the PRLR [197]. Also, deleting the first nine residues $(\Delta 1-9)$ at the $\mathrm{N}$-terminus in the G129R-hPRL proved to enhance the effectiveness of the antagonist [197]. To study the effects of blocking the PRL action in prostate tumorigenesis, Rouet et al. in 2010 developed the $\Delta 1-9-G 129 \mathrm{R}-\mathrm{hPRL}$ transgenic mouse line driven by $M t 1$ promoter/enhancer for ubiquitous expression of the antagonist [198].

Phenotype These mice express about $200 \mathrm{ng} / \mathrm{ml}$ of circulating PRL antagonist. No prostate hypertrophy is observed in these mice. However, increased pituitary weight is observed in both sexes [199, 200]. Inhibition of lactotroph cell proliferation and increased apoptosis are also observed when mice are treated with dopamine agonist (D2R) and then treated with PRL [200]. In 2010, the latter team also generated a double transgenic mouse by crossing Pb-PRL (rat $\mathrm{Prl}$ expressed only in the prostates) with $\Delta 1-9-\mathrm{G} 129 \mathrm{R}$ hPRL mice. The weight of dorsal prostate in these mice is reduced at 6-month of age as compared to Pb-PRL mice. These mice also had a stark reduction in STAT5 phosphorylation in dorsal prostates and reduced tumorigenesis. Overall, these findings point to the role of endocrine PRLR antagonists in preventing early prostate tumorigenesis [198].

In summary, PRL is closely related to GH as both belong to the same cytokine family, have approximately the same mass, similar quaternary structures, bind to a homo-dimerized cognate receptor like GHR, and activate STAT5 in their downstream signaling. PRL-PRLR axis plays important physiological roles especially in lactation and in maintaining fertility. Also, blocking PRL can retard/inhibit prostate tumorigenesis. 


\section{Global, temporal and tissue-specific GHRKO mice}

For GH to elicit a response in cells, it must bind to its cognate receptor, the GHR, which is a pre-formed single membrane spanning dimer and a member of the cytokine family receptors-all lacking a kinase domain. After GH binds to the preformed GHR homodimer, the intracellular domain associated JAK2 kinases then phosphorylate one another and begin the process of GH induced GHR signal transduction. Inactivating mutations in the GHR or down-stream signaling intermediates lead to GH insensitivity. In humans this condition is called Laron Syndrome (LS). LS is characterized by low IGF1, elevated GH, short stature, obesity, and resistance to cancer [76]. Furthermore, the Ecuadorian cohort which is the largest cohort of individuals with LS, exhibit extreme insulin sensitivity and resistance to cancer and diabetes. In mice, GHR gene disruption (GHR-/-) produces a similar phenotype to humans with LS [31]. To date, GHR-/mice have been used in over 130 published studies that have greatly enhanced our knowledge of GH action in vivo. In addition to global GHR-/- mice, temporal and tissue-specific GHR gene disrupted mice have been generated (Table 2) as will be discussed in the subsequent section.

\section{Global GHRKO}

\section{GHR knockout mice (Ghr-/-; GHR-/- or GHRKO)}

Origin To determine the effects of a lack of GH action, the GHR null or GHR-/- or GHRKO mouse line was developed by Zhou et al. in the Kopchick laboratory in 1997 through a targeted mutation in which a NeoR gene was used to replace a major portion of exon 4 of the $G h r$ along with $\sim 500$ bp of intron $4 / 5$ [30].

Phenotype The resulting homozygous null mice are dwarf with decreased body length and weight. These mice experience delayed sexual maturation and decreased litter sizes [30, 201]. GHR-/- mice have 50-100 fold increase in serum GH and a 90\% decrease in serum IGF1 levels [30]. In regard to body composition, these mice have increased fat mass and decreased lean mass [202]. Surprisingly, the largest increase in adiposity occurs in the subcutaneous white AT depot. Although obese, these mice show improved insulin sensitivity and decreased serum insulin [31]. However, GHR -/- mice have impaired glucose tolerance due to decreased pancreatic islet size and function [203, 204]. Additionally, these mice have normal to high levels of serum leptin $[148,205,206]$ and adiponectin $[148,205,207]$ with normal to low levels of cholesterol [206, 208] and T3 and T4 [209]. GHR-/- mice have increased oxygen consumption and lower respiratory quotient values, which indicate a shift towards fat oxidation [210, 211]. Additionally, these mice show $23-26 \%$ greater neuron density in the somatosensory cortex of the brain along with improved memory retention and reduced memory loss with age [212]. Remarkably, these mice display resistance to several disease states, including the development of certain types of cancer [33-35], nephropathy when type 1 diabetes is induced [213], resistance to T2D when placed on a HFD [32] and age-related loss of grip strength [214]. Finally, these mice have increased longevity $[37,215]$ and hold a world record for the longestlived laboratory mouse [31].

\section{Temporal GHRKO}

\section{Global adult onset-aGHRKO mice}

Origin To investigate the physiological effects of disrupting GH action in adulthood, Junnila et al. in the Kopchick laboratory in 2016 generated a mouse line with ablated GHR at 1.5 months of age using the Cre gene transcriptionally driven by ROSA26 gene promotor/enhancer [60].

Phenotype Adult-onset GHRKO (aGHRKO) mice have a variable but significant decrease in tissue specific GHR gene expression, with liver and AT showing the greatest reduction, and skeletal muscle and heart, the least [60]. In terms of phenotype, the aGHRKO mice have reduced circulating IGF1 and elevated circulating GH when compared to control mice. These mice have reduced body weight and body size (5-10\%), with an increase in fat mass and a decrease in lean mass when compared to controls. Despite the increased adiposity, both male and female aGHRKO mice show increased insulin sensitivity and decreased circulating insulin levels. Similar to the germline GHR-/mice, aGHRKO mice have decreased glucose tolerance in comparison to controls. The adipokine profile is altered in these mice with increased adiponectin but no difference in leptin levels. Changes in circulating IGFBPs were also seen in the aGHRKO mice when compared to WT mice. That is, similar to GHR-/- mice, aGHRKO mice exhibit a decrease in IGFBP3 and an increase in IGFBP1, 2 and 6. Therefore, while IGFBP3 is known to be positively associated with GH action, IGFBP1, 2, and 6 appear to be negatively associated with it. Finally, longevity studies show that aGHRKO females have an increased maximal lifespan when compared to female controls.

\section{Tissue-specific GHRKO}

\section{Liver-specific GHR knockout mice}

Liver is one of the most important organs in the GH/IGF1 axis since it is the site where the majority of circulating $\mathrm{GH}-$ stimulated IGF1 is produced. It is estimated that $75-90 \%$ 
of circulating IGF1 is produced from the liver [48, 216]. Indicative of this importance, there are five liver-specific GHR knockout mouse lines that have been independently produced by different laboratories between 2009-2019.

GHRLD Origin In 2009, Fan et al. produced the first liverspecific GHR knockout (GHRLD) mouse in the laboratory of Mark Sperling [38]. To produce these mice, an albumin promoter/enhancer was used to drive Cre recombinase in liver hepatocytes.

Phenotype These mice have decreased serum IGF1 and elevated serum GH levels [38]. Despite the reduction to circulating IGF1, these mice show no change in body weight, body length, tibia length or body composition. Several organs are altered in size in these mice including increased liver weight and decreased kidney weight. Glucose homeostasis in these mice is negatively affected, as GHRLD mice are glucose intolerant and insulin resistant. Additionally, male mice exhibit increased liver steatosis. Finally, these mice have increased hepatic fibrosis, circulating inflammatory cytokines and decreased bone density.

LiGHRKO Origin In 2014, List et al. in the Kopchick laboratory produced the second liver-specific GHR knockout mouse (LiGHRKO) [48]. To produce these mice, an albumin promoter/enhancer was used to drive Cre recombinase specifically in the liver hepatocytes.

Phenotype The resulting mice are significantly smaller with decreased body weight and body length at 6 months of age [48]. Analysis of body composition shows a higher percentage of body fat at early ages followed by a lower percentage in adulthood similar to the body composition profile of bGH mice that results from elevated GH levels. In some sense, these animals could be considered mice with 'extrahepatic acromegaly'. For example, liver IGF1 mRNA is quite low yet the levels are increased in skeletal muscle and AT. Interestingly, there is a male-specific development of fatty liver. Similar to GHRLD, LiGHRKO mice have impaired glucose homeostasis with an increase in several adipokines, including leptin, resistin and adiponectin, and increased inflammatory cytokines (IL-6 and MCP-1). These null mice also have increased grip strength compared to controls. Additionally, LiGHRKO mice have smaller kidneys and spleens and increased liver, heart and lung mass relative to body weight. Aging studies at two separate institutions reveal that liver-specific disruption of the GHR does not alter lifespan in LiGHRKO mice [52] despite severe reductions to circulating IGF1 [48]. We suspect that the benefits of lower circulating IGF1 in LiGHRKO- which normally favors lifespan extension - were offset by impaired glucose homeostasis and elevated circulating $\mathrm{GH}$, that in turn increased local IGF1 in non-hepatic tissues. To date, no other liver-specific mouse lines have been evaluated for lifespan.

aLivGHRkd Origin To investigate the role of GH in hepatic fat production and accumulation, Cordoba et al. produced an adult-onset (induction at 10-12 weeks of age), liver GHR knockdown mouse (aLivGHRkd) in the laboratory of Rhonda Kineman in 2015 [55]. These mice were generated utilizing a Cre system driven by the thyroxine-binding promoter/enhancer.

Phenotype Both male and female mice have reduced circulating IGF1 and hepatic IgfI mRNA levels, although the reduction is less pronounced in females [55]. There is also an increase in GH, GHRHR and the ghrelin receptor (previously known as the GH secretagogue receptor 1a) in male mice. These mice have increased liver weight, hepatic de novo lipogenesis, triglycerides, and glycolysis-driving factors, such as glucokinase and fructose 2,6-bisphosphate.

Li-GHRKO Origin To investigate the role of hepatic GH on lipid and carbohydrate metabolism, Liu et al. produced the liver-specific GHR deletion mouse (Li-GHRKO) in the laboratory of Shoshana Yakar in 2016 [59]. These mice were produced using a Cre system driven by an albumin promoter/enhancer.

Phenotype There is no change in body weight of these mice, but there is an increase in fat mass, as seen before in other mouse lines [59]. Similarly, these mice have reduced serum IGF1 levels with increased blood glucose and serum insulin, as well as impaired insulin tolerance. They also have increased serum triglycerides, cholesterol, FFAs and leptin levels. Furthermore, the liver weight of these mice is increased, as well as hepatic triglyceride and fatty acid content. Finally, hepatic glycogen is increased, as well as enzyme markers for gluconeogenesis (i.e., glucokinase, PCK1).

L-Ghr-/- Origin To investigate the role of liver-specific GH on CR, Fang et al. produced the L-Ghr-/- mouse using a Cre system driven by an albumin promoter/enhancer in the laboratory of Guosheng Liang in 2019 [63].

Phenotype There is no resulting change in body weight or body composition [63]. Additionally, these mice have blood glucose levels comparable to controls. However, when placed on a CR diet, the mice have decreased blood glucose resulting in a hypoglycemic state. They also have an increase in plasma $\mathbf{G H}$ and ghrelin. Differing from previous findings in the other liver-specific GHR KO mouse lines, the livers of these mice have decreased triglycerides and reduction in autophagic vacuoles.

Overall, physiological data obtained from these five liver-specific $G h r$ gene disrupted mouse lines are in agreement with only a few discrepancies. Most notably, Fan et al. 
reports that deletion of GHR in liver does not affect body composition or growth as measured by total body weight and body length. In contrast, List et al. found that LiGHRKO mice have a higher percentage of adiposity at a young age, then a lower percentage in adulthood when compared to controls. Furthermore, List et al. found that body weight and body length are all significantly decreased in LiGHRKO mice compared to controls. While the precise reason for the inconsistencies is unknown, we suspect that they may be due to the age at which these measures are recorded, and/or the numbers of mice used in each study. Specifically, Fan et al. evaluated these parameters at 16 weeks of age using a $n$ of 6 to 8 , while List et al. measured growth factors at 6 months of age using a $n$ of 15 to 16 and body composition over time up to 22 months of age using a $n$ of 13 to 19. Importantly, List et al. observed no changes in weight until later in life, which may explain why Fan et al. observed no differences in growth.

\section{Muscle-specific GHRKO mice}

Since GH has significant anabolic effects on muscle, three muscle-specific GHR knockout mouse lines have been generated independently to understand the roles of the GH-axis on muscle size, fiber type, metabolism, glucose homeostasis and longevity.

$\Delta$ GHR Origin In 2010, Mavelli et al. created a musclespecific GHR knockout mouse ( $\Delta \mathrm{GHR}$ ) in the laboratory of Thomas Clemens [40]. These mice were produced using the Mef-2c-73k promoter/enhancer to drive Cre expression in muscle. However, off target expression is reported for this Cre line (described below in comparison of the three muscle-specific knockout mouse lines).

Phenotype These mice show no change in either serum GH or IGF1 levels [40]. In terms of phenotype, these mice reveal an increase in body weight over controls, starting at 12 weeks of age. Body composition analysis shows that these mice also have increased fat mass compared to controls. Additionally, $\Delta$ GHR mice have increased glucose and triglyceride levels, indicating the development of insulin resistance.

mGHRKO Origin In 2012, Vijayakumar et al. produced the muscle GHRKO mouse (mGHRKO) in the laboratory of Derek LeRoith [42].

Phenotype These mice were produced utilizing the Cre system driven by the mouse muscle creatine kinase $(\mathrm{Ckmm})$ transcriptional regulatory region [42]. No difference is seen in GH and IGF1 levels. While body size is comparable to WT controls, the lean mass of the mGHRKO mice is significantly decreased. Additionally, both subcutaneous and gonadal AT are significantly reduced along with an increase in serum adiponectin levels.

MuGHRKO Origin In 2015, to understand the effects of muscle GHR on glucose homeostasis and aging, List et al. in the Kopchick laboratory produced the MuGHRKO mouse [54]. These mice were produced utilizing the Cre system driven by the mouse muscle creatine kinase $(\mathrm{Ckmm})$ promoter/enhancer, which is specifically expressed in skeletal and cardiac muscle.

Phenotype No changes to the GH/IGF1 axis are found [54]. Body length and weight are comparable to controls, and no difference is observed in fat or lean mass as measured over time. Male MuGHRKO mice have enhanced insulin sensitivity and increased lifespan although this increase does not recapitulate that seen in global GHR-/- mice.

Comparison of the three muscle-specific Ghr gene disrupted mouse lines shows conflicting results. Mavalli et al. [40] report that muscle-specific disruption of the GHR in male mice produces increased adiposity with insulin resistance and glucose intolerance. In contrast, both List et al. and Vijayakumar et al. report reduced adiposity and overall improvement in glucose homeostasis [42, 54]. The difference among Mavalli's results [40] and those of the two other laboratories $[42,54]$ likely reflects the use of different promoter/enhancers driving Cre expression. Both List et al. and Vijayakumar et al. used muscle creatine kinase $(\mathrm{Ckmm})$ promoter/enhancer [42, 54], which drives Cre expression in postnatal skeletal and cardiac muscle [217] while Mavalli et al. used the $m e f-2 c$ promoter/enhancer, which directs $\mathrm{Cre}$ expression in postnatal skeletal muscle [44]. Unfortunately, while $m e f-2 c$ Cre expression was thought to exclusively target skeletal muscle, more recently it has been shown that it is an important regulator of brain, bone, lymphocyte, blood vessel, endothelium, neural crest, craniofacial, and melanocyte development $[218,219]$. Therefore, it is likely that unanticipated expression of Cre by the $m e f-2 c$ promoter/ enhancer in tissues other than muscle accounts for the differences between mice generated by Mavalli et al. versus other two mouse lines.

\section{Brain-specific GHRKO mice}

To understand the roles of GH axis on brain, four independent GHR brain-specific mouse lines have been generated between 2017-2019.

Lepr ${ }^{\text {EYFPAGHR }}$ Origin To comprehend the role of GHR signaling on the CNS, Cady et al. produced the Lepr ${ }^{\text {EYFP } \Delta \text { GHR }}$ mouse in the laboratory of Marianna Sadagurski in 2017 [61]. A Cre/loxP system was used to ablate $G h r$ in the leptin receptor-expressing neurons. 
Phenotype No changes to body weight, length or composition are observed, and there is no change in serum IGF1 or GH levels [61]. Lepr ${ }^{\text {EYFP } \triangle G H R}$ mice do show impaired glucose homeostasis when compared to controls but normal insulin tolerance. This impaired glucose homeostasis may be due to the observed increase in hepatic gluconeogenesis.

AgRP-IRES-Cre Origin To investigate the role of brainspecific GH action on energy homeostasis, Furigo et al. produced an agouti-related protein (AgRP) GHR knockout (AgRP-IRES-Cre) mouse in the laboratory of Jose Donato in 2019 [64]. These mice were produced by crossing mice carrying loxP-flanked $G h r$ alleles with AgRP-IRES-Cre

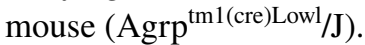

Phenotype There is no change in glucose tolerance or insulin sensitivity, body weight, length or composition of these mice [64]. Also, no changes are observed in leptin sensitivity, ghrelin-induced food intake or ghrelin-induced c-Fos expression in the arcuate nucleus (ARH) of these mice. While there is no change in number of AgRP cells of the ARH, there is a reduction in c-Fos positive cells in a food-deprived state. These mice also show an attenuated neuroendocrine response that normally aids in energy conservation, when under food deprivation. Moreover, in this state, these mice show increased weight loss and decreased blood glucose compared to controls.

LepR-IRES-Cre Origin In the same publication from the laboratory of Jose Donato (mentioned above) for AgRPIRES-Cre mice, Furigo et al. reported the generation of a leptin receptor-presenting-cell-specific GHR knockout (LepR-IRES-Cre) mouse [64]. These mice were produced by crossing mice carrying loxP-flanked $G h r$ alleles with

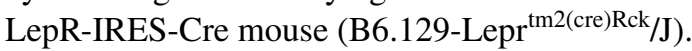

Phenotype These mice have an increase in body weight and body length, as well as a reduction in body fat mass [64]. There are no changes to food intake, leptin sensitivity or energy expenditure, but there is a decrease in serum leptin levels. Under food deprivation, these mice have increased weight loss with some mice becoming lethargic.

Nestin-Cre Origin Furigo et al. produced an entire brain GHR knockout (Nestin-Cre) mouse in their 2019 publication [64]. As the name implies, these mice were produced using a Cre system driven by the nestin promoter/enhancer.

Phenotype Nestin-Cre mice have increased body weight and body length with an increase in lean mass [64]. There is also an upregulation of GHRH expression in the hypothalamus. While there is no change in food intake, leptin sensitivity or energy expenditure, an increase in weight loss is observed during food deprivation in these mice compared to controls.
Disruption of GHR in the brain has helped establish that $\mathrm{GH}$ has a role in neurological processes. By targeting $G h r$ in various regions of the brain, researchers have established that hypothalamic GHR controls hepatic glucose production in nutrient-sensing, leptin receptor-expressing neurons [61], and GH regulates responses to weight loss in AgRP neurons [64]. Given the intricacies of the brain and the vast number of cell populations, we anticipate that many more brain-specific GHR knockout mice will be generated and evaluated.

\section{Fat-specific GHRKO mice}

GH plays an important role in AT catabolism. To understand how the GH-axis in AT affects glucose homeostasis and longevity, three fat-specific GHR knockout mice have been independently generated and characterized.

FaGHRKO Origin The first fat-specific GHR knockout mouse line (FaGHRKO) was produced by List et al. in the Kopchick laboratory in 2013, utilizing the Cre/LoxP system driven by $a P 2$, also known as Fabp 4 promotor/enhancer [44].

Phenotype These mice show increased body weight with a $96 \%$ increase in total fat mass and an overall increase in body fluid when compared to controls [44]. Additionally, female mice show an $8 \%$ increase in lean mass. Both brown AT and all white AT depots are significantly increased in these mice. While no change is seen in insulin sensitivity, female mice show an increase in IGFBP5, IL-6 and leptin. Both male and female mice show a decrease in adipsin, with male mice displaying an additional decrease in adiponectin and IGF1 levels. Finally, these mice have a shortened lifespan when compared to WT controls.

AdGHRKO Origin Later, expression of the aP2 promoter/ enhancer was found in non-ATs, interfering with the interpretation of results seen in the FaGHRKO mice. To use a more reliable and robust model to investigate the direct effects of GH on AT, List et al. produced the AdGHRKO mouse, an adipocyte-specific GHR knockout mouse driven by adipoenctin/Cre [220].

Phenotype These mice exhibit no change in body length or body weight, though they have increased fat mass [220]. More specifically, all white AT depots had increased mass in female mice, and all but the perigonadal depot are increased in males. There is also an increase in brown AT in female mice. Adipocyte size is increased in these mice, with the only exception, again, being the perigonadal depot in male mice. These mice have improved glucose homeostasis with an increase in insulin sensitivity and no change in glucose tolerance. Furthermore, there is no change in serum GH, IGF1 or fasting blood glucose, but there is a decrease in total insulin in male mice. These mice also have a reduction 
in liver triglycerides. Overall, the more recent AdGHRKO mouse line has an AT profile remarkably like the previously reported FaGHRKO produced in the same laboratory.

Fat-Ghr-/- Origin To investigate the role of adipocyte-specific GH-action on CR, Fang et al. produced the Fat-Ghr-/mouse in the laboratory of Guosheng Liang in 2019 using the Cre/LoxP system driven by an adiponectin promoter/ enhancer [63].

Phenotype Differing from AdGHRKO mice, Fat-Ghr-/mice have no change in body fat mass. When placed on $\mathrm{CR}$, there is no change in blood glucose, plasma ghrelin or plasma GH levels [63].

Three distinct fat-specific GHRKO mouse lines have been created. FaGHRKO and AdGHRKO lines generated in the same laboratory by List et al. have a similar AT profile, with increased adiposity resulting in an overall increase in percent body fat. In contrast, Fat-Ghr-/- mice generated by Fang et al. have no phenotypic change in any parameter including percent body fat. The difference between these mouse lines is unknown but may result from incomplete disruption of the GHR in AT. Genetic background is likely not a factor since all three lines were produced in a mixed C57BL/6 N x C57BL/6 J background, where floxed mice were generated in C57BL/6 $\mathrm{N}$ then crossed to Cre mice in a C57BL/6 J background. It should be noted that both FaGHRKO and AdGHRKO mouse lines were generated using the same floxed mouse - generated in the Kopchick laboratory, while Fat-Ghr-/- mice were generated using floxed mice generated in the Liang laboratory. Thus, it is possible that differences in the floxed mouse lines may exist.

\section{Other GHRKO mouse lines}

In the following section, we will discuss several individual mouse lines generated to explore the tissue-specific effects of GH and GHR on the heart, bone and intestines or cell types such as macrophages, beta-cells and hematopoietic stem cells.

\section{Macrophage-GHRMacD}

Origin While GHRs are expressed on macrophages, little is known about the role of $\mathrm{GH}$ in macrophage function. Accordingly, in 2010, Lu et al. produced the GHRMacD mouse in the laboratory of Ram Menon [39]. These mice were produced using the Cre/LoxP system driven by the Lyzs locus, expressed specifically in macrophages, monocytes and granulocytes (neutrophils, basophils, etc.).

Phenotype In vivo characterization is not described for this mouse line in this initial paper; however, in vitro studies show that cultured media collected from primary macrophages in the stromal vascular compartment (SVC) of AT from GHRMacD mice have an inhibitory effect on preadipocyte differentiation when placed on 3T3-L1 cells [39]. This finding indicates that intact $\mathrm{GH}$-action in primary macrophages increases preadipocyte differentiation. However, GH does not increase IGF1 expression in macrophages. There is no difference between IGF1 levels in GHRMacD macrophages and control macrophages when treated with GH. In a follow up study in live mice, the Menon laboratory showed that GHRMacD mice (also called MacGHR KO mice in this paper) have no observable phenotypic changes except when challenged with a HFD [47]. When fed a HFD, GHRMacD mice had increased macrophage abundance in AT resulting in increased AT crown like structures and increased expression of pro-inflammatory cytokines (IL-1 $\beta$, TNF- $\alpha$, IL-6, and osteopontin) in AT stromal vascular fraction. These results support the possibility that GH may have beneficial effects on diet induced obesity related chronic inflammation.

\section{Beta cell- $\beta$ GHRKO}

Origin To determine the role of the GHR in $\beta$-cell mass and function, Wu et al. created the $\beta$-cell GHR knockout mouse ( $\beta$ GHRKO) in the laboratory of Derek LeRoith in 2011 [41]. $\beta$ GHRKO mice were generated by crossing GHR floxed mice with a rat insulin 2 promoter (RIP)/Cre/hGH mouse line constructed by Pedro Herrera [221].

Phenotype When fed a standard chow diet, $\beta$ GHRKO mice show no difference in body weight, body composition or IGF1 and insulin levels compared to controls [221]. However, these mice show a significant decrease in islet cell size and number, suggesting that GH stimulates the growth and proliferation of islet cells. On a HFD, $\beta$ GHRKO mice show a significant decrease in $\beta$-cell mass and higher glucose levels.

It should be noted that there is controversy surrounding the Cre line used in this study as it inadvertently expresses $\mathrm{h} G H$, thus results obtained by studies using $\beta$ GHRKO mice are difficult to interpret. More specifically, multiple laboratories have demonstrated that fusion genes containing the $\mathrm{h} G H$ minigene used to enhance transgene expression and thought to not be transcribed or translated do in fact produce significant amounts of hGH [222, 223]. Furthermore, GH expressed in pancreatic islets can bind to the PRLR thus augmenting phenotypic factors such as beta cell mass and insulin content [222].

\section{Hematopoietic stem cells (HSC)}

Origin To investigate the impact of GH signaling on hematopoietic stem cells (HSC), Stewart et al. produced the $\mathrm{Ghr}^{\mathrm{fl} / \mathrm{f}} ; \mathrm{Vav} \mathrm{I}^{\mathrm{Cre} / \mathrm{H}}$ mouse in the laboratory of Rossi in 2014, 
using the Cre/LoxP system driven by vavl gene transcriptional regulatory sequences [50].

Phenotype Ex vivo analyses conducted using primary hematopoietic stem cells from these mice show no significant 'blood cell' differences apart from a decrease in number of platelets [50]. Also, there are no changes in progenitor compartments, progenitor cell action or in peripheral blood engraftment following the primary and secondary competitive transplants. These results suggest that GH signaling is dispensable for HSC function.

\section{Bone-DMP-GHRKO}

Origin To investigate the role of GHR action on bone growth, Liu et al. produced the DMP-GHRKO mouse in the laboratory of Shoshana Yakar in 2016, using the Cre/ LoxP system driven by a dentin matrix protein 1 ( $D m p l)$ promoter/enhancer [224].

Phenotype These mice show no change in body weight or composition [224]. Also, there is no change in osteocyte morphology or serum IGF1 levels. Serum GH is increased at 8 weeks and is similar to controls by 16 weeks of age. The DMP-GHRKO mice have decreased lacunae and crosssectional area, resulting in a slender bone phenotype. Additionally, female mice have similar cortical bone thickness to controls but decreased bone marrow area. Males, however, have decreased cortical bone thickness and increased marrow area. DMP-GHRKO mice also have reduced levels of parathyroid hormone. To further understand the role of autocrine/paracrine IGF1 in bones, a DMP-IGF1RKO mouse, as more thoroughly described below, was produced. These mice have increased cortical bone cross-sectional area and reduced bone thickness and marrow area. Thus, the authors suggest that IGF1R and GHR may have overlapping as well as distinct effects on osteocytes [224].

\section{Heart-iC-GHRKO}

Origin To study the role of GH-action on the heart, Jara et al. produced the adult-inducible cardiac-specific GHR knockout mouse (iC-GHRKO) in the Kopchick laboratory in 2016, using a Cre/LoxP system driven by myosin heavy chain 6 promoter/enhancer [58].

Phenotype These mice show no change in body weight or length; however, they do have changes in body composition [58]. That is, the knockout mice have reduced fat mass and increased lean mass when compared to controls. There is no change in circulating insulin, with a decrease in circulating IGF1 only at 12.5 months of age. At 6.5 months, there is no change in glucose tolerance, but an increase in insulin sensitivity is observed. At 12.5 months, however, these mice have decreased glucose tolerance and increased insulin resistance. The iC-GHRKO mice have no changes in cardiac dimension but have decreased cardiac wall thickness. Additionally, blood pressure is unaltered in iC-GHRKO mice compared to age matched controls. Thus, taken together, removal of GHR in cardiac tissue specifically, has no observable effect on cardiac physiology but results in a decreased cardiac wall thickness and altered whole body glucose homeostasis.

\section{Intestine-IntGHRKO}

Origin In 2019, to investigate the effect of GH on the intestines, Young et al. produced the intestinal epithelial cellspecific GHR knockout mouse (IntGHRKO) in the Kopchick laboratory, utilizing the Cre/LoxP system driven by a villin promoter/enhancer [65].

Phenotype These mice have comparable body weights to controls, with no persistent body composition differences [65]. In male mice, there is a decrease in large intestine length. Also, there is a trend, albeit not significant, towards shorter villi in the small intestine, as well as decreased crypt depth in both small and large intestines. Female mice have decreased glucose tolerance and show insulin resistance, while males do not. In terms of intestinal permeability measurements, male mice have increased expression of occludin and females have decreased fecal albumin, indicating that there is a modest improvement to barrier function. Finally, males present with decreased fat absorption. These results demonstrate that removal of GH-action in the intestinal epithelial cells has modest and sex-specific effects on intestinal morphology and function.

\section{Mouse lines downstream of GHR}

GH induced intracellular signaling molecules downstream of the GHR have been manipulated in mice and include Janus kinases (JAK), signal transducers and activators of transcription (STAT), suppressors of cytokine signaling (SOCS), acid-labile subunits (ALS), IGF1 and IGFBPs. These molecules play critical roles in growth and development, glucose homeostasis and other physiological processes; thus, mouse lines with alterations in the levels or actions of these molecules are of interest and will be discussed below. Results related to some of these mouse lines are summarized in Tables 3 and 4.

\section{JAKs, STATs, SOCSS}

The canonical GH intracellular signaling pathway, through JAK2 and STAT5b phosphorylation, has been targeted in addition to the other JAK and STAT proteins. In fact, almost every member of the JAK family and the STAT family has been knocked out in a mouse line, and a transgenic line overexpressing STAT4 has also been reported. Importantly, the 
JAK/STAT pathway is shared among many different hormones and cytokines; as such, disruption of genes in this pathway generally results in impaired immune response and decreased growth and are difficult to attribute solely to GH action. Further downstream from JAK/STAT are SOCS proteins that serve as important inhibitors of this signaling pathway. Specific phenotypes of each gene disruption or transgenic mouse will be discussed below. All of the knockouts discussed in this section were generated using homologous recombination; for detailed description of the methods used for each mouse line, the reader is referred to the original publications.

\section{JAK family knockout mice}

Global JAK knockout mice Origin Janus kinase proteins are intracellular tyrosine kinases that transduce signals of many cytokines. There are four members of the family: JAK1, JAK2, JAK3 and Tyrosine Kinase 2 (TYK2), each of which has been disrupted in a mouse line. Jak1-/- mice were first reported in 1998 by Rodig et al. [225]. Jak2-/- mice were produced in 1998 by both the Pfeffer laboratory and Ihle laboratory [226, 227]. JAK3 expression is more limited than JAK1 or JAK2, specific to hematopoietic cells and epithelial cells, so the creation of Jak3-/- mice was driven in part by the desire to develop a new mouse line of immunodeficiency. Jak3-/- mice were produced by Park et al. in 1995 [228]. TYK2 is ubiquitously expressed, and its disruption in a mouse was first reported by Shimoda et al. in 2000 [229].

Phenotype Jakl -/- mice have decreased size compared to controls and an impaired immune response [225]. They also have a failure to nurse, leading to death within days of birth, indicating a broad range of cytokine signaling disruptions. In contrast, Jak2-/- mice die in utero, presumably due to their impaired erythropoiesis, as stem cells from Jak2/- mice respond to interferon $\alpha$ but not to erythropoietin or interferon $\gamma$ [226, 227]. Jak3-/- mice are born in the expected Mendelian ratio (when heterozygous mice are bred, 25\% of the resultant offspring are Jak3-/-) and survive to adulthood but have impaired lymphocyte development [228]. Specifically, they have decreased $\mathrm{B}$ and $\mathrm{T}$ cells and lack peripheral lymph nodes, natural killer cells and $\gamma \delta \mathrm{T}$ cells in the skin and intestines. Tyk2-/- mice develop normally, but have impaired IFN $\alpha$ signaling and their response to interleukin (IL)-12 is completely disrupted [229]. Interestingly, these mice also develop obesity and glucose intolerance due to abnormal BAT development [230].

Mice with tissue specific disruption of JAK2 Origin Although systemic JAK2 gene disruption is fatal, at least two tissuespecific JAK2 gene disrupted mice with direct relevance to GH's metabolic effects have been reported. Liver-specific disruption of JAK2 (JAK2L mice) was first reported by
Sos et al. in 2011, using the Cre/LoxP system with albumin promoter/enhancer to drive Cre [231]. To further explore the relationship between JAK2 and metabolism, the same laboratory developed an adipose-specific JAK2 disrupted (JAK2A) mouse line (first reported in 2013), also using the Cre/LoxP system with adiponectin promoter/enhancer driving Cre expression [232].

Phenotype JAK2L mice exhibit impaired lipid metabolism, with increased liver triglycerides and serum free fatty acids [231]. JAK2A mice have decreased lipolysis and increased body fat, as one would expect when GH signaling is disrupted in fat [232]. Interestingly, when the JAK2L and JAK2A mice are crossed to produce JAK2LA mice, those with JAK2 disruption in both tissues show the same increase in body fat and decreased lipolysis, but without interfering with liver lipid metabolism seen in JAK2L mice, indicating that the regulation of lipid metabolism through JAK2 involves coordination among multiple tissues [232].

\section{STAT transgenic and STAT knockout mice}

The STAT family are proteins that lie downstream of JAKs in various cytokine signaling pathways. The STAT family consists of 7 members-STAT1, STAT2, STAT3, STAT4, STAT5a, STAT5b, and STAT6 - each of which has been disrupted in a mouse line; STAT4 transgenic mice have also been reported.

STAT1-/- mice Origin Because STAT1 is a central factor in interferon signaling and involved in the signaling of other cytokines, Stat1-/- mice were generated in 1996 by Meraz et al. and Durbin et al. to determine whether STAT1 is necessary for all interferon-induced signaling, as well as signaling of other cytokines [233, 234].

Phenotype STAT1 deficient mice have normal reproduction [233, 234]. Despite GH's ability to activate STAT1, this mouse line has no change in body size and responds normally to $\mathrm{GH}$ administration, gaining the same amount of weight as vehicle-treated controls. Stat1-/- mice also have normal responses to epidermal growth factor (EGF), IL-10, and IL-6. The most prominent phenotype of Stat1-/- mice is their complete lack of responsiveness to interferon ( $\alpha$ and $\gamma)$ [233, 234], leading to a strong susceptibility to infection by both bacteria and viruses, despite normal immune cell populations. The specificity of interferon signaling disruption in Stat1-/- mice has led to their common use as a model of interferon deficiency.

STAT2-/- and STAT3-/- mice Origin STAT2, in contrast to STAT1, is specific to type 1 interferon ( $\alpha$ and $\beta$ ) signaling. Stat2-/- mice were first reported by Park et al. in 2000 [235]. STAT3 was initially identified as a downstream effector of IL-6, but later found to be activated in response to other 
cytokines. In an attempt to clarify the role of STAT3 in cytokine signaling, Stat3-/- mice were developed in 1997 by Takeda et al. [236].

Phenotype As expected, Stat2-/- animals have increased susceptibility to infection but have unique deficiencies in $\mathrm{T}$ cells and macrophages as well as decreased STAT1 expression in some tissues [235]. STAT3 knockout mice die early in embryogenesis, thus limiting the utility of this mouse line [236].

STAT4 transgenic and STAT4-/- mice Origin STAT4 is predominantly associated with IL-12 signaling, and both STAT4 transgenic and null mice were generated to confirm this specificity. STAT4 transgenic mice were first reported in 1999 by Wirtz et al. using the cytomegalovirus (CMV) promoter/enhancer to drive expression of murine Stat4 cDNA [237]. Stat4-/- mice were first reported in 1996 by Thierfelder et al. and Kaplan et al. [238, 239].

Phenotype Although no transgenic Stat4 mRNA is initially detected in the colon, STAT4 expression is induced by injecting dinitrophenyl-keyhole limpet hemocyanin, and upon this treatment, colitis developed in the transgenic mice [237]. This phenotype agrees with the finding that IL-12 is associated with Crohn's disease in humans. In contrast to STAT4 transgenic mice, Stat4-/- mice also have normal growth and reproduction but an impaired immune system $[238,239]$. STAT4 ablation in mice did result in disrupted IL-12 signaling, which causes decreased interferon- $\gamma$ secretion, decreased $\mathrm{T}$ cell proliferation, decreased natural killer cell toxicity, and a shift from Th1 to Th2 cell differentiation.

STAT5a-/-, STAT5b-/- and STAT5a-/-5b-/- mice Origin STAT5 denotes two highly similar proteins, STAT5a and STAT5b, which have unique and overlapping functions, and may work together through the formation of heterodimers. As such, each has been knocked out in mice individually, as well as jointly. Stat5a-/- mice were first reported in 1997 by Liu et al. [240], while Stat5b-/- mice were reported in the same year by Udy et al. [241], and Stat $5 a-/-5 b-/-$ were reported the following year (1998) by Teglund et al. [242].

Phenotype Stat5a-/- mice exhibit normal size, weight, and fertility, but they are unable to lactate, indicating a probable disruption of PRL signaling [240]. These mice also exhibit an impaired IL-2 response in T cells that can be overcome by IL-2 administration. STAT5b is part of the canonical GH signaling pathway and thus, disruption of the Stat5b gene, yields an expected decrease in growth [241]. Unexpectedly, this growth deficit is limited to males. The ablation of STAT5b also results in a sex-specific pattern of gene expression in the liver (e.g. CYP and MUP). IL-2 resistance is more pronounced in Stat5b-/- mice, as excess IL-2 does not ameliorate this resistance. Stat5b-/- mice also exhibit IL-15 resistance. When STAT5a and STAT5b are knocked out in combination, a stronger phenotype is observed [242]. These double null mice have decreased lymphocytes in circulation and are infertile due to impaired corpus luteum formation. Similar to GHR-/- animals, Stat5a/-5b-/- mice are dwarf and have low serum IGF1 levels and decreased epididymal fat. Interestingly, about $1 / 3$ of the double knockout mice in the initial study died within $48 \mathrm{~h}$ of birth. The results from these three mouse lines underscore the importance of STAT5a and STAT5b in growth, lactation, and reproduction.

STAT6-/- mice Origin STAT6 is considered a key component in IL-4 signaling. To examine this relationship, Takeda et al. generated Stat6-/- mice [243].

Phenotype: Stat6-/- mice are similar in phenotype to many of the other STAT null mice and are also relatively "normal", with no reported change to body length, body weight, or reproduction. As expected, Stat6-/- mice experience disrupted IL-4 signaling, resulting in decreased MHC class II and CD23 expression. Stat6-/- animals also have impaired immunoglobin class switching, lymphocyte proliferation, and Th2 cell development [243]. Thus, STAT6 is important in adaptive and humoral immunity.

\section{SOCSs transgenic and SOCS-/- mice}

Further downstream of the GHR are SOCS proteins. As their name implies, SOCS proteins inhibit cytokine signaling in the JAK-STAT pathway. There are eight members of the SOCS family: SOCS1-SOCS7 and CISH, and each has been disrupted in a mouse line (except for SOCS4 and CISH). Transgenic models overexpressing CISH, SOCS1, SOCS2, SOCS3, SOCS5, and SOCS6 have also been reported. For more detail on SOCS family transgenic and null mouse lines, see a previous review on the subject [244].

SOCS1 transgenic and SOCS1-/- mice Origin The SOCS1 protein has been shown to inhibit GHR signaling [245], and thus Socsl-/- mice were generated by Starr et al. in 1998 [246]. SOCS1 transgenic mice were generated by expressing the transgene in the $\mathrm{T}$ cell lineage of mice via fusion of the cDNA to the lck tyrosine kinase proximal promoter / enhancer (first reported by Fujimoto et al. in 2000) [247].

Phenotype Socs 1-/- mice are normal size at birth but show decreased growth and die before weaning [246]. The role of SOCS1 in immune development is further substantiated by the principal phenotypes of both SOCS1 transgenic and null animals. In the T-cell specific SOCS1 transgenic mice, impaired $\mathrm{T}$ cell development is observed. In addition, Socs1-/- mice present phenotypic differences associated with alterations to the interferon gamma (IFN $\gamma$ ) pathway, ranging from lymphopenia to monocyte infiltration into organs [246]. When IFN $\gamma$ is knocked out alongside SOCS1, chronic 
inflammation and perturbed T cell development is detected, along with polycystic kidneys [248].

SOCS2, SOCS3 transgenic and SOCS2-/-, SOCS3-/- mice Origin SOCS 2 and SOCS3 were among the earliest SOCS proteins discovered, and both transgenic and null animals were generated for each gene/protein. Socs2-/- mice were reported by Metcalf et al., in 2000 [22], while SOCS2 transgenic mice were generated by Greenhalgh et al. in 2002 using the UBC promoter to drive gene expression [249]. SOCS3 transgenic and Socs3-/- mice were reported by Marine et al. in 1999 [250].

Phenotype Due to the role of SOCS2 in inhibiting the GH axis, Socs2-/- mice display gigantism [22]. These mice also show increased collagen deposition in their skin, another indication of increased GH action, and decreased levels of major urinary protein (MUP) in the urine. Interestingly, in SOCS2 transgenic mice, a counterintuitive result is observed; that is, the mice are giant [249]. These results suggest that excess or deficit of SOCS2 activate the GH/ IGF axis, while moderate levels inhibit GH action. It is hypothesized that this activation of the GH/IGF axis is due to SOCS2 outcompeting SOCS3 (a more potent GHR inhibitor) for GHR-binding at high concentrations. The status of SOCS3 as a more potent GHR inhibitor is demonstrated by the more extreme phenotype seen when SOCS3 is altered. Because of embryonic lethality, no growth-associated phenotypes could be assessed in SOCS3 null and transgenic mice [250].

SOCS5 transgenic and SOCS5-/- mice Origin Another member of the SOCS family, SOCS5 is also believed to be involved in immune development, but knowledge of its association lags that surrounding other SOCS proteins. To help rectify this, SOCS5 transgenic and null mice were developed, in 2002 by Seki et al. [251] and in 2004 by Brender et al. [252], respectively. In the transgenic mice, a FLAG tagged SOCS5 protein is expressed in mice under the control of the lck proximal promoter/enhancer.

Phenotype Alterations to SOCS5 seem to have milder phenotypes than those seen with SOCS1 manipulation, which may explain why relatively little was known about SOCS5. In SOCS5 transgenic mice, the phenotype is limited to decreased Th2 cell differentiation [251]. Socs5-/- mice, on the other hand, have no alteration in phenotype [252].

\section{SOCS6, CISH transgenic and SOCS6-/-, SOCS7-/-mice Origin} Transgenic mice that overexpress SOCS6 were generated by $\mathrm{Li}$ et al. in 2004 using the elongation factor 1 (EF1) promoter/enhancer to drive Socs6 expression [253], and CISH transgenic mice were generated by Matsumoto et al. in 1999 using the $\beta$-actin promoter to drive Cis1 expression [254]. The SOCS6 and SOCS7 genes have also been disrupted in mouse lines, with Socs6-/- mice being reported by Krebs et al. in 2002 [255] and Socs7-/- mice reported in 2005 by Banks et al. [256].

Phenotype SOCS6 and SOCS7 manipulation results in phenotypes marked by alterations in glucose metabolism. Specifically, in SOCS6 transgenic mice, an improvement in glucose metabolism is observed [253]. Socs7-/- exhibit increased pancreatic islet size and improved glucose metabolism [256]. Socs6 gene disruption (Socs6-/-), on the other hand, causes mild dwarfism with no reported change to glucose metabolism [255]. CISH transgenic mice phenotypically resemble Stat5-/- mice with normal development but with a defect in GH signaling [254]. Features of CISH transgenic mice include lactation deficiencies, indicating prolactin inhibition, as well as decreased body size, indicating the inhibition of the GH axis. However, CISH transgenic mice have normal fertility, differentiating them from Stat5/- mice. CISH transgenic mice also have alterations to their $\mathrm{T}$ cells [decreased $\gamma \delta \mathrm{T}$ cells, natural killer (NK) cells, and NK T Cells and a shift in Th1/Th2 differentiation towards Th2 cells], further illustrating the many roles of CISH.

The strong phenotypes of some of the molecules downstream of the GHR demonstrate the complex regulation of GH signaling even before the main effector of $\mathrm{GH}$ action, IGF1, is taken into account.

\section{IGF1, IGF1R, and tissue-specific KO}

As one of the most important products of GH action, IGF1 and its receptor have been manipulated in numerous mouse lines to study its endocrine, autocrine and paracrine effects both globally and in specific tissues or cells. The IGFs are synthesized by almost all tissues and are important mediators of cell growth, differentiation, and transformation. IGFs have a fundamental role in both prenatal and postnatal development and exert their physiologic effects by binding to the IGF receptors or, albeit with less affinity, the insulin receptor. In addition, IGF1's effects are modulated by multiple IGF binding proteins (BP). In the following section, we will summarize the transgenic and knockout mouse lines relating to both IGF1 and its receptor. Details regarding each mouse line can also be found in Table 3 .

\section{IGF1 transgenic mice}

Origin In 1988, Palmiter's laboratory generated IGF1 transgenic mice containing a fusion chimeric gene with $M t 1$ promoter/enhancer, a sequence encoding the rat somatostatin secretory signal sequence to allow for secretion, the human $I G F 1$ cDNA, and a sequence containing the human $G H$ 3'-RNA processing signals [257].

Phenotype These mice express 1.5 times higher circulating IGF1 levels than controls and, as expected, decreased 
GH levels [257]. No phenotypic differences are evident until 6-8 weeks of age. Overall, IGF1 transgenic mice display 1.3 times higher weight gain compared to WT mice though no increase in skeletal growth is observed. The spleen, pancreas, kidneys, and brain display increased growth. Also, fertility is not affected. Notably, changes in kidney structure have been identified in IGF1 transgenic mice by Striker's laboratory [258]. That is, IGF1 transgenic mice have enlarged glomeruli without glomerulosclerosis, in contrast to GH transgenic mice that display enlarged glomeruli with sclerosis. This implies that GH plays a direct role in the formation of kidney sclerosis while IGF1 stimulates increased glomerular size.

IGF2+/- mice (lgf2+/-)

Origin IGF2+/- (or Igf2+/-) mice were generated in 1990 by T. DeChiara in Robertson's laboratory by deleting a portion of exon 2 of the mouse Igf 2 gene [259].

Phenotype No homozygous Igf2-/- pups survive [259]. Heterozygous $I g f 2+/$ - pups display considerably smaller body size ( $60 \%$ of normal size). Genotyping of heterozygous embryos reveals that the mutant allele exerts its effect in the early embryonic stage (earlier than day 16) and maintains its effect in post-natal growth. Despite their diminutive size, the heterozygous mice appear normal and display normal reproductive capacity. Interestingly, this was the first study to identify the presence of imprinted genes (paternal), verifying previous hypotheses regarding this epigenetic phenomenon.

\section{IGF1-/- and IGF1R-/- mice, and associated double mutants}

IGF1-/- mice (Igf1-/-) Origin In 1993, the Efstratiadis laboratory reported the generation of the IGF1-/- (Igfl-/-) mouse generated via the deletion of exon 4 of the mouse Igfl gene [260].

Phenotype Igfl-/- mice experience increased neonatal lethality, although the rate of survivability is $10-68 \%$, which is dependent on genetic background [260]. At birth, Igfl-/mice display decreased body mass (65\% of normal size). Post-natal effects include a progressively decreased growth rate, displaying $30 \%$ of control mouse size in adulthood [261]. The heterozygous $I g f l+/-$ progeny do not display any obvious phenotypic difference from control littermates.

IGF1R-/- mice (Igf1r-/-) Origin In the same 1993 publication for the generation of IGF1-/- mice, the Efstratiadis group also reported generation of the Igflr-/- mice via the deletion of exon 3 in the gene encoding Igflr [260].

Phenotype These mice display severe growth deficiency with a body mass reduction of $45 \%$ compared to WT mice at birth. The mutant neonates, however, are not viable due to respiratory issues, and unlike IGF1-/- mice, lethality appears independent of the genetic background strain of the mice. In addition, mutant IGF1R-/- mice exhibit delayed ossification of bones in the extremities and trunk by 1-2 days post-birth.

IGF1-/- with IGF1R-/- mice Origin This same paper by Estratiadis also describes double mutants (Igfl-/- with Igflr-/-) [260].

Phenotype The phenotype of the double knockout does not differ from the IGF1R-/- mice [260].

Overall, the role of IGF1/IGF1R in mouse embryonic development appears essential for viability, and the absence of which shows a considerable impact on bone development, muscle development and growth.

IGF1R-/- with GHR-/- mice Origin In 2001, the Efstratiadis laboratory also reported the crossing of mutant mice lacking either IGF1, GHR or both simultaneously to examine the impact of GH and IGF1 in controlling postnatal growth [262]. Note that GHR null mice were generated using a targeting vector that replace exons $7,8 \mathrm{a}$, and 8 , distinct from that reported by Zhou et al., which is described above, but with a similar growth phenotype [30].

Phenotype With respect to growth, these studies estimated that $17 \%$ of body weight is attributed to processes unrelated to GH or IGF1 while IGF1 accounts for 35\% of growth and 14\% for GH [262]. Importantly, the study reveals that $34 \%$ of growth is associated with overlapping functions of GH and IGF1. This study also assesses chondrocytes and bone ossification and reports that GH and IGF1 have independent and overlapping functions in chondrocytes since the phenotype of double mutants is more severe than that manifested in either class of single mutant. Thus, these mutants provide conclusive evidence of the importance of both of these hormones acting independently and in concert to support body growth.

\section{Tissue-specific IGF1 and IGF1R manipulation}

To understand the role of IGF1 in specific tissues and cell types, IGF1 and IGF1R have been either knocked in or out in specific tissues and cell types. In the following section, we describe numerous tissue-specific mouse lines and provide additional details about each in Table 3 .

Liver-specific IGF1 transgenic and KO mice (i) Hepatic IGF1 transgenic (TTR-IGF-I) mice

Origin In 2006, Xu's laboratory created hepatic IGF1 transgenic (TTR-IGF-I) mice using a fusion gene consisting of the promoter/enhancer of the transthyretin (TTR) gene, the mouse Igfl cDNA, and the SV40t polyadenylation-signal [263]. Note that the TTR promoter/enhancer targets transgene expression specifically to the liver, and the 
authors estimate approximately three copies of the TTRIGF1 transgene in these mice.

Phenotype As expected with increased circulating levels of IGF1, these mice show decreased levels of GH and increased IGFBP3 levels [263]. As Pegvisomant treatment does not alter IGFBP3 levels in WT mice, these results collectively indicate that IGFBP3 is not a direct target of the GH signaling pathway. The authors suggest that liverexpressed IGF1 can stimulate IGFBP3 expression and stabilize IGF1 under GH-deficient conditions. These mice display a larger body size and organ weight, presumably due to the higher circulating IGF1 levels. When TTR-IGF-I mice are bred with MMTV-ErbB2 mice to investigate the effect of elevated IGF1 on ErbB2 driven mammary carcinogenesis, the high levels of systemic IGF1 appear to have no effect on promoting ErbB2 driven mammary carcinogenesis [264].

(ii) Hepatic IGF1 transgenic (HIT) mice and KO-HIT mice

Origin In 2009, LeRoith and colleagues, developed the hepatic IGF1 transgenic (HIT) mice, which overexpresses the rat Igfl transgene in the liver of mice, as well as KO-HIT mice, in which only the liver produces IGF1 (i.e. mice that have a null $I g f I$ gene in all tissues but overexpress a rat $I g f I$ transgene specifically in the liver) [265].

Phenotype HIT mice have increased IGF1, unaffected GH levels, increased body mass, organ sizes and skeletal sizes, but decreased adiposity [265]. In contrast, KO-HIT mice have total absence of tissue IGF1, but elevated levels of serum IGF1, which can support normal body size and weight at puberty and postpubertal ages. Early deficits in skeletal structure of KO-HIT mice are restored by adulthood [266]. Insulin sensitivity is not altered by elevated levels of serum IGF1. Female KO-HIT mice have insufficient tissue IGF1 to fully support the female reproductive system, while male mice reproductive function is not affected. Overall, KO-HIT mice show that most autocrine/paracrine actions of IGF1 related to tissue growth and function can be offset by elevated levels of endocrine IGF1 although autocrine/ paracrine IGF1 appears critical for neonatal development.

(iii) GHRKO-HIT mice

Origin In 2013 Yakar et al. combined the GHRKO mouse with the HIT mouse to generate the GHRKO-HIT mouse [267].

Phenotype The results with GHRKO-HIT suggest that, with the absence of GH-GHR mediated action, serum IGF1 is not sufficient to restore body and skeletal size, but sufficient to restore impaired glucose tolerance in GHRKO mice [267].

(iv) LID mice

Origin The first liver specific IGF1 KO (LID) mouse line was produced by Yakar and LeRoith in 1999 via crossing albumin Cre mice with Igfl floxed mice.
Phenotype LID mice have increased GH and decreased IGF1 levels due to IGF1 ablation in the liver [268]. Their body weight, selected organ weights (kidney, fat, muscle, spleen, and heart), body length and femur length are not different from WT controls. LID mice exhibit decreased insulin sensitivity and display normal reproductive capacity. Interestingly, when treated with GH, female LID mice exhibit an accelerated growth rate compared to males [216]. LID mice also show decreased cancer incidence and an increased lifespan in females compared to controls [21, 269] presumably attributing to lowered levels of circulating IGF1. These results challenged the idea that circulating IGF1 is critical for normal growth and development and suggest that growth is preserved even when IGF1 is absent from the liver and/ or the importance of the autocrine/paracrine role of IGF1.

(v) Conditional liver IGF1KO mice (LI-IGF-I-/-)

Origin In 1999, Sjögren et al. produced conditional liver IGF1KO mice (referred to in the paper as LI-IGF-I-/- mice) by crossing mice with a Mx Cre (Mx dynamin-like GTPase 1) promoter/enhancer, which is activated in an interferondependent manner, to $I g f l$ floxed mice [270].

Phenotype Similar to LID mice, these mice have increased GH levels, decreased IGF1 levels in serum $(\sim 75 \%)$ and exhibit no changes in postnatal growth with induction of interferon at $\sim 1$ month and measurements at $\sim 2$ months after induction. Interestingly, kidneys are slightly smaller and the livers larger in LI-IGF-I-/- mice than in controls [270]. At 13 months of age, these mice have decreased fat mass and become insulin resistant [271]. The female mice also have an increased mean lifespan [272].

In summary, these results suggest that decreased endocrine IGF1 has a critical role in decreasing cancer incidence and extending lifespan, but it does not affect growth and development significantly. These findings are in contrast to what is observed in LiGHRKO mice in which lifespan is not altered and body size is decreased [48]. In these cases, GH and local IGF1 may be able to sustain growth of the whole organism and organs. On the other hand, increased IGF1 levels could further increase body size, organ weight and glucose tolerance.

Adipose-specific IGF1R KO mice (i) $a P 2$ adipose-specific IGF1R KO mice

Origin Different transcriptional regulators have been used to determine the physiological role of the IGF1R signaling in AT. Initially, an $a P 2$ promoter/enhancer-driven Cre was utilized by Kloting et al. in 2008 [273].

Phenotype These ap2 adipose-specific IGF1R KO mice have a marked increase in somatic growth with increases in both body weight and body length [273]. They also have elevated circulating IGF1 and IGFBP3 levels with no change in GH. The authors suggest that the $\sim 20 \%$ increase in circulating IGF1 is responsible for the increased growth. 
Other notable metabolic features in these mice include elevated glucose levels and suppressed adiponectin levels, despite normal glucose and insulin tolerance. Regarding their AT phenotype, these mice have increased fat mass, more prominent in the gonadal region versus the subcutaneous region, and significant increases in adipocyte size. The increase in lipid accumulation is attributed to an increase in IRs and insulin-stimulated glucose uptake into adipocytes with the deletion of the IGF1R. Importantly, these authors reveal a decrease in IGF1R protein not only in AT but also in the brain. More recently, other groups have confirmed the promiscuity of the ap 2 promoter in several tissues including regions of the brain [274-276]. The "leaky" nature of this promoter sheds doubts on whether the phenotype observed in these mice is due to a deletion of IGF1R AT or other tissues. Regardless, the authors conclude that IGF1R signaling in adipocytes is not crucial for the development and differentiation of AT/adipocytes but does seem to participate in regulating circulating IGF1 levels.

(ii) Adiponectin adipose-specific IGF1R KO mice

Origin To uncover the specific role of IGF1R in adipocytes, a second adipocyte-specific IGF1R KO mouse was created using the adiponectin promoter/enhancer by Ron Kahn's group in 2016 [277].

Phenotype These mice have a distinct phenotype as compared to the first mouse line made with the ap2 Cre. The adipo-Cre IGF1R KO mice have modest reductions in both white AT and brown AT mass ( 25\%), despite a 73\% increase in circulating IGF1 levels [277]. They also have reduced expression of lipogenic genes in intra-abdominal fat depots, reduced levels of circulating leptin and adiponectin [277] with no change in ectopic fat deposition. However, these mice have no appreciable changes in response to a glucose or insulin challenge or basal insulin or glucose levels. In comparison, insulin receptor adipocyte-specific KO results in a severe lipodystrophic state, severely impaired glucose metabolism (higher basal glucose and insulin, impaired GTT and ITT), and increased ectopic fat deposition than IGF1R KO mice. Thus, the authors conclude that insulin and IGF1 signaling play essential but distinct roles in the development and function of white and brown fat.

Brain-specific IGF1R KO mice (bIGF1RKO+/-and bIGF1RKO-/-) Origin In 2008, Holzenberger's laboratory generated brain-specific IGF1R KO mice by crossing IgfI floxed females with Nestin-Cre transgenic males (flox/+; NesCre +/0) [278]. Nestin driven Cre recombinase is specific to neural and glial precursors early in neural development.

Phenotype Homozygous double mutants express no IGF1R on CNS neurons or glia [278]. The homozygous animals have microcephaly with severe growth retardation; they are also infertile and exhibit abnormal behavior (e.g. male $\mathrm{KO}$ mice have impaired exploratory behavior and are less anxious) but have normal lifespans. On the other hand, heterozygotes, whose IGF1R levels are depleted by half in the neurons and glia, exhibit healthier aging (delayed mortality and longer mean lifespan) and behave normally. By 90 days, heterozygote adults weigh $90 \%$ of WT controls and are 5\% shorter in length. They have normal IGF1 levels in peripheral tissues but lower plasma GH and IGF1 levels. Adult pituitaries are 30-40\% smaller with markedly fewer somatotrophs, and most other organs are smaller in adult bIGF1RKO +/- mice with the exception of AT, which is significantly increased in both adult males and females. Adult heterozygous males also have significantly higher circulating lipid levels (triglyceride, HDL, total cholesterol and free fatty acid) compared to WT animals. Both sexes of heterozygous mice have impaired glucose tolerance. Like homozygous mice, there is no change in maximum lifespan of heterozygous mice; however, heterozygous mice do have an increase in mean lifespan, which is attributed to fewer degenerative diseases as well as tumors compared to WT. Overall, the authors conclude that partially lowered GH/ IGF1 signaling in the brain favors lifespan extension and that the ability to alter somatotropic function in stressful environments allows the organism to decelerate growth and preserve resources, and thereby improve health span.

Muscle-specific IGF1 transgenic and IGF1R KO mice (i) Skeletal muscle IGF1 transgenic Mice

Origin Striated muscle-specific IGF1 transgenic mice were created in 1995 by the Schwartz laboratory using the avian skeletal $\alpha$-actin gene proximal promoter/enhancer appended to the human IGF1 gene [279].

Phenotype Striated muscle-specific IGF1 transgenic mice have no changes in serum IGF1 levels or body weight [279]. However, concentrations of IGF1 in muscle are 47-fold greater in transgenic mice compared to WT controls, causing myofiber hypertrophy with a change in overall fiber types and increased superficial gluteus muscle.

(ii) MKR Mice

Origin In 2001, Le Roith's laboratory generated skeletal muscle-specific transgenic mice by overexpressing a dominant-negative IGF1R (MKR mice) via fusion of mutant $I G F 1 R$ (KR-hIGF1R) cDNA downstream of the musclecreatine kinase (MCK) promoter/enhancer [280]. In these mice, the mutated gene encodes a protein that has lysine at position 1003 changed to arginine (KR mutant), which abolishes the ATP-binding within the $\beta$-subunit of the human IGFIR cDNA.

Phenotype In these mice, expression at the protein level results in the formation of hybrid receptors between mutant and endogenous IGF1R and IRs, abrogating their normal function and resulting in a marked decrease in glucose uptake upon stimulation with either IGF1 or insulin [280]. 
Although normal glucose tolerance is maintained, peripheral insulin resistance and pancreatic beta cell dysfunction develop by seven to twelve weeks of age in MKR mice, contributing to a chronic hyperglycemic state. Overall, body glucose disposal, glycolysis and glycogen synthesis are significantly reduced in MKR mice. In the skeletal muscle and brown AT of these mice, glucose transport activity is reduced by $50 \%$. There is also a marked increase in the number of glycogen deposits, FFAs, and triglycerides in the livers consistent with an aggravation of the insulin-resistant state. MKR mice also exhibit a $10-20 \%$ reduction in body weight relative to WT controls.

(iii) MIGIRKO Mice

Origin A double knockout mouse (MIGIRKO), which has a loss of both IR and IGF1R signaling reported by O'Neill et al., in 2015, was generated via the use of a Cre/LoxP system using a skeletal muscle actin promoter/enhancer [281].

Phenotype MIGIRKO mice exhibit a $60 \%$ decrease in muscle mass, accompanied by loss of both muscle strength and endurance, and a shortened lifespan (6 months) due to atrophy of the diaphragm [281]. These mice have normal glucose and insulin tolerance but lower fasting glucose levels and increased basal glucose uptake. The alteration in glucose metabolism is due to increased membrane localization of glucose transporters (Glut 4 and Glut 1) as a result of decreased TBC1D1, a protein critical to the regulation of glucose transport in muscle cells.

(iv) M-IGF1R KO Mice

Origin In 2016, O'Neil et al. also reported the characterization of muscle-specific IGF1R KO mice (M-IGF1R KO) [282].

Phenotype M-IGF1R KO has no significant reduction in muscle mass in contrast to MIGIRKO, most likely due to compensation on behalf of functional IR signaling [282]. Overall, these mice do not display a dramatic phenotype resulting from disruption of solely IGF1 action in muscle, again, likely due to compensation via functional IR signaling.

Cardiac-specific IGF1 transgenic and IGF1R KO mice (i) Cardiac-specific IGF1 transgenic mice

Origin In 1996, IGF1 transgenic mice were generated by the Anversa laboratory using human IGFI cDNA placed under transcriptional control of rat $\alpha$-myosin heavy chain promoter/enhancer [283].

Phenotype These transgenic mice have increased serum IGF1 despite cardiomyocytes being the only source of transgenic IGF1 [283]. This finding is similar to what is reported above for cardiac-specific GHR disruption by Jara et al. [58] and emphasizes the significant contribution of cardiomyocytes to endocrine IGF1. These mice have significantly greater total heart mass, liver, brain, spleen and kidney due to the increase in IGF1. The enlarged hearts are attributed to overexpression of IGF1-induced myocyte proliferation, suggesting that local and endocrine IGF1 increase organ sizes and promote myocyte proliferation.

(ii) Cardiomyocyte IGF1 transgenic mice

Origin Another cardiomyocyte IGF1 transgenic mouse line was created using mouse $\alpha$-myosin heavy chain promoter/enhancer by the Rosenthal group in 2007 [284].

Phenotype In these mice, local IGF1 expression results in accelerated postnatal cardiac growth and greater heart size [284]. These mice have the capacity to repair their hearts more efficiently both morphologically and functionally in response to injuries induced by cardiotoxin or ligation.

(iii) CIGF1RKO mice

Origin In 2008, the laboratory of Abel developed a constitutive cardiac-specific IGF1R knockout mouse (CIGF1RKO) [285].

Phenotype These mice are resistant to exercise-induce cardiac hypertrophy, implicating IGF1 in this process [285].

(iv) iCMIGF-IRKO mice

Origin Adult heart, tamoxifen-inducible, cardiomyocytespecific IGF1R KO mice (iCMIGF-IRKO) were reported in 2012 by Gödecke et al. [286]. Mice with tamoxifen induction at 3 months and 11 months of age, with measurements taken 6 weeks after gene deletion, are described.

Phenotype Younger induction ( 3 months) results in no functional or structural consequences; however, induction at the older age (11 months) results in cardiac dysfunction without structural abnormality [286].

In summary, these studies show that autocrine/paracrine IGF1 promotes heart repair in response to injury and conservation of cardiac function. However, the absence of IGF1 signaling in cardiomyocytes does not affect the morphology or function of hearts significantly, unless induction occurs at a later age (11-month-old). Similarly, the removal of GH action in heart at adult age (4-month-old) affects neither the local IGF1 levels nor the function of hearts [58] even though endocrine IGF1 levels are altered.

Endothelial IGF1R transgenic and KO mice (i) Endothelial IGF1R transgenic mice (hIGFREO)

Origin Generated by Kearney et al. team in 2012, the endothelial IGF1R transgenic mice (hIGFREO) were produced by overexpressing human IGFIR following the Tie 2 (mouse endothelial-specific receptor tyrosine kinase) promoter/enhancer [287].

Phenotype These transgenic mice exhibit no change in size/weight or glucose homeostasis [287]. Reduced basal and insulin-stimulated eNOS activity is reported in these mice. As for cardiac function, no difference in endothelial cell eNOS is observed with only enhanced aortic constriction in response to phenylephrine. These mice have normal blood pressure and aortic response to acetylcholine (ACH) 
and nitroprusside but increased endothelial cell migration and regeneration.

(ii) EC IGF-1R KO mice

Origin Also reported by Kearney et al. in 2011, opposite results are observed for the endothelium-specific IGF1R KO mouse (EC IGF-1R KO) produced by Tie2 Cre [288]. A second endothelial cell (EC)-specific IGF1-R KO mouse line was generated by Cheng and colleague in 2015 within the context of chronic kidney disease (CDK)-induced pathology via vascular epithelial (VE)-cadherin-Cre [289].

Phenotype Kearney et al. report that male EC IGF-1R KO mice show normal glucose homeostasis with enhanced basal and insulin-stimulated eNOS phosphorylation[288]. As for cardiac function, there is blunted aortic constriction in response to phenylephrine and enhanced aortic constriction in response to 1-NG-nitro-l-arginine methyl ester (L-NMMA). No difference in endothelial cell eNOS is observed. The EC specific IGF1-R KO mice produced by Cheng et al. have no changes in overall body size, weight, or reproductive capacity [289]. However, these KO mice display significantly more severe tubular injury and interstitial collagen deposition in obstructed kidneys compared to WT. The phosphorylation state of VE-cadherin, correlating with the disassembly of EC junctions, is significantly higher, along with markedly increased platelet accumulation and vascular permeability in null animals.

Collectively, these results support an important role for IGF1R within a physiological range in regulating nitric oxide bioavailability and vascular repair, which are hallmarks of several human diseases involving tissue growth and vascularization.

\section{Myeloid and macrophage-specific IGF1R KO mice (i) MIKO mice}

Origin In 2016, Dixit and colleagues at Yale University created myeloid-specific IGF1R KO mice (MIKO) with Cre driven by Lys $M$ promotor/enhancer [290, 291].

Phenotype MIKO mice have decreased NLRP3 (NOD-, LRR- and pyrin domain-containing protein 3) inflammasome activation in aging macrophages [290]. They also exhibit increased adiposity, with fewer macrophages in the stromal vascular fraction of visceral AT and a decrease in M2 macrophage activation, unlike the increase in visceral AT M2 macrophage polarization reported in GHRKO mice [291]. Interestingly, these mice show delayed resolution from helminth infection (which induces an adaptive immune response characterized by a distinct $\mathrm{T}$ helper cell driven cellular and cytokine profile) and have increased insulin resistance when placed on a HFD.

(ii) MФ-IGF1RKO mice

Origin As autocrine/paracrine action of IGF1 plays an important role in increasing macrophage activities [290], in 2016, Delafontaine and colleagues created a monocyte/ macrophage-specific IGF1R KO mouse (M $\Phi$-IGF1RKO), bred on an apolipoprotein E-deficient genetic background [292].

Phenotype These mice show increased atherosclerotic lesion formation with less stable plaques and marked by increased macrophage content [292]. Plaque-associated macrophages exhibit increased inflammatory responses to stimulation, as well as increased expression of antioxidant genes. Production of cytokines or chemokines such as IL-1 $\alpha$, IL-6, TNF $\alpha$, MPC1 and fractalkine (an unusual chemokine encoded by the gene CX3CL that can act as either a soluble or membrane-bound mediator), are associated with increases in NFKB activity. These macrophages also demonstrate decreased expression of ATP-binding cassette transporters $\mathrm{ABCA} 1$ and $\mathrm{ABCG} 1$ and, therefore, a significant reduction in HDL-dependent cholesterol efflux, which leads to atherogenesis.

In conclusion, these studies suggest that macrophage IGF1 signaling exerts anti-atherogenic effects through suppressing macrophage activities, atherosclerotic lesion formation, and reducing plaque vulnerability.

Bone-specific IGF1 transgenic and IGF1(R) KO mice (i) Osteoblast-specific IGF1 transgenic mice

Origin In 2000, Clemens' Laboratory created the osteoblast-specific IGF1 transgenic by fusing the rIgfl cDNA transgene to the human osteocalcin $(O C)$ promoter/enhancer [293]. Another osteoblast-lineage IGF1 transgenic mouse reported by Kream's group in 2006 utilized the upstream regulatory sequence of rat Collal gene followed by murine Igfl [294].

Phenotype The mice from Clemens' group have increased bone formation rate and cortical and trabecular bone mass density [295]. The mice generated by Kream's group show increased bone formation and resorption; male transgenic mice have increased serum IGF1 levels and body weight [294].

(ii) Osteoblast IGF1R KO mice and OBIGF1R-/- mice

Origin Osteoblast IGF1R KO mice were generated by Clemens's group in 2002 (human osteocalcin promoter/ enhancer) [296-298] and OBIGF1R-/- mice (Coll $\alpha 1$ promotor/enhancer) by Bikle's laboratory in 2015 [296-298].

Phenotype Both mice have decreased bone formation rate and cancellous bone volume/connectivity with normal body size [296-298]. These mice also have increased trabecular bone separation with a decrease in trabecular number.

(iii) Chondrocyte IGF1 KO mice

Origin Chondrocyte IGF1 KO mice originated using the procollagen Col $2 \alpha 1$ gene promoter/enhancer driven Cre by Mohan's laboratory in 2007 [299, 300].

Phenotype These mice exhibit decreased bone mineral content, bone mineral density, bone size, weight and body length when compared to WT [299, 300]. 
(iv) Osteocyte IGF1 KO mice

Origin In 2013, Lau and colleagues created the osteocyte IGF1 KO mice using dentin matrix protein $1(\mathrm{Dmpl})$ driven Cre [301].

Phenotype These mice have significantly smaller periosteal diameter of femurs, shorter femur lengths, reduction in bone mineral contents, bone formation and bone turnover [301].

(v) DMP-IGF-1R KO mice

Origin Osteocyte IGF1R KO mice (DMP-IGF-1R KO) were generated by Yakar et al. in 2016 [224].

Phenotype DMP-IGF-1R KO mice show an increase in total cross-sectional areas of femora with reductions in bone area but significant increases to marrow area. DMP-IGF-1R KO mice also exhibit cortical bone thickness with enlarged marrow area, which indicates increased endosteal resorption [224]. When DMP-GHR KO mice are compared with DMPIGF-1R KO, there is a decrease in bone accrual for both [224]. These results imply that GH and IGF1 share some overlapping yet distinct effects on osteocytes.

In summary, the GH/IGF1 axis controls skeletal growth through an endocrine and autocrine/paracrine fashion. Studies above clearly show that IGF1 signaling regulates bone length, radial bone growth, cortical and trabecular bone properties through chondrocyte, osteoblast and osteocyte function. Detailed information can be found in the review from Yakar et al., 2018 [302].

Ovarian granulosa cells IGF1R KO mice Origin In 2017, Stocco's laboratory generated ovarian granulosa cell specific IGF1R KO mice (IGF1R ${ }^{\text {gcko }}$ ) using Cre driven by the estrogen receptor $\beta$ (Esr2) and the aromatase (Cyp19) promoter/enhancers [303].

Phenotype These mice do not possess antral follicles, even with gonadotropin stimulation. They are sterile and have smaller ovaries [303]. Serum estradiol levels are decreased by $90 \%$ compared to controls, while follicle stimulation hormone (FSH) receptor expression is not altered. Their insulin sensitivity is unchanged in comparison to control mice. Activation of AKT is significantly dampened, and apoptosis levels in follicles from primary to secondary stages are increased. Overall, these data suggest that IGF1R has an essential role in granulosa cell function and, as a result, in female fertility.

Pancreatic $\beta$ Cell IGF1R KO mice (i) $\beta$ cell IGF-1R KO mice Origin In 2002, Efstratiadis' laboratory generated $\beta$ Cell IGF-1R KO mice using Cre driven by the rat insulin promoter/enhancer (InsPr-Cre) [304]. Another $\beta$ Cell IGF1R KO mouse was generated in Kahn's laboratory in 2002, also using InsPr-Cre [305].

Phenotype The lack of IGF1R in the mice produced by Efstratiadis's laboratory does not affect $\beta$ cell mass but does lead to age-dependent glucose intolerance and decreased insulin secretion in response to arginine and glucose [304]. With these results, the authors suggest that IGF1R signaling is a requirement in regulating insulin secretion. The finding from Kahn's laboratory corroborates those of the Efstratiadis laboratory, except that they report normal insulin secretion in vivo in response to arginine [305]. Kahn's mice also have a decrease in insulin secretion in response to glucose.

(ii) $\beta \mathrm{DKO}$ mice

Origin $\beta \mathrm{DKO}$ mice with disruptions in both IR and IGF1R in $\beta$ cells were generated using an Ins/Pr-Cre [306].

Phenotype These double KO mice have low insulin levels with high levels of glucagon and are highly glucose-intolerant [306]. Both the mass and insulin content of pancreatic $\beta$ cells are decreased. While $\beta$ cell-specific IGF-1R KO and IR KO are both glucose intolerant, a more severe intolerance is observed in $\beta \mathrm{DKO}$ mice, probably due to the overlapping functions of IGF1 and insulin.

Steroidogenic cell IGF1R KO mice (i) Steroidogenic cell IGF1R KO mice

Origin In 2018, Nef's laboratory developed IGF1R KO mice with IGF1R deleted in steroidogenic cells using Cre driven by the human $\mathrm{P} 450^{\mathrm{SCC}}$ promoter/enhancer [307].

Phenotype IGF1R KO in steroidogenic cells result in mice that grow normally, have normal adrenal gland development, and no change in corticoid synthesis [307]. Male $\mathrm{KO}$ mice have significantly decreased testicular weight in comparison to control mice, but seminal vesicle size and anogenital index are unchanged. Leydig cells, which are steroidogenic cells that produce androgens, are found to have decreased responsiveness to human chorionic gonadotropin (hCG). The authors indicate that IGF1R signaling is necessary for the development of Leydig cells and their steroidogenic activity as adults. They also noted that disruption of IGF1R signaling did not have a significant effect on adrenal gland development or function.

(ii) Steroidogenic cell IGF1R;IR KO mice

Origin Nef's laboratory also developed IGF1R;IR KO mice with both IR and IGF1R deleted in steroidogenic cells using Cre driven by the human $\mathrm{P} 450^{\mathrm{SCC}}$ promoter/enhancer [307].

Phenotype The phenotype of IGF1R;IR double KO mouse is dramatic [307]. That is, Leydig cells fail to mature, resulting in impaired steroidogenic function, decreased steroidogenic cells and serum testosterone levels. These mice have a substantial reduction in the size of the adrenal cortex and testis and are infertile. After weaning, survival rate of these mice is significantly reduced due to disparity in salt and water metabolism.

Somatotroph IGF1R KO mice (i) SIGFRKO mice 
Origin In 2010, Radovick's laboratory generated somatotroph-specific IGF1R KO mice (SIGFRKO) using Cre driven by the GH promoter/enhancer (rGHpCre) [308].

Phenotype SIGFRKO mice do not respond to feedback by IGF1 [308]. By 14 weeks of age, these mice grow normally but weigh significantly less than controls; and body length is unchanged in comparison to control mice at all life stages. These mice have increases in the levels of fasting serum GH and IGF1 and have altered body composition with decreased fat mass but no change in lean mass. Average weights of many tissues (brain, heart, lungs, and kidney) are unchanged although liver and spleen mass are increased. Additionally, IGFBP3 levels are unchanged and ALS levels increased. There are also decreased mRNA levels of GHRH and increased mRNA levels of somatostatin in pituitary tissue, likely contributing to the growth deficiency observed by 14 weeks of age. Glucose and insulin tolerance are both unchanged in SIGFRKO mice [308].

(ii) HiGH mice

Origin In 2011, Kineman's laboratory generated somatotroph IGF1R and IR KO mice (HiGH) with somatotroph specific inactivation of both the IR and IGF1R using the rat $G h$ promoter/enhancer driving Cre [309].

Phenotype HiGH mice are characterized by increased levels of GH and IGF1 [309]. From birth to 3 weeks of age, these mice are the same size as control mice, but their weight is modestly increased in adult life. The increase in GH promotes a lean phenotype but has minimal effects on adiposity in males, even in response to HFD. These mice have decreased insulin sensitivity and elevated insulin levels. HiGH mice also have a mild elevation in the GH/IGF1 axis and provide a means to understand the role of the $\mathrm{GH} /$ IGF1 axis within more physiological levels than transgenic GH mice, which have extraordinarily high levels of GH.

Thyrocyte-specific IGF1R KO mice Origin In 2011, Müller et al. generated thyrocyte-specific IGF-1R KO mice using Cre driven by the thyroid-specific thyroglobulin promoter/ enhancer [310]. Mice lacking one or two alleles of the Igflr (Igflr+/-or Igflr-/-) were characterized.

Phenotype These mice have no difference in thyroid weights; however, both $I g f 1 r^{f l o x / w t}$ and IgfI $r^{\text {flox/flox }}$ mice exhibit a more abnormally large thyroid follicles than controls [310]. They also have a greater number of papillary structures resembling papillary thyroid hyperplasia, increased thyroid-stimulating hormone (TSH) levels, and normal thyroid hormone synthesis. Igfl $r^{f l o x}$ flox males exhibit increases in body weight consistent with latent hypothyroidism. Conversely, the weights of female $I g f 1 r^{f l o x / f l o x}$ remain lower compared to WT. There is also a sex- and age-dependent alteration in perigonadal fat mass. Both $I g f l r^{f l o x / w t}$ and

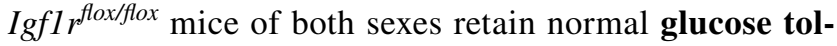

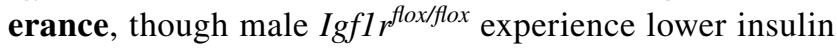

resistance. Overall, specific ablation of IGF1R in thyrocytes does not affect thyroid hormones synthesis, but it does affect thyroid homeostasis and systemic alterations in metabolism.

\section{IGF Binding Proteins (IGFBPs) and Acid Labile Subunit (ALS)}

\section{IGFBPs transgenic and knockout mice}

In circulation and in tissues, most IGF molecules are bound by one of the six distinct members of the IGF-binding protein family (IGFBP) designated as IGFBP1 through IGFBP6 [311]. IGFBPs bind to IGF molecules with high affinity, regulating their bioavailability and functions. In addition, several IGFBPs have been reported to have cellular actions that are independent of their IGF binding. To determine the specific function of each IGFBP in vivo, different mouse lines have been generated. Mice with IGFBP 1, 2, 3, 4, and 5 expressed as transgenes or knockouts have been reported. For IGFBP6, data are only published for transgenic mice. Due to the overlapping functions of IGFBPs, some phenotypes of transgenic or null mice are mild. More details for the mice described in this section are provided in Table 4.

\section{Human IGFBP1 transgenic and IGFBP1-/- mice (i) IGFBP1} transgenic mice

Origin The hIGFBP1 transgenic mice were created by D'Ercole et al. in 1995 in which gene expression was controlled by the mouse $M t 1$ promoter/enhancer [312]. The inserted transgene was a full-length human IGFBPI (hIGFBP1) cDNA, which was truncated at the 3' untranslated (3'UT) region.

Phenotype IGFBP1 is expressed ubiquitously in these animals [312] whereas liver is the major site of expression in nontransgenic mice [313]. Transgenic hIGFBP1 mice have lower body weight, smaller brains, as well as smaller and sometimes dysmorphic bone structure [312, 314]. Mice display insulin resistance in skeletal muscle, hyperglycemia and impaired glucose tolerance with advancing age [315], reduced fertility in the female mice due to changes in follicular growth [316], and increased extracellular matrix deposition and glomerulosclerosis in kidneys [317].

(ii) IGFBP1-/- mice

Origin Igfbpl-/- mice, reported by the Taub laboratory in 2003, used a SpeI restriction enzyme to insert a NeoR gene that disrupted the Igfbp 1 gene [318].

Phenotype These null mice present with increased serum IGF1 levels that normalizes by 4-months of age [318]. These mice show no major alterations in their metabolic phenotype or insulin sensitivity. When crossed with c-Myc transgenic mice to induce prostate cancer, there is no significant difference in the incidence of cancer though the prostate tumor size tends to be smaller, and proliferation is 
decreased [319]. Overall, the impact of lost IGFBP1 action appears to be minimal.

IGFBP2 transgenic and IGFBP2-/- mice (i) IGFBP2 transgenic mice

Origin IGFBP2 transgenic mice were generated via the $\mathrm{CMV}$ promoter/enhancer fused to the Igfbp 2 cDNA by Hoeflich et al. in 1999 [320].

Phenotype The CMV transcriptional regulatory region is known to direct expression in multiple cell types with transgene expression being highest in the pancreas and stomach, whereas IGFBP2 is normally produced primarily in the liver and kidneys in adult nontransgenic mice [313]. IGFBP2 transgenic mice display no changes in circulating levels of GH or IGF1, total body weight, or bone size; however, a reduction in body length and a significant increase in fat mass in males is observed [321]. These mice also have reduced serum insulin levels and increased insulin sensitivity as well as lower systolic blood pressure [321, 322]. When subjected to HFD, IGFBP2 mice are more resistant to obesity when compared to WT controls and have decreased leptin levels, increased glucose sensitivity, and lower blood pressure. Surprisingly, IGFBP2 transgene expression has a protective effect against colon cancer due to decreased cell proliferation and is protective against metabolic diseases [321, 322].

(ii) IGFBP2-/- mice

Origin Igfbp $2-/$ - mice were generated by the Pintar group in 2000 via deletion of exon 3 in the Igfbp2 gene [323].

Phenotype Igfbp 2-/- mice have no noticeable changes in circulating GH, IGF1 or body weight when compared with WT controls [323]. However, organ specific differences are observed, with a notable increase in liver size and a decrease in the size of the spleen, heart, and kidneys. There are no differences in insulin sensitivity, other metabolic parameters or fertility. Blocking IGFBP2 action can improve cancer outcomes, at least in mice susceptible to glioblastoma due to reduced immunosuppression caused by IGFBP2 [324]. This indicates that IGFBP2 has tissue dependent effects on susceptibility to cancers although a comprehensive analysis of cancer incidence for $I g f b p 2-/-$ mice are not reported.

\section{Human IGFBP3 transgenic and IGFBP3-/- mice (i) IGFBP3 transgenic mice}

Origin IGFBP3 transgenic mice were generated by Murphy et al. in 1995 using a $M t 1$ promoter/enhancer and the cDNA of the human IGFBP3 transgene [325]. IGFBP3 transgenic mice created using the $\mathrm{CMV}$ promotor/enhancer or the phosphoglycerate kinase (PGK) promoter/enhancer have also been reported (called CMVBP-3 and PGKBP-3 mice) [326].

Phenotype IGFBP3 is normally expressed predominantly in the kidneys of adult nontransgenic mice and is also highest in the kidneys of transgenic mice as well $[313,325]$. Transgenic mouse using $M t l$ promotor/enhancer exhibits greater spleen, liver, heart, and fat weight. Other detectable changes include reduced alveoli size and a significant age-related decrease in pancreatic beta cell mass $[313,325$, 327]. Although not assessed in IGFBP 3 mice made with the $M t 1$ promoter/enhancer, other IGFBP3 transgenic mice (CMVBP-3 or PGKBP-3) show no change in fertility for males or females [326].

(ii) IGFBP3-/- mice

Origin Igfbp 3 -/- mice were generated by the laboratory of Pintar in 2006 [328] using a NeoR cassette inserted between exon 1 and 3 of the Igfbp 3 gene.

Phenotype These mice have no change in body weight or size [328, 329]. The initial analysis of these animals reveals a decreased metabolic rate and reduced plasma triglyceride and adiponectin levels [329]. When challenged with a HFD, Igfbp3-/- animals also maintain hepatic insulin sensitivity despite impaired fasting glucose. Null mice show an increase in lung tumorigenesis due to IGFBP3's influence on IGF1 signaling [330]. Changes in reproductive capabilities are not reported. In summary, gene disruption of IGFBP3 creates a mouse that has some positive effects on metabolism, but a negative effect as it relates to at least one type of cancer.

IGFBP4 transgenic and IGFBP4-/- mice (i) IGFBP4 transgenic mice

Origin In 1998 and as first reported by Fagin's group, IGFBP4 transgenic mice were generated via microinjection of murine Igfbp $4 \mathrm{cDNA}$ cloned downstream of $\alpha$-actin 5 '-flanking region [331].

Phenotype IGFBP4 is expressed mainly in the adult kidney, liver, and spleen of nontransgenic mice although transgene expression is highest in the bladder and the aorta of transgenic animals $[313,331]$. The expression of the transgene negatively affects cellular proliferation in lymphoid tissues although total lymphocyte development is not inhibited. Further, growth of the thymus is limited via the increased stimulation of apoptosis in the thymocytes. No data about the fertility of IGFBP4 transgenic mice are reported.

(ii) IGFBP4-/- mice

Origin Igfbp4-/- mice were also generated by Pintar's group in 2006 [328].

Phenotype These mice have no significant changes in metabolic parameters or serum levels of any other IGFBPs or IGF1. Although these mice exhibit a standard growth rate in later life, they never catch up to achieve full WT size [332] and have reductions in fat mass, total body length and femur length [333, 334]. Igfbp4-/- mice are reproductively viable, though pups show decreased growth in utero and are $10-15 \%$ smaller than WT controls through 14 weeks of age. 
IGFBP5 transgenic and IGFBP5-/- mice (i) IGFBP5 transgenic mice

Origin Expression of IGFBP5 in transgenic mice was directed to the mammary gland via the $\beta$-lactoglobulin promoter/enhancer. This mouse line was first reported by Tonner et al. in 2002 [335]. WT mice normally have highest IGFBP5 expression in the kidney, muscle, ovaries among other tissues [313].

Phenotype After birth, IGFBP5 transgenic mice exhibit a decrease in total body weight as compared to controls. A reduction in total muscle mass and a transient decrease in bone volume and mineral density through 8 weeks of age is reported [336, 337]. Females show reduced fertility with an increase in the mortality of neonates.

(ii) IGFBP5-/- mice

Origin In 2006, Pintar's group reported on Igfbp5-/- mice, which were achieved by insertion of a NeoR cassette into exon 1 of the Igfbp 5 gene [328].

Phenotype Null mice have a similar total body size, with a modest increase in lung weight [338], an increase in adiposity, a mild glucose intolerance and increased susceptibility to diet-induced obesity as compared to controls [339]. No impact on fertility of null mice is reported.

IGFBP6 transgenic mice Origin IGFBP6 transgenic mice were developed by Bienvenu et al. in 2004 using human IGFBP6 cDNA with a glial fibrillary acidic protein (GFAP) promoter/enhancer [340]. Igfbp6-/- mice have not been reported.

Phenotype Transgene expression in these mice is high in the CNS [340], while nontransgenic mice normally express the highest levels of IGFBP6 in the lungs and heart with variable amounts in other tissues [313]. Transgenic mice exhibit increased levels of IGFBP6 between 3 and 15 days of age, along with decreased detected plasma IGF1 levels at 15 days [340]. This change is transient with IGF1 levels being the same as the WT group at both 1 and 3 months of age. Mice have reduced litter size, with sterility in 5-20\% of females. They also exhibit growth retardation as neonates through three months of age. These mice have a reduction in the size of the cerebellum [340] along with cerebellar abnormalities although changes in cognition or behavior are not reported. With diet-induced obesity, these mice develop mild insulin resistance and obesity. They also show a decrease in brown AT UCP-1 expression, along with an increase in plasma levels of glucose, insulin, and leptin [341].

\section{ALS transgenic and ALS-/- mice (or lgfals-/-)}

Origin The acid-labile subunit (ALS) is component of the IGF1 ternary complex along with IGF1 and IGFBP3, mediating the stability and bioavailability of IGF1. ALS transgenic mice were generated in 2001 by a group led by
Murphy using the $A L S$ cDNA driven by the CMV promoter/ enhancer [342]. Igfals-/- mice were reported in 2000 by the Boisclair group and were made by replacing the Igfals gene with a neomycin phosphotransferase gene [343].

Phenotype ALS transgenic mice have decreased body size but no change in circulating IGF1 or IGFBP3 levels [342]. Therefore, it is hypothesized that the decreased body size is due to altered tissue availability of IGF1. The authors also report decreased litter size in ALS transgenic mothers, suggested to be due to IGF1's role in ovarian follicular development. Igfals-/- mice have decreased serum IGF1 and IGFBP3 levels, with a corresponding decrease in body size [343]. Interestingly, there is no significant change in IgfI or Igfbp 3 mRNA expression, indicating that the decrease in protein level is due to decreased stability in the serum, as is often seen when IGFs are not sequestered in ternary complexes. A later study published by Yakar's group in 2010 reported the same decrease in body size and serum IGF1 levels but with an additional skeletal phenotype [344], i.e. Igfals-/- mice had a sex- and age-dependent decrease in the periosteum formation around the femur leading to decreased bone formation. This decrease in bone thickness is compensated with an increase in the endosteal surface inside the bone that covers the bone marrow. Thus, the outer layer of the bones becomes thinner but the inner layer increases in thickness. Overall, it appears that disruption of ALS in mice decreases size in mice and affects skeletal shape.

\section{PAPP-A-/- (Pregnancy-associated plasma protein-A)}

Pregnancy-associated plasma protein A (PAPP-A) modulates the activity and bioavailability of IGF1 by cleaving IGFBP2, IGFBP4, and IGFBP5. Importantly, while IGFBP2 and IGFPB5 may be cleaved by other proteases, the proteolysis of IGFBP4 seems to be limited to PAPP-A [345].

Origin Germline Pappa-/- (PAPP-A-/- or PAPP-A-null) mice were reported in 2004 by Conover et al. [346]. To evaluate the phenotype of PAPP-A disruption at an adult age, a separate mouse line was reported by Bale et al., in 2017 [346]. This mouse line was generated using the tamoxifeninducible Cre/LoxP system in which the Pappa gene was disrupted at five months of age (fPAPP-A/pos).

Phenotype Pappa-/- mice are dwarf with a $40 \%$ body size reduction and have compromised fertility, with an $80 \%$ reduction in litter size [346, 347]. Pappa-/- mice have normal circulating $\mathbf{G H}$ and IGF1 levels compared to controls. They also have significantly increased longevity, with males showing a $33 \%$ and females a $41 \%$ lifespan extension [348]. Although these mice do not show changes in glucose metabolism, food intake, and total energy expenditure and resting energy [349], they do show a decrease in the prevalence and severity of age-related diseases, such as cardiomyopathy, nephropathy, and cancer [346, 350, 351]. Treadmill 
experiments provide evidence of improved skeletal muscle function with a decrease in fatigue and an increase in endurance in PAPP-A-null mice [352]. Postnatal ablation of the Pappa gene in fPAPP-A/pos mice results in a significant extension of lifespan with an increase in median lifespan of $21 \%$ compared to control mice $[351,353]$. As tamoxifen can induce scrotal enlargement and subsequent complications in male mice, only female mice are used in the longevity study. Thus, although germline disruption of Pappa shows positive results in terms of aging and some age-related diseases in both male and female mice, it is unknown if adult disruption of the Pappa gene will also lead to lifespan extension in male mice. It is interesting to note that disruption of GHR at an adult age also leads to lifespan extension in females [60]. As both strategies - PAPP-A and GHR ablation - lead to reduced IGF1 action, it is of interest to test if the PAPP-A system is also regulated by GH. To that end, AT of GHR-/and bGH mice show no change in gene expression of Igfbp 4 and Pappa when compared to WT mice, although protein levels of IGFBP4 are increased in bGH mice compared to GHR-/- mice. Furthermore, the C terminal-IGFBP4 fragment, which is generated after PAPP-A-cleavage, does not differ among bGH, GHR-/-, and WT mice [354]. Despite no change in AT, PAPP-A is expressed in different tissues [345]; thus, it is possible that PAPP-A expression and activity is modulated by GH in other tissues.

\section{Concluding remarks}

The above review characterizes 137 mouse strains in which genes in the GH/IGF1 family have been altered. A few of these alterations are via 'natural gene mutations;' however, the majority are via genetic manipulations, namely (1) generation of transgenic mice that express a gene or cDNA encoding a component of the family or (2) disruption of specific genes within the family. A summary of the published data is presented, including authors, date of publication, corresponding references as well as salient physiological consequences of the gene alterations. Also, we had a 'personal laboratory reason' for generating this review; namely, we often need a consolidated document that can be easily used and referenced when preparing new manuscripts that refer to subsets of these mice. The reader is encouraged to use this review in a similar manner and, when doing so, a few new tidbits of information may be acquired. Although 137 different mouse lines are described, we are sure we missed some, and for that we apologize. Also, we tried to extract the salient physiological points from the published data when describing these mice. Again, if we missed some of these points or mistakenly described them, we are very sorry. Finally, I (JJK) am indebted to the authors of this review, which includes Ohio University faculty, staff of the Edison
Biotechnology Institute, post-doctoral fellows, graduate students, undergraduate students, medical students, and technicians. Without their effort, this review would not have been accomplished.

Acknowledgements We thank Delaney Geitgey, Jaycie Kuhn, Savannah McKenna, Cole Smith, and Grace Lach for their support and contribution to this work. Most of this review was written during the pandemic. Thus, we dedicate it to those who suffered with, fought against, or died from COVID-19.

Funding This work was supported, in part, by the State of Ohio's Eminent Scholar Program that includes a gift from Milton and Lawrence Goll to J.J.K., NIH-R01AG059779.

\section{Declarations}

Conflict of interest The authors have no conflicts of interest to declare that are relevant to the content of this article.

Ethical approval The authors of this review have abided by and are compliant with all typical ethical standards.

Research involving human and animal rights This review only documents mice with alterations in the GH/IGF family. Thus, no research was discussed or cited related to humans. Also, we believe that each research group involved in generation of the various mouse strains used animal use and care procedures that were approved by their individual university/hospital/institute.

Data availability Not applicable.

Code availability Not applicable.

\section{References}

1. Evans HM, Long JA (1921) The effect of the anterior lobe administered intraperitoneally upon growth, maturity and estrous cycles of the rat. Anat Rec 21:62-63

2. Buchman M, Bell S, Kopchick JJ (2018) Growth hormone discovery and structure. Pediatr Endocrinol Rev 16(Suppl 1):2-10. https://doi.org/10.17458/per.vol16.2018.bbk.ghdiscoverystru cture

3. Houssay BA (1936) The hypophysis and metabolism. N Engl J Med 214:961-971. https://doi.org/10.1056/nejm19360514214 2001

4. Li CH, Evans HM (1944) The isolation of pituitary growth hormone. Science 99(2566):183-184. https://doi.org/10.1126/scien ce.99.2566.183

5. Li CH, Papkoff H (1956) Preparation and properties of growth hormone from human and monkey pituitary glands. Science 124(3235):1293-1294. https://doi.org/10.1126/science.124.3235. 1293

6. Frasier SD (1997) The not-so-good old days: working with pituitary growth hormone in North America, 1956 to 1985. J Pediatr 131(1 Pt 2):S1-4. https://doi.org/10.1016/s0022-3476(97) 70001-5

7. Flodh H (1986) Human growth hormone produced with recombinant DNA technology: development and production. Acta Paediatr Scand Suppl 325:1-9. https://doi.org/10.1111/j.1651-2227. 1986.tb10356.x 
8. Laron Z (2018) The era of cadaveric pituitary extracted human growth hormone (1958-1985): biological and clinical aspects. Pediatr Endocrinol Rev 16(Suppl 1):11-16. https://doi.org/10. 17458/per.vol16.2018.la.hghcadavericpituitary

9. Raben MS (1958) Treatment of a pituitary dwarf with human growth hormone. J Clin Endocrinol Metab 18(8):901-903. https://doi.org/10.1210/jcem-18-8-901

10. Ranke MB, Wit JM (2018) Growth hormone-past, present and future. Nat Rev Endocrinol 14(5):285-300. https://doi.org/10. 1038/nrendo.2018.22

11. Barsh GS, Seeburg PH, Gelinas RE (1983) The human growth hormone gene family: structure and evolution of the chromosomal locus. Nucleic Acids Res 11(12):3939-3958. https://doi. org/10.1093/nar/11.12.3939

12. Fiddes JC, Seeburg PH, DeNoto FM, Hallewell RA, Baxter JD, Goodman HM (1979) Structure of genes for human growth hormone and chorionic somatomammotropin. Proc Natl Acad Sci USA 76(9):4294-4298. https://doi.org/10.1073/pnas.76.9.4294

13. Dehkhoda F, Lee CMM, Medina J, Brooks AJ (2018) The growth hormone receptor: mechanism of receptor activation, cell signaling, and physiological aspects. Front Endocrinol (Lausanne) 9:35. https://doi.org/10.3389/fendo.2018.00035

14. Brooks AJ, Dai W, O'Mara ML, Abankwa D, Chhabra Y, Pelekanos RA, Gardon O, Tunny KA, Blucher KM, Morton CJ, Parker MW, Sierecki E, Gambin Y, Gomez GA, Alexandrov K, Wilson IA, Doxastakis M, Mark AE, Waters MJ (2014) Mechanism of activation of protein kinase JAK2 by the growth hormone receptor. Science 344(6185):1249783. https://doi.org/10.1126/science. 1249783

15. van den Eijnden MJ, Lahaye LL, Strous GJ (2006) Disulfide bonds determine growth hormone receptor folding, dimerisation and ligand binding. J Cell Sci 119(Pt 15):3078-3086. https://doi. org $/ 10.1242 /$ jcs.03036

16. Waters MJ, Brooks AJ (2015) JAK2 activation by growth hormone and other cytokines. Biochem J 466(1):1-11. https://doi. org/10.1042/bj20141293

17. Ross RJ, Leung KC, Maamra M, Bennett W, Doyle N, Waters MJ, Ho KK (2001) Binding and functional studies with the growth hormone receptor antagonist, B2036-PEG (pegvisomant), reveal effects of pegylation and evidence that it binds to a receptor dimer. J Clin Endocrinol Metab 86(4):1716-1723. https://doi. org/10.1210/jcem.86.4.7403

18. Hansen LH, Wang X, Kopchick JJ, Bouchelouche P, Nielsen JH, Galsgaard ED, Billestrup N (1996) Identification of tyrosine residues in the intracellular domain of the growth hormone receptor required for transcriptional signaling and Stat5 activation. J Biol Chem 271(21):12669-12673. https://doi.org/10.1074/jbc.271.21. 12669

19. Wang X, Darus CJ, Xu BC, Kopchick JJ (1996) Identification of growth hormone receptor (GHR) tyrosine residues required for GHR phosphorylation and JAK2 and STAT5 activation. Mol Endocrinol 10(10):1249-1260. https://doi.org/10.1210/mend.10. 10.9121492

20. Xu BC, Wang X, Darus CJ, Kopchick JJ (1996) Growth hormone promotes the association of transcription factor STAT5 with the growth hormone receptor. J Biol Chem 271(33):19768-19773

21. Aaronson DS, Horvath CM (2002) A road map for those who don't know JAK-STAT. Science 296(5573):1653-1655. https:// doi.org/10.1126/science. 1071545

22. Metcalf D, Greenhalgh CJ, Viney E, Willson TA, Starr R, Nicola NA, Hilton DJ, Alexander WS (2000) Gigantism in mice lacking suppressor of cytokine signalling-2. Nature 405(6790): 10691073. https://doi.org/10.1038/35016611

23. Linossi EM, Babon JJ, Hilton DJ, Nicholson SE (2013) Suppression of cytokine signaling: the SOCS perspective. Cytokine
Growth Factor Rev 24(3):241-248. https://doi.org/10.1016/j. cytogfr.2013.03.005

24. Kershaw NJ, Murphy JM, Liau NP, Varghese LN, Laktyushin A, Whitlock EL, Lucet IS, Nicola NA, Babon JJ (2013) SOCS3 binds specific receptor-JAK complexes to control cytokine signaling by direct kinase inhibition. Nat Struct Mol Biol 20(4):469476. https://doi.org/10.1038/nsmb.2519

25. Palmiter RD, Brinster RL, Hammer RE, Trumbauer ME, Rosenfeld MG, Birnberg NC, Evans RM (1982) Dramatic growth of mice that develop from eggs microinjected with metallothioneingrowth hormone fusion genes. Nature 300(5893):611-615. https://doi.org/10.1038/300611a0

26. Chen WY, Wight DC, Wagner TE, Kopchick JJ (1990) Expression of a mutated bovine growth hormone gene suppresses growth of transgenic mice. Proc Natl Acad Sci USA 87(13):5061-5065. https://doi.org/10.1073/pnas.87.13.5061

27. Chen WY, Wight DC, Mehta BV, Wagner TE, Kopchick JJ (1991) Glycine 119 of bovine growth hormone is critical for growth-promoting activity. Mol Endocrinol 5(12):1845-1852. https://doi.org/10.1210/mend-5-12-1845

28. Okada S, Chen WY, Wiehl P, Kelder B, Goodman HM, Guller S, Sonenberg M, Kopchick JJ (1992) A growth hormone (GH) analog can antagonize the ability of native $\mathrm{GH}$ to promote differentiation of 3T3-F442A preadipocytes and stimulate insulin-like and lipolytic activities in primary rat adipocytes. Endocrinology 130(4):2284-2290. https://doi.org/10.1210/endo.130.4.1547740

29. Cunningham BC, Ultsch M, De Vos AM, Mulkerrin MG, Clauser KR, Wells JA (1991) Dimerization of the extracellular domain of the human growth hormone receptor by a single hormone molecule. Science 254(5033):821-825. https://doi.org/10.1126/ science. 1948064

30. Zhou Y, Xu BC, Maheshwari HG, He L, Reed M, Lozykowski M, Okada S, Cataldo L, Coschigamo K, Wagner TE, Baumann G, Kopchick JJ (1997) A mammalian model for Laron syndrome produced by targeted disruption of the mouse growth hormone receptor/binding protein gene (the Laron mouse). Proc Natl Acad Sci USA 94(24):13215-13220. https://doi.org/10.1073/pnas.94. 24.13215

31. List EO, Sackmann-Sala L, Berryman DE, Funk K, Kelder B, Gosney ES, Okada S, Ding J, Cruz-Topete D, Kopchick JJ (2011) Endocrine parameters and phenotypes of the growth hormone receptor gene disrupted (GHR-/-) mouse. Endocr Rev 32(3):356386. https://doi.org/10.1210/er.2010-0009

32. Berryman DE, List EO, Kohn DT, Coschigano KT, Seeley RJ, Kopchick JJ (2006) Effect of growth hormone on susceptibility to diet-induced obesity. Endocrinology 147(6):2801-2808. https:// doi.org/10.1210/en.2006-0086

33. Wang Z, Prins GS, Coschigano KT, Kopchick JJ, Green JE, Ray VH, Hedayat S, Christov KT, Unterman TG, Swanson SM (2005) Disruption of growth hormone signaling retards early stages of prostate carcinogenesis in the $\mathrm{C} 3(1) / \mathrm{T}$ antigen mouse. Endocrinology 146(12):5188-5196. https://doi.org/10.1210/en. 2005-0607

34. Zhang X, Mehta RG, Lantvit DD, Coschigano KT, Kopchick JJ, Green JE, Hedayat S, Christov KT, Ray VH, Unterman TG, Swanson SM (2007) Inhibition of estrogen-independent mammary carcinogenesis by disruption of growth hormone signaling. Carcinogenesis 28(1):143-150. https://doi.org/10.1093/carcin/ bg1138

35. Ikeno Y, Hubbard GB, Lee S, Cortez LA, Lew CM, Webb CR, Berryman DE, List EO, Kopchick JJ, Bartke A (2009) Reduced incidence and delayed occurrence of fatal neoplastic diseases in growth hormone receptor/binding protein knockout mice. J Gerontol A 64(5):522-529. https://doi.org/10.1093/gerona/glp017

36. Basu R, Qian Y, Kopchick JJ (2018) MECHANISMS IN ENDOCRINOLOGY: lessons from growth hormone receptor 
gene-disrupted mice: are there benefits of endocrine defects? Eur J Endocrinol 178(5):R155-R181. https://doi.org/10.1530/ eje-18-0018

37. Coschigano KT, Holland AN, Riders ME, List EO, Flyvbjerg A, Kopchick JJ (2003) Deletion, but not antagonism, of the mouse growth hormone receptor results in severely decreased body weights, insulin, and insulin-like growth factor I levels and increased life span. Endocrinology 144(9):3799-3810. https:// doi.org/10.1210/en.2003-0374

38. Fan Y, Menon RK, Cohen P, Hwang D, Clemens T, DiGirolamo DJ, Kopchick JJ, Le Roith D, Trucco M, Sperling MA (2009) Liver-specific deletion of the growth hormone receptor reveals essential role of growth hormone signaling in hepatic lipid metabolism. J Biol Chem 284(30):19937-19944. https://doi.org/ 10.1074/jbc.M109.014308

39. Lu C, Kumar PA, Fan Y, Sperling MA, Menon RK (2010) A novel effect of growth hormone on macrophage modulates macrophage-dependent adipocyte differentiation. Endocrinology 151(5):2189-2199. https://doi.org/10.1210/en.2009-1194

40. Mavalli MD, DiGirolamo DJ, Fan Y, Riddle RC, Campbell KS, van Groen T, Frank SJ, Sperling MA, Esser KA, Bamman MM, Clemens TL (2010) Distinct growth hormone receptor signaling modes regulate skeletal muscle development and insulin sensitivity in mice. J Clin Invest 120(11):4007-4020. https://doi.org/10. 1172/jci42447

41. Wu Y, Liu C, Sun H, Vijayakumar A, Giglou PR, Qiao R, Oppenheimer J, Yakar S, LeRoith D (2011) Growth hormone receptor regulates beta cell hyperplasia and glucose-stimulated insulin secretion in obese mice. J Clin Invest 121(6):2422-2426. https:// doi.org/10.1172/jci45027

42. Vijayakumar A, Wu Y, Sun H, Li X, Jeddy Z, Liu C, Schwartz GJ, Yakar S, LeRoith D (2012) Targeted loss of GHR signaling in mouse skeletal muscle protects against high-fat diet-induced metabolic deterioration. Diabetes 61(1):94-103. https://doi.org/ $10.2337 / \mathrm{db} 11-0814$

43. Vijayakumar A, Wu Y, Buffin NJ, Li X, Sun H, Gordon RE, Yakar S, LeRoith D (2012) Skeletal muscle growth hormone receptor signaling regulates basal, but not fasting-induced, lipid oxidation. PLoS ONE 7(9):e44777. https://doi.org/10.1371/journ al.pone. 0044777

44. List EO, Berryman DE, Funk K, Gosney ES, Jara A, Kelder B, Wang X, Kutz L, Troike K, Lozier N, Mikula V, Lubbers ER, Zhang H, Vesel C, Junnila RK, Frank SJ, Masternak MM, Bartke A, Kopchick JJ (2013) The role of GH in adipose tissue: lessons from adipose-specific GH receptor gene-disrupted mice. Mol Endocrinol 27(3):524-535. https://doi.org/10.1210/ me.2012-1330

45. Vijayakumar A, Buffin NJ, Gallagher EJ, Blank J, Wu Y, Yakar S, LeRoith D (2013) Deletion of growth hormone receptors in postnatal skeletal muscle of male mice does not alter muscle mass and response to pathological injury. Endocrinology 154(10):3776-3783. https://doi.org/10.1210/en.2013-1209

46. Li X, Bartke A, Berryman DE, Funk K, Kopchick JJ, List EO, Sun L, Miller RA (2013) Direct and indirect effects of growth hormone receptor ablation on liver expression of xenobiotic metabolizing genes. Am J Physiol Endocrinol Metab 305(8):E942-950. https://doi.org/10.1152/ajpendo.00304.2013

47. Lu C, Kumar PA, Sun J, Aggarwal A, Fan Y, Sperling MA, Lumeng CN, Menon RK (2013) Targeted deletion of growth hormone $(\mathrm{GH})$ receptor in macrophage reveals novel osteopontin-mediated effects of $\mathrm{GH}$ on glucose homeostasis and insulin sensitivity in diet-induced obesity. J Biol Chem 288(22):1572515735. https://doi.org/10.1074/jbc.M113.460212

48. List EO, Berryman DE, Funk K, Jara A, Kelder B, Wang F, Stout MB, Zhi X, Sun L, White TA, LeBrasseur NK, Pirtskhalava T, Tchkonia T, Jensen EA, Zhang W, Masternak MM, Kirkland
JL, Miller RA, Bartke A, Kopchick JJ (2014) Liver-specific GH receptor gene-disrupted (LiGHRKO) mice have decreased endocrine IGF-I, increased local IGF-I, and altered body size, body composition, and adipokine profiles. Endocrinology 155(5):1793-1805. https://doi.org/10.1210/en.2013-2086

49. Fan Y, Fang X, Tajima A, Geng X, Ranganathan S, Dong H, Trucco M, Sperling MA (2014) Evolution of hepatic steatosis to fibrosis and adenoma formation in liver-specific growth hormone receptor knockout mice. Front Endocrinol (Lausanne) 5:218. https://doi.org/10.3389/fendo.2014.00218

50. Stewart MH, Gutierrez-Martinez P, Beerman I, Garrison B, Gallagher EJ, LeRoith D, Rossi DJ (2014) Growth hormone receptor signaling is dispensable for HSC function and aging. Blood 124(20):3076-3080. https://doi.org/10.1182/ blood-2014-05-575308

51. Gesing A, Wang F, List EO, Berryman DE, Masternak MM, Lewinski A, Karbownik-Lewinska M, Kopchick JJ, Bartke A (2015) Expression of apoptosis-related genes in liver-specific growth hormone receptor gene-disrupted mice is sex dependent. J Gerontol A 70(1):44-52. https://doi.org/10.1093/gerona/glu008

52. Dominick G, Berryman DE, List EO, Kopchick JJ, Li X, Miller RA, Garcia GG (2015) Regulation of mTOR activity in Snell dwarf and GH receptor gene-disrupted mice. Endocrinology 156(2):565-575. https://doi.org/10.1210/en.2014-1690

53. Zawada I, Masternak MM, List EO, Stout MB, Berryman DE, Lewinski A, Kopchick JJ, Bartke A, Karbownik-Lewinska M, Gesing A (2015) Gene expression of key regulators of mitochondrial biogenesis is sex dependent in mice with growth hormone receptor deletion in liver. Aging (Albany NY) 7(3):195-204. https://doi.org/10.18632/aging.100733

54. List EO, Berryman DE, Ikeno Y, Hubbard GB, Funk K, Comisford R, Young JA, Stout MB, Tchkonia T, Masternak MM, Bartke A, Kirkland JL, Miller RA, Kopchick JJ (2015) Removal of growth hormone receptor (GHR) in muscle of male mice replicates some of the health benefits seen in global GHR-/- mice. Aging (Albany NY) 7(7):500-512. https://doi.org/10.18632/ aging. 100766

55. Cordoba-Chacon J, Majumdar N, List EO, Diaz-Ruiz A, Frank SJ, Manzano A, Bartrons R, Puchowicz M, Kopchick JJ, Kineman RD (2015) Growth hormone inhibits hepatic de novo lipogenesis in adult mice. Diabetes 64(9):3093-3103. https://doi.org/ $10.2337 / \mathrm{db} 15-0370$

56. Sadagurski M, Landeryou T, Cady G, Kopchick JJ, List EO, Berryman DE, Bartke A, Miller RA (2015) Growth hormone modulates hypothalamic inflammation in long-lived pituitary dwarf mice. Aging Cell 14(6):1045-1054. https://doi.org/10.1111/acel. 12382

57. Liu Y, Knop E, Knop N, Sullivan DA, List EO, Kopchick JJ, Kam WR, Ding J (2016) Growth hormone influence on the morphology and size of the mouse meibomian gland. J Ophthalmol 2016:5728071. https://doi.org/10.1155/2016/5728071

58. Jara A, Liu X, Sim D, Benner CM, Duran-Ortiz S, Qian Y, List EO, Berryman DE, Kim JK, Kopchick JJ (2016) Cardiac-specific disruption of $\mathrm{GH}$ receptor alters glucose homeostasis while maintaining normal cardiac performance in adult male mice. Endocrinology 157(5):1929-1941. https://doi.org/10.1210/en. 2015-1686

59. Liu Z, Cordoba-Chacon J, Kineman RD, Cronstein BN, Muzumdar R, Gong Z, Werner H, Yakar S (2016) Growth hormone control of hepatic lipid metabolism. Diabetes 65(12):3598-3609. https://doi.org/10.2337/db16-0649

60. Junnila RK, Duran-Ortiz S, Suer O, Sustarsic EG, Berryman DE, List EO, Kopchick JJ (2016) Disruption of the GH receptor gene in adult mice increases maximal lifespan in females. Endocrinology 157(12):4502-4513. https://doi.org/10.1210/en.2016-1649 
61. Cady G, Landeryou T, Garratt M, Kopchick JJ, Qi N, GarciaGaliano D, Elias CF, Myers MG Jr, Miller RA, Sandoval DA, Sadagurski M (2017) Hypothalamic growth hormone receptor (GHR) controls hepatic glucose production in nutrient-sensing leptin receptor (LepRb) expressing neurons. Mol Metab 6(5):393-405. https://doi.org/10.1016/j.molmet.2017.03.001

62. List EO, Berryman DE, Jensen EA, Kulkarni P, McKenna S, Kopchick JJ (2019) New insights of growth hormone (GH) actions from tissue-specific GH receptor knockouts in mice. Arch Endocrinol Metab 63(6):557-567. https://doi.org/10.20945/ 2359-3997000000185

63. Fang F, Shi X, Brown MS, Goldstein JL, Liang G (2019) Growth hormone acts on liver to stimulate autophagy, support glucose production, and preserve blood glucose in chronically starved mice. Proc Natl Acad Sci USA 116(15):7449-7454. https://doi. org/10.1073/pnas.1901867116

64. Furigo IC, Teixeira PDS, de Souza GO, Couto GCL, Romero GG, Perello M, Frazao R, Elias LL, Metzger M, List EO, Kopchick JJ, Donato J Jr (2019) Growth hormone regulates neuroendocrine responses to weight loss via AgRP neurons. Nat Commun 10(1):662. https://doi.org/10.1038/s41467-019-08607-1

65. Young JA, Jensen EA, Stevens A, Duran-Ortiz S, List EO, Berryman DE, Kopchick JJ (2019) Characterization of an intestinespecific GH receptor knockout (IntGHRKO) mouse. Growth Horm IGF Res 46-47:5-15. https://doi.org/10.1016/j.ghir.2019. 05.001

66. Kato Y, Murakami Y, Sohmiya M, Nishiki M (2002) Regulation of human growth hormone secretion and its disorders. Intern Med 41(1):7-13. https://doi.org/10.2169/internalmedicine.41.7

67. Snell GD (1929) Dwarf, a new mendelian recessive character of the house mouse. Proc Natl Acad Sci USA 15(9):733-734. https://doi.org/10.1073/pnas.15.9.733

68. Li S, Crenshaw EB 3rd, Rawson EJ, Simmons DM, Swanson LW, Rosenfeld MG (1990) Dwarf locus mutants lacking three pituitary cell types result from mutations in the POU-domain gene pit-1. Nature 347(6293):528-533. https://doi.org/10.1038/ $347528 \mathrm{a} 0$

69. Brown-Borg HM, Bartke A (2012) GH and IGF1: roles in energy metabolism of long-living GH mutant mice. J Gerontol A 67(6):652-660. https://doi.org/10.1093/gerona/gls086

70. Flurkey K, Papaconstantinou J, Miller RA, Harrison DE (2001) Lifespan extension and delayed immune and collagen aging in mutant mice with defects in growth hormone production. Proc Natl Acad Sci USA 98(12):6736-6741. https://doi.org/10.1073/ pnas. 111158898

71. Bartke A (1965) The response of two types of dwarf mice to growth hormone, thyrotropin, and thyroxine. Gen Comp Endocrinol 5(4):418-426. https://doi.org/10.1016/0016-6480(65) 90102-4

72. Levine R, Luft R (1964) The relation between the growth and diabetogenic effects of the so-called growth hormone of the anterior pituitary. Diabetes 13:651-655. https://doi.org/10.2337/diab. 13.6.651

73. Bratusch-Marrain PR, Smith D, DeFronzo RA (1982) The effect of growth hormone on glucose metabolism and insulin secretion in man. J Clin Endocrinol Metab 55(5):973-982. https://doi.org/ 10.1210/jcem-55-5-973

74. Kim SH, Park MJ (2017) Effects of growth hormone on glucose metabolism and insulin resistance in human. Ann Pediatr Endocrinol Metab 22(3):145-152. https://doi.org/10.6065/apem.2017. 22.3.145

75. Vila G, Jorgensen JOL, Luger A, Stalla GK (2019) Insulin resistance in patients with acromegaly. Front Endocrinol (Lausanne) 10:509. https://doi.org/10.3389/fendo.2019.00509

76. Guevara-Aguirre J, Balasubramanian P, Guevara-Aguirre M, Wei M, Madia F, Cheng CW, Hwang D, Martin-Montalvo A,
Saavedra J, Ingles S, de Cabo R, Cohen P, Longo VD (2011) Growth hormone receptor deficiency is associated with a major reduction in pro-aging signaling, cancer, and diabetes in humans. Sci Transl Med 3(70):70ra13. https://doi.org/10.1126/scitranslm ed.3001845

77. Brooks NL, Trent CM, Raetzsch CF, Flurkey K, Boysen G, Perfetti MT, Jeong YC, Klebanov S, Patel KB, Khodush VR, Kupper LL, Carling D, Swenberg JA, Harrison DE, Combs TP (2007) Low utilization of circulating glucose after food withdrawal in Snell dwarf mice. J Biol Chem 282(48):35069-35077. https:// doi.org/10.1074/jbc.M700484200

78. Tallaksen-Greene SJ, Sadagurski M, Zeng L, Mauch R, Perkins M, Banduseela VC, Lieberman AP, Miller RA, Paulson HL, Albin RL (2014) Differential effects of delayed aging on phenotype and striatal pathology in a murine model of Huntington disease. J Neurosci 34(47):15658-15668. https://doi.org/10.1523/ JNEUROSCI.1830-14.2014

79. Vergara M, Smith-Wheelock M, Harper JM, Sigler R, Miller RA (2004) Hormone-treated snell dwarf mice regain fertility but remain long lived and disease resistant. J Gerontol A 59(12):1244-1250. https://doi.org/10.1093/gerona/59.12.1244

80. Rader EP, Naimo MA, Ensey J, Baker BA (2018) VCAM-1 upregulation accompanies muscle remodeling following resistance-type exercise in Snell dwarf (Pit1(dw/dw) ) mice. Aging Cell 17(5):e12816. https://doi.org/10.1111/acel.12816

81. Hochereau-de Reviers MT, de Reviers MM, Monet-Kuntz C, Perreau C, Fontaine I, Viguier-Martinez MC (1987) Testicular growth and hormonal parameters in the male Snell dwarf mouse. Acta Endocrinol (Copenh) 115(3):399-405. https://doi.org/10. 1530/acta.0.1150399

82. Karolyi IJ, Dootz GA, Halsey K, Beyer L, Probst FJ, Johnson KR, Parlow AF, Raphael Y, Dolan DF, Camper SA (2007) Dietary thyroid hormone replacement ameliorates hearing deficits in hypothyroid mice. Mamm Genome 18(8):596-608. https://doi. org/10.1007/s00335-007-9038-0

83. Schaible R, Gowen JW (1961) A new dwarf mouse. Abstr. Genetics $46: 896$

84. Bartke A, Brown-Borg H (2004) Life extension in the dwarf mouse. Curr Top Dev Biol 63:189-225. https://doi.org/10.1016/ s0070-2153(04)63006-7

85. Wang Z, Al-Regaiey KA, Masternak MM, Bartke A (2006) Adipocytokines and lipid levels in Ames dwarf and calorie-restricted mice. J Gerontol A 61(4):323-331. https://doi.org/10.1093/ gerona/61.4.323

86. Dominici FP, Hauck S, Argentino DP, Bartke A, Turyn D (2002) Increased insulin sensitivity and upregulation of insulin receptor, insulin receptor substrate (IRS)-1 and IRS-2 in liver of Ames dwarf mice. J Endocrinol 173(1):81-94. https://doi.org/10.1677/ joe. 0.1730081

87. Borg KE, Brown-Borg HM, Bartke A (1995) Assessment of the primary adrenal cortical and pancreatic hormone basal levels in relation to plasma glucose and age in the unstressed Ames dwarf mouse. Proc Soc Exp Biol Med 210(2):126-133. https://doi.org/ 10.3181/00379727-210-43931

88. Hill CM, Fang Y, Miquet JG, Sun LY, Masternak MM, Bartke A (2016) Long-lived hypopituitary Ames dwarf mice are resistant to the detrimental effects of high-fat diet on metabolic function and energy expenditure. Aging Cell 15(3):509-521. https://doi. org/10.1111/acel.12467

89. Darcy J, McFadden S, Fang Y, Huber JA, Zhang C, Sun LY, Bartke A (2016) Brown adipose tissue function is enhanced in longlived. Male Ames Dwarf Mice Endocrinol 157(12):4744-4753. https://doi.org/10.1210/en.2016-1593

90. Hunter WS, Croson WB, Bartke A, Gentry MV, Meliska CJ (1999) Low body temperature in long-lived Ames dwarf mice 
at rest and during stress. Physiol Behav 67(3):433-437. https:// doi.org/10.1016/s0031-9384(99)00098-0

91. Darcy J, McFadden S, Bartke A (2017) Altered structure and function of adipose tissue in long-lived mice with growth hormone-related mutations. Adipocyte 6(2):69-75. https://doi.org/ 10.1080/21623945.2017.1308990

92. Bokov AF, Lindsey ML, Khodr C, Sabia MR, Richardson A (2009) Long-lived ames dwarf mice are resistant to chemical stressors. J Gerontol A 64(8):819-827. https://doi.org/10.1093/ gerona/glp052

93. Ikeno Y, Bronson RT, Hubbard GB, Lee S, Bartke A (2003) Delayed occurrence of fatal neoplastic diseases in ames dwarf mice: correlation to extended longevity. J Gerontol A 58(4):291296. https://doi.org/10.1093/gerona/58.4.b291

94. Bartke A, Coschigano K, Kopchick J, Chandrashekar V, Mattison J, Kinney B, Hauck S (2001) Genes that prolong life: relationships of growth hormone and growth to aging and life span. $\mathrm{J}$ Gerontol A 56(8):B340-349. https://doi.org/10.1093/gerona/56.8. b340

95. Brown-Borg HM, Borg KE, Meliska CJ, Bartke A (1996) Dwarf mice and the ageing process. Nature 384(6604):33. https://doi. org/10.1038/384033a0

96. Bartke A, Wright JC, Mattison JA, Ingram DK, Miller RA, Roth GS (2001) Extending the lifespan of long-lived mice. Nature 414(6862):412. https://doi.org/10.1038/35106646

97. Ikeno Y, Hubbard GB, Lee S, Dube SM, Flores LC, Roman MG, Bartke A (2013) Do Ames dwarf and calorie-restricted mice share common effects on age-related pathology? Pathobiol Aging Age Relat Dis. https://doi.org/10.3402/pba.v3i0.20833

98. Chandrashekar V, Bartke A (1993) Induction of endogenous insulin-like growth factor-I secretion alters the hypothalamicpituitary-testicular function in growth hormone-deficient adult dwarf mice. Biol Reprod 48(3):544-551. https://doi.org/10.1095/ biolreprod48.3.544

99. Moore JP Jr, Morrison DG, Hyde JF (1994) Galanin gene expression is increased in the anterior pituitary gland of the human growth hormone-releasing hormone transgenic mouse. Endocrinology 134(5):2005-2010. https://doi.org/10.1210/endo.134.5. 7512494

100. Peng XD, Park S, Gadelha MR, Coschigano KT, Kopchick JJ, Frohman LA, Kineman RD (2001) The growth hormone (GH)-axis of GH receptor/binding protein gene-disrupted and metallothionein-human GH-releasing hormone transgenic mice: hypothalamic neuropeptide and pituitary receptor expression in the absence and presence of GH feedback. Endocrinology 142(3):1117-1123. https://doi.org/10.1210/endo.142.3.8005

101. Asa SL, Kovacs K, Stefaneanu L, Horvath E, Billestrup N, Gonzalez-Manchon C, Vale W (1990) Pituitary mammosomatotroph adenomas develop in old mice transgenic for growth hormonereleasing hormone. Proc Soc Exp Biol Med 193(3):232-235. https://doi.org/10.3181/00379727-193-3-rc1

102. Asa SL, Kovacs K, Stefaneanu L, Horvath E, Billestrup N, Gonzalez-Manchon C, Vale W (1992) Pituitary adenomas in mice transgenic for growth hormone-releasing hormone. Endocrinology 131(5):2083-2089. https://doi.org/10.1210/endo.131.5. 1425411

103. Donangelo I, Melmed S (2006) Implication of pituitary tropic status on tumor development. Front Horm Res 35:1-8. https:// doi.org/10.1159/000094259

104. Luque RM, Soares BS, Peng XD, Krishnan S, Cordoba-Chacon J, Frohman LA, Kineman RD (2009) Use of the metallothionein promoter-human growth hormone-releasing hormone (GHRH) mouse to identify regulatory pathways that suppress pituitary somatotrope hyperplasia and adenoma formation due to GHRHreceptor hyperactivation. Endocrinology 150(7):3177-3185. https://doi.org/10.1210/en.2008-1482
105. Debeljuk L, Wright JC, Phelps C, Bartke A (1999) Transgenic mice overexpressing the growth-hormone-releasing hormone gene have high concentrations of tachykinins in the anterior pituitary gland. Neuroendocrinology 70(2):107-116. https://doi. org/10.1159/000054465

106. Hyde JF, Moore JP, Cai A (1998) Galanin in normal and hyperplastic anterior pituitary cells. From pituitary tumor cell lines to transgenic mice. Ann N Y Acad Sci 863:48-55. https://doi.org/ 10.1111/j.1749-6632.1998.tb10682.x

107. Hyde JF, Morrison DG, Drake KW, Moore JP Jr, Maley BE (1996) Vasoactive intestinal polypeptide mRNA and peptide levels are decreased in the anterior pituitary of the human growth hormone-releasing hormone transgenic mouse. J Neuroendocrinol 8(1):9-15. https://doi.org/10.1111/j.1365-2826.1996. tb00681.x

108. Alba M, Salvatori R (2004) A mouse with targeted ablation of the growth hormone-releasing hormone gene: a new model of isolated growth hormone deficiency. Endocrinology 145(9):41344143. https://doi.org/10.1210/en.2004-0119

109. Fintini D, Alba M, Schally AV, Bowers CY, Parlow AF, Salvatori $R$ (2005) Effects of combined long-term treatment with a growth hormone-releasing hormone analogue and a growth hormone secretagogue in the growth hormone-releasing hormone knock out mouse. Neuroendocrinology 82(3-4):198-207. https://doi. org/10.1159/000092520

110. Recinella L, Shohreh R, Salvatori R, Orlando G, Vacca M, Brunetti L (2013) Effects of isolated GH deficiency on adipose tissue, feeding and adipokines in mice. Growth Horm IGF Res 23(6):237-242. https://doi.org/10.1016/j.ghir.2013.08.004

111. Leone S, Chiavaroli A, Shohreh R, Ferrante C, Ricciuti A, Manippa F, Recinella L, Di Nisio C, Orlando G, Salvatori R, Vacca M, Brunetti L (2015) Increased locomotor and thermogenic activity in mice with targeted ablation of the GHRH gene. Growth Horm IGF Res 25(2):80-84. https://doi.org/10.1016/j. ghir.2014.12.007

112. Bartke A, Westbrook R (2012) Metabolic characteristics of longlived mice. Front Genet 3:288. https://doi.org/10.3389/fgene. 2012.00288

113. Sun LY, Spong A, Swindell WR, Fang Y, Hill C, Huber JA, Boehm JD, Westbrook R, Salvatori R, Bartke A (2013) Growth hormone-releasing hormone disruption extends lifespan and regulates response to caloric restriction in mice. Elife 2:e01098. https://doi.org/10.7554/eLife.01098

114. Matzkin ME, Miquet JG, Fang Y, Hill CM, Turyn D, Calandra RS, Bartke A, Frungieri MB (2016) Alterations in oxidative, inflammatory and apoptotic events in short-lived and long-lived mice testes. Aging (Albany NY) 8(1):95-110. https://doi.org/10. 18632/aging. 100875

115. Beamer WH, Eicher EM (1976) Stimulation of growth in the little mouse. J Endocrinol 71(1):37-45. https://doi.org/10.1677/ joe. 0.0710037

116. Eicher EM, Beamer WG (1976) Inherited ateliotic dwarfism in mice. Characteristics of the mutation, little, on chromosome 6. J Hered 67(2):87-91. https://doi.org/10.1093/oxfordjournals. jhered.a108682

117. Godfrey P, Rahal JO, Beamer WG, Copeland NG, Jenkins NA, Mayo KE (1993) GHRH receptor of little mice contains a missense mutation in the extracellular domain that disrupts receptor function. Nat Genet 4(3):227-232. https://doi.org/10.1038/ ng0793-227

118. Liang H, Masoro EJ, Nelson JF, Strong R, McMahan CA, Richardson A (2003) Genetic mouse models of extended lifespan. Exp Gerontol 38(11-12):1353-1364. https://doi.org/10.1016/j. exger.2003.10.019

119. Donahue LR, Beamer WG (1993) Growth hormone deficiency in "little" mice results in aberrant body composition, reduced 
insulin-like growth factor-I and insulin-like growth factor-binding protein-3 (IGFBP-3), but does not affect IGFBP-2, -1 or -4. J Endocrinol 136(1):91-104. https://doi.org/10.1677/joe.0.13600 91

120. Deitel K, Dantzer D, Ferguson P, Pollak M, Beamer W, Andrulis I, Bell R (2002) Reduced growth of human sarcoma xenografts in hosts homozygous for the lit mutation. J Surg Oncol 81(2):75-79. https://doi.org/10.1002/jso.10136

121. Takahara K, Tearle H, Ghaffari M, Gleave ME, Pollak M, Cox ME (2011) Human prostate cancer xenografts in lit/lit mice exhibit reduced growth and androgen-independent progression. Prostate 71(5):525-537. https://doi.org/10.1002/pros.21268

122. Yang XF, Beamer WG, Huynh H, Pollak M (1996) Reduced growth of human breast cancer xenografts in hosts homozygous for the lit mutation. Cancer Res 56(7):1509-1511

123. Mohan S, Richman C, Guo R, Amaar Y, Donahue LR, Wergedal J, Baylink DJ (2003) Insulin-like growth factor regulates peak bone mineral density in mice by both growth hormone-dependent and -independent mechanisms. Endocrinology 144(3):929-936. https://doi.org/10.1210/en.2002-220948

124. Palmiter RD, Norstedt G, Gelinas RE, Hammer RE, Brinster RL (1983) Metallothionein-human GH fusion genes stimulate growth of mice. Science 222(4625):809-814. https://doi.org/10. 1126/science.6356363

125. Wolf E, Kahnt E, Ehrlein J, Hermanns W, Brem G, Wanke R (1993) Effects of long-term elevated serum levels of growth hormone on life expectancy of mice: lessons from transgenic animal models. Mech Ageing Dev 68(1-3):71-87. https://doi. org/10.1016/0047-6374(93)90141-d

126. Bartke A, Steger RW, Hodges SL, Parkening TA, Collins TJ, Yun JS, Wagner TE (1988) Infertility in transgenic female mice with human growth hormone expression: evidence for luteal failure. J Exp Zool 248(1):121-124. https://doi.org/10.1002/jez.14024 80116

127. Hurley DL, Bartke A, Wagner TE, Wee BE, Phelps CJ (1994) Increased hypothalamic somatostatin expression in mice transgenic for bovine or human GH. J Neuroendocrinol 6(5):539-548. https://doi.org/10.1111/j.1365-2826.1994.tb00617.x

128. Selden RF, Wagner TE, Blethen S, Yun JS, Rowe ME, Goodman HM (1988) Expression of the human growth hormone variant gene in cultured fibroblasts and transgenic mice. Proc Natl Acad Sci USA 85(21):8241-8245. https://doi.org/10.1073/pnas.85.21. 8241

129. Dudley GA, Portanova R (1987) Histochemical characteristics of soleus muscle in hGH transgenic mice. Proc Soc Exp Biol Med 185(4):403-408. https://doi.org/10.3181/00379727-185-42561

130. Bartke A, Naar EM, Johnson L, May MR, Cecim M, Yun JS, Wagner TE (1992) Effects of expression of human or bovine growth hormone genes on sperm production and male reproductive performance in four lines of transgenic mice. J Reprod Fertil 95(1):109-118. https://doi.org/10.1530/jrf.0.0950109

131. Tornell J, Carlsson B, Pohjanen P, Wennbo H, Rymo L, Isaksson O (1992) High frequency of mammary adenocarcinomas in metallothionein promoter-human growth hormone transgenic mice created from two different strains of mice. J Steroid Biochem Mol Biol 43(1-3):237-242. https://doi.org/10.1016/0960-0760(92) 90213-3

132. Tornell J, Rymo L, Isaksson OG (1991) Induction of mammary adenocarcinomas in metallothionein promoter-human growth hormone transgenic mice. Int J Cancer 49(1):114-117. https:// doi.org/10.1002/ijc.2910490121

133. Wennbo $\mathrm{H}$, Gebre-Medhin $\mathrm{M}$, Gritli-Linde $\mathrm{A}$, Ohlsson C, Isaksson OG, Tornell J (1997) Activation of the prolactin receptor but not the growth hormone receptor is important for induction of mammary tumors in transgenic mice. J Clin Invest 100(11):2744-2751. https://doi.org/10.1172/jci119820
134. Wennbo H, Tornell J (2000) The role of prolactin and growth hormone in breast cancer. Oncogene 19(8):1072-1076. https:// doi.org/10.1038/sj.onc.1203349

135. Jin Y, Lu SY, Fresnoza A, Detillieux KA, Duckworth ML, Cattini PA (2009) Differential placental hormone gene expression during pregnancy in a transgenic mouse containing the human growth hormone/chorionic somatomammotropin locus. Placenta 30(3):226-235. https://doi.org/10.1016/j.placenta.2008.12.011

136. Vakili H, Jin Y, Nagy JI, Cattini PA (2011) Transgenic mice expressing the human growth hormone gene provide a model system to study human growth hormone synthesis and secretion in non-tumor-derived pituitary cells: differential effects of dexamethasone and thyroid hormone. Mol Cell Endocrinol 345(1-2):48-57. https://doi.org/10.1016/j.mce.2011.07.010

137. Jarmasz JS, Jin Y, Vakili H, Cattini PA (2020) Sleep deprivation and diet affect human GH gene expression in transgenic mice in vivo. Endocr Connect 9(12):1135-1147. https://doi.org/10. 1530/EC-20-0354

138. Vakili H, Jin Y, Cattini PA (2016) Evidence for a circadian effect on the reduction of human growth hormone gene expression in response to excess caloric intake. J Biol Chem 291(26):1382313833. https://doi.org/10.1074/jbc.M116.722744

139. Gunzburg WH, Salmons B, Zimmermann B, Muller M, Erfle V, Brem G (1991) A mammary-specific promoter directs expression of growth hormone not only to the mammary gland, but also to Bergman glia cells in transgenic mice. Mol Endocrinol 5(1):123-133. https://doi.org/10.1210/mend-5-1-123

140. Devinoy E, Thepot D, Stinnakre MG, Fontaine ML, Grabowski H, Puissant C, Pavirani A, Houdebine LM (1994) High level production of human growth hormone in the milk of transgenic mice: the upstream region of the rabbit whey acidic protein (WAP) gene targets transgene expression to the mammary gland. Transgenic Res 3(2):79-89. https://doi.org/10.1007/bf01974085

141. Bartke A, Kopchick JJ (2015) The forgotten lactogenic activity of growth hormone: important implications for rodent studies. Endocrinology 156(5):1620-1622. https://doi.org/10.1210/en. 2015-1097

142. Naraoka H, Ito K, Suzuki M, Naito K, Tojo H (2006) Analysis of gender difference of cardiac risk biomarkers using hGH-transgenic mice. Exp Anim 55(1):1-9. https://doi.org/10.1538/expan im. 55.1

143. Thepot D, Devinoy E, Fontaine ML, Stinnakre MG, Massoud M, Kann G, Houdebine LM (1995) Rabbit whey acidic protein gene upstream region controls high-level expression of bovine growth hormone in the mammary gland of transgenic mice. Mol Reprod Dev 42(3):261-267. https://doi.org/10.1002/mrd.1080420302

144. Naar EM, Bartke A, Majumdar SS, Buonomo FC, Yun JS, Wagner TE (1991) Fertility of transgenic female mice expressing bovine growth hormone or human growth hormone variant genes. Biol Reprod 45(1):178-187. https://doi.org/10.1095/biolr eprod45.1.178

145. Hammer RE, Brinster RL, Palmiter RD (1985) Use of gene transfer to increase animal growth. Cold Spring Harb Symp Quant Biol 50:379-387. https://doi.org/10.1101/sqb.1985.050.01.048

146. Palmer AJ, Chung MY, List EO, Walker J, Okada S, Kopchick JJ, Berryman DE (2009) Age-related changes in body composition of bovine growth hormone transgenic mice. Endocrinology 150(3):1353-1360. https://doi.org/10.1210/en.2008-1199

147. Asa SL, Coschigano KT, Bellush L, Kopchick JJ, Ezzat S (2000) Evidence for growth hormone $(\mathrm{GH})$ autoregulation in pituitary somatotrophs in GH antagonist-transgenic mice and GH receptor-deficient mice. Am J Pathol 156(3):1009-1015. https://doi. org/10.1016/s0002-9440(10)64968-1

148. Berryman DE, List EO, Coschigano KT, Behar K, Kim JK, Kopchick JJ (2004) Comparing adiposity profiles in three 
mouse models with altered GH signaling. Growth Horm IGF Res 14(4):309-318. https://doi.org/10.1016/j.ghir.2004.02.005

149. Bollano E, Omerovic E, Bohlooly-y M, Kujacic V, Madhu B, Tornell J, Isaksson O, Soussi B, Schulze W, Fu ML, Matejka G, Waagstein F, Isgaard J (2000) Impairment of cardiac function and bioenergetics in adult transgenic mice overexpressing the bovine growth hormone gene. Endocrinology 141(6):2229-2235. https://doi.org/10.1210/endo.141.6.7486

150. Ding J, Berryman DE, Kopchick JJ (2011) Plasma proteomic profiles of bovine growth hormone transgenic mice as they age. Transgenic Res 20(6):1305-1320. https://doi.org/10.1007/ s11248-011-9499-5

151. Hjortebjerg R, Berryman DE, Comisford R, Frank SJ, List EO, Bjerre M, Frystyk J, Kopchick JJ (2017) Insulin, IGF-1, and $\mathrm{GH}$ receptors are altered in an adipose tissue depot-specific manner in male mice with modified GH action. Endocrinology 158(5):1406-1418. https://doi.org/10.1210/en.2017-00084

152. Olsson B, Bohlooly YM, Fitzgerald SM, Frick F, Ljungberg A, Ahren B, Tornell J, Bergstrom G, Oscarsson J (2005) Bovine growth hormone transgenic mice are resistant to diet-induced obesity but develop hyperphagia, dyslipidemia, and diabetes on a high-fat diet. Endocrinology 146(2):920-930. https://doi.org/ 10.1210/en.2004-1232

153. Wang Z, Masternak MM, Al-Regaiey KA, Bartke A (2007) Adipocytokines and the regulation of lipid metabolism in growth hormone transgenic and calorie-restricted mice. Endocrinology 148(6):2845-2853. https://doi.org/10.1210/en.2006-1313

154. Quaife CJ, Mathews LS, Pinkert CA, Hammer RE, Brinster RL, Palmiter RD (1989) Histopathology associated with elevated levels of growth hormone and insulin-like growth factor I in transgenic mice. Endocrinology 124(1):40-48. https://doi.org/ 10.1210/endo-124-1-40

155. McGrane MM, de Vente J, Yun J, Bloom J, Park E, WynshawBoris A, Wagner T, Rottman FM, Hanson RW (1988) Tissuespecific expression and dietary regulation of a chimeric phosphoenolpyruvate carboxykinase/bovine growth hormone gene in transgenic mice. J Biol Chem 263(23):11443-11451

156. McGrane MM, Yun JS, Moorman AF, Lamers WH, Hendrick GK, Arafah BM, Park EA, Wagner TE, Hanson RW (1990) Metabolic effects of developmental, tissue-, and cell-specific expression of a chimeric phosphoenolpyruvate carboxykinase (GTP)/bovine growth hormone gene in transgenic mice. J Biol Chem 265(36):22371-22379

157. Ogueta S, Olazabal I, Santos I, Delgado-Baeza E, Garcia-Ruiz JP (2000) Transgenic mice expressing bovine GH develop arthritic disorder and self-antibodies. J Endocrinol 165(2):321-328. https://doi.org/10.1677/joe.0.1650321

158. Junnila RK, List EO, Berryman DE, Murrey JW, Kopchick JJ (2013) The GH/IGF-1 axis in ageing and longevity. Nat Rev Endocrinol 9(6):366-376. https://doi.org/10.1038/nrendo.2013. 67

159. Bartke A (2003) Can growth hormone $(\mathrm{GH})$ accelerate aging? Evidence from GH-transgenic mice. Neuroendocrinology 78(4):210-216. https://doi.org/10.1159/000073704

160. Doi T, Striker LJ, Quaife C, Conti FG, Palmiter R, Behringer R, Brinster R, Striker GE (1988) Progressive glomerulosclerosis develops in transgenic mice chronically expressing growth hormone and growth hormone releasing factor but not in those expressing insulinlike growth factor-1. Am J Pathol 131(3):398-403

161. Martinez CS, Piazza VG, Gonzalez L, Fang Y, Bartke A, Turyn D, Miquet JG, Sotelo AI (2016) Mitogenic signaling pathways in the liver of growth hormone $(\mathrm{GH})$-overexpressing mice during the growth period. Cell Cycle 15(5):748-759. https://doi.org/10. 1080/15384101.2016.1148844
162. Bacigalupo ML, Piazza VG, Cicconi NS, Carabias P, Bartke A, Fang Y, Sotelo AI, Rabinovich GA, Troncoso MF, Miquet JG (2019) Growth hormone upregulates the pro-tumorigenic galectin 1 in mouse liver. Endocr Connect 8(8):1108-1117. https:// doi.org/10.1530/ec-19-0292

163. Miquet JG, Freund T, Martinez CS, Gonzalez L, Diaz ME, Micucci GP, Zotta E, Boparai RK, Bartke A, Turyn D, Sotelo AI (2013) Hepatocellular alterations and dysregulation of oncogenic pathways in the liver of transgenic mice overexpressing growth hormone. Cell Cycle 12(7):1042-1057. https://doi.org/10.4161/ cc. 24026

164. Snibson KJ, Bhathal PS, Hardy CL, Brandon MR, Adams TE (1999) High, persistent hepatocellular proliferation and apoptosis precede hepatocarcinogenesis in growth hormone transgenic mice. Liver 19(3):242-252. https://doi.org/10.1111/j.1478-3231. 1999.tb00042.x

165. Snibson KJ (2002) Hepatocellular kinetics and the expression of growth hormone $(\mathrm{GH})$ in the livers and liver tumours of $\mathrm{GH}$ transgenic mice. Tissue Cell 34(2):88-97. https://doi.org/10. 1016/s0040-8166(02)00012-5

166. Kong X, Wu W, Yuan Y, Pandey V, Wu Z, Lu X, Zhang W, Chen Y, Wu M, Zhang M, Li G, Tan S, Qian P, Perry JK, Lobie PE, Zhu T (2016) Human growth hormone and human prolactin function as autocrine/paracrine promoters of progression of hepatocellular carcinoma. Oncotarget 7(20):29465-29479. https://doi. org/10.18632/oncotarget.8781

167. List EO, Berryman DE, Buchman M, Jensen EA, Funk K, DuranOrtiz S, Qian Y, Young JA, Slyby J, McKenna S, Kopchick JJ (2019) GH Knockout Mice have increased subcutaneous adipose tissue with decreased fibrosis and enhanced insulin sensitivity. Endocrinology 160(7):1743-1756. https://doi.org/10.1210/en. 2019-00167

168. Luque RM, Lin Q, Cordoba-Chacon J, Subbaiah PV, Buch T, Waisman A, Vankelecom H, Kineman RD (2011) Metabolic impact of adult-onset, isolated, growth hormone deficiency (AOiGHD) due to destruction of pituitary somatotropes. PLoS ONE 6(1):e15767. https://doi.org/10.1371/journal.pone.0015767

169. Kopchick JJ, McAndrew SJ, Shafer A, Blue WT, Yun JS, Wagner TE, Chen WY (1990) In-vitro mutagenesis of the bovine growth hormone gene. J Reprod Fertil Suppl 41:25-35

170. Chen WY, White ME, Wagner TE, Kopchick JJ (1991) Functional antagonism between endogenous mouse growth hormone $(\mathrm{GH})$ and a $\mathrm{GH}$ analog results in dwarf transgenic mice. Endocrinology 129(3):1402-1408. https://doi.org/10.1210/ endo-129-3-1402

171. Wang YD, Wood WI (1995) Amino acids of the human growth hormone receptor that are required for proliferation and JakSTAT signaling. Mol Endocrinol 9(3):303-311. https://doi.org/ 10.1210/mend.9.3.7539888

172. Chen WY, Chen NY, Yun J, Wagner TE, Kopchick JJ (1994) In vitro and in vivo studies of antagonistic effects of human growth hormone analogs. J Biol Chem 269(22):15892-15897

173. Kopchick JJ (2003) Discovery and mechanism of action of pegvisomant. Eur J Endocrinol 148(Suppl 2):S21-25. https://doi.org/ 10.1530/eje.0.148s021

174. Comisford R, Lubbers ER, Householder LA, Suer O, Tchkonia T, Kirkland JL, List EO, Kopchick JJ, Berryman DE (2016) Growth hormone receptor antagonist transgenic mice have increased subcutaneous adipose tissue mass, altered glucose homeostasis and no change in white adipose tissue cellular senescence. Gerontology 62(2):163-172. https://doi.org/10.1159/000439050

175. Li Y, Knapp JR, Kopchick JJ (2003) Enlargement of interscapular brown adipose tissue in growth hormone antagonist transgenic and in growth hormone receptor gene-disrupted dwarf mice. Exp Biol Med (Maywood) 228(2):207-215. https://doi.org/10.1177/ 153537020322800212 
176. Yang T, Householder LA, Lubbers ER, List EO, Troike K, Vesel C, Duran-Ortiz S, Kopchick JJ, Berryman DE (2015) Growth hormone receptor antagonist transgenic mice are protected from hyperinsulinemia and glucose intolerance despite obesity when placed on a HF diet. Endocrinology 156(2):555-564. https://doi. org/10.1210/en.2014-1617

177. Bernard V, Young J, Binart N (2019) Prolactin-a pleiotropic factor in health and disease. Nat Rev Endocrinol 15(6):356-365. https://doi.org/10.1038/s41574-019-0194-6

178. Freeman ME, Kanyicska B, Lerant A, Nagy G (2000) Prolactin: structure, function, and regulation of secretion. Physiol Rev 80(4):1523-1631. https://doi.org/10.1152/physrev.2000.80.4. 1523

179. Enjalbert A, Bertrand P, Le Dafniet M, Epelbaum J, Hugues JN, Kordon C, Moyse E, Peillon F, Shu C (1986) Somatostatin and regulation of prolactin secretion. Psychoneuroendocrinology 11(2):155-165. https://doi.org/10.1016/0306-4530(86)90050-8

180. Willoughby JO, Jervois PM, Menadue MF, Blessing WW (1986) Activation of GABA receptors in the hypothalamus stimulates secretion of growth hormone and prolactin. Brain Res 374(1):119-125. https://doi.org/10.1016/0006-8993(86)90400-2

181. Bole-Feysot C, Goffin V, Edery M, Binart N, Kelly PA (1998) Prolactin (PRL) and its receptor: actions, signal transduction pathways and phenotypes observed in PRL receptor knockout mice. Endocr Rev 19(3):225-268. https://doi.org/10.1210/edrv. 19.3.0334

182. Goffin V, Bernichtein S, Touraine P, Kelly PA (2005) Development and potential clinical uses of human prolactin receptor antagonists. Endocr Rev 26(3):400-422. https://doi.org/10.1210/ er.2004-0016

183. Wennbo H, Kindblom J, Isaksson OG, Tornell J (1997) Transgenic mice overexpressing the prolactin gene develop dramatic enlargement of the prostate gland. Endocrinology 138(10):4410 4415. https://doi.org/10.1210/endo.138.10.5461

184. Kindblom J, Dillner K, Sahlin L, Robertson F, Ormandy C, Tornell J, Wennbo H (2003) Prostate hyperplasia in a transgenic mouse with prostate-specific expression of prolactin. Endocrinology 144(6):2269-2278. https://doi.org/10.1210/en.2002-0187

185. Tworoger SS, Hankinson SE (2008) Prolactin and breast cancer etiology: an epidemiologic perspective. J Mammary Gland Biol Neoplasia 13(1):41-53. https://doi.org/10.1007/ s10911-008-9063-y

186. Rose-Hellekant TA, Arendt LM, Schroeder MD, Gilchrist K, Sandgren EP, Schuler LA (2003) Prolactin induces ERalphapositive and ERalpha-negative mammary cancer in transgenic mice. Oncogene 22(30):4664-4674. https://doi.org/10.1038/sj. onc. 1206619

187. Arendt LM, Rugowski DE, Grafwallner-Huseth TA, GarciaBarchino MJ, Rui H, Schuler LA (2011) Prolactin-induced mouse mammary carcinomas model estrogen resistant luminal breast cancer. Breast Cancer Res 13(1):R11. https://doi.org/10. $1186 / \mathrm{bcr} 2819$

188. Horseman ND, Zhao W, Montecino-Rodriguez E, Tanaka M, Nakashima K, Engle SJ, Smith F, Markoff E, Dorshkind K (1997) Defective mammopoiesis, but normal hematopoiesis, in mice with a targeted disruption of the prolactin gene. EMBO J 16(23):6926-6935. https://doi.org/10.1093/emboj/16.23.6926

189. LaPensee CR, Horseman ND, Tso P, Brandebourg TD, Hugo ER, Ben-Jonathan N (2006) The prolactin-deficient mouse has an unaltered metabolic phenotype. Endocrinology 147(10):46384645. https://doi.org/10.1210/en.2006-0487

190. Ormandy CJ, Camus A, Barra J, Damotte D, Lucas B, Buteau H, Edery M, Brousse N, Babinet C, Binart N, Kelly PA (1997) Null mutation of the prolactin receptor gene produces multiple reproductive defects in the mouse. Genes Dev 11(2):167-178. https://doi.org/10.1101/gad.11.2.167
191. Kelly PA, Binart N, Lucas B, Bouchard B, Goffin V (2001) Implications of multiple phenotypes observed in prolactin receptor knockout mice. Front Neuroendocrinol 22(2):140-145. https:// doi.org/10.1006/frne.2001.0212

192. Freemark M, Avril I, Fleenor D, Driscoll P, Petro A, Opara E, Kendall W, Oden J, Bridges S, Binart N, Breant B, Kelly PA (2002) Targeted deletion of the PRL receptor: effects on islet development, insulin production, and glucose tolerance. Endocrinology 143(4):1378-1385. https://doi.org/10.1210/endo.143.4. 8722

193. Robertson FG, Harris J, Naylor MJ, Oakes SR, Kindblom J, Dillner K, Wennbo H, Tornell J, Kelly PA, Green J, Ormandy CJ (2003) Prostate development and carcinogenesis in prolactin receptor knockout mice. Endocrinology 144(7):3196-3205. https://doi.org/10.1210/en.2003-0068

194. Saunier E, Dif F, Kelly PA, Edery M (2003) Targeted expression of the dominant-negative prolactin receptor in the mammary gland of transgenic mice results in impaired lactation. Endocrinology 144(6):2669-2675. https://doi.org/10.1210/en. 2002-221038

195. Binart N, Imbert-Bollore P, Baran N, Viglietta C, Kelly PA (2003) A short form of the prolactin (PRL) receptor is able to rescue mammopoiesis in heterozygous PRL receptor mice. Mol Endocrinol 17(6):1066-1074. https://doi.org/10.1210/me. 2002-0181

196. Le JA, Wilson HM, Shehu A, Mao J, Devi YS, Halperin J, Aguilar T, Seibold A, Maizels E, Gibori G (2012) Generation of mice expressing only the long form of the prolactin receptor reveals that both isoforms of the receptor are required for normal ovarian function. Biol Reprod 86(3):86. https://doi.org/10.1095/biolr eprod.111.095927

197. Bernichtein S, Kayser C, Dillner K, Moulin S, Kopchick JJ, Martial JA, Norstedt G, Isaksson O, Kelly PA, Goffin V (2003) Development of pure prolactin receptor antagonists. J Biol Chem 278(38):35988-35999. https://doi.org/10.1074/jbc.M305687200

198. Rouet V, Bogorad RL, Kayser C, Kessal K, Genestie C, Bardier A, Grattan DR, Kelder B, Kopchick JJ, Kelly PA, Goffin $\mathrm{V}$ (2010) Local prolactin is a target to prevent expansion of basal/stem cells in prostate tumors. Proc Natl Acad Sci USA 107(34):15199-15204. https://doi.org/10.1073/pnas.0911651107

199. Ferraris J, Boutillon F, Bernadet M, Seilicovich A, Goffin V, Pisera D (2012) Prolactin receptor antagonism in mouse anterior pituitary: effects on cell turnover and prolactin receptor expression. Am J Physiol Endocrinol Metab 302(3):E356-364. https:// doi.org/10.1152/ajpendo.00333.2011

200. Ferraris J, Zarate S, Jaita G, Boutillon F, Bernadet M, Auffret J, Seilicovich A, Binart N, Goffin V, Pisera D (2014) Prolactin induces apoptosis of lactotropes in female rodents. PLoS ONE 9(5):e97383. https://doi.org/10.1371/journal.pone.0097383

201. Danilovich N, Wernsing D, Coschigano KT, Kopchick JJ, Bartke A (1999) Deficits in female reproductive function in GH-R-KO mice; role of IGF-I. Endocrinology 140(6):2637-2640. https:// doi.org/10.1210/endo.140.6.6992

202. Berryman DE, List EO, Palmer AJ, Chung MY, Wright-Piekarski J, Lubbers E, O'Connor P, Okada S, Kopchick JJ (2010) Twoyear body composition analyses of long-lived GHR null mice. $\mathrm{J}$ Gerontol A 65(1):31-40. https://doi.org/10.1093/gerona/glp175

203. Liu JL, Coschigano KT, Robertson K, Lipsett M, Guo Y, Kopchick JJ, Kumar U, Liu YL (2004) Disruption of growth hormone receptor gene causes diminished pancreatic islet size and increased insulin sensitivity in mice. Am J Physiol Endocrinol Metab 287(3):E405-413. https://doi.org/10.1152/ajpendo.00423. 2003

204. Guo Y, Lu Y, Houle D, Robertson K, Tang Z, Kopchick JJ, Liu YL, Liu JL (2005) Pancreatic islet-specific expression of an insulin-like growth factor-I transgene compensates islet cell growth 
in growth hormone receptor gene-deficient mice. Endocrinology 146(6):2602-2609. https://doi.org/10.1210/en.2004-1203

205. Al-Regaiey KA, Masternak MM, Bonkowski M, Sun L, Bartke A (2005) Long-lived growth hormone receptor knockout mice: interaction of reduced insulin-like growth factor i/insulin signaling and caloric restriction. Endocrinology 146(2):851-860. https://doi.org/10.1210/en.2004-1120

206. Egecioglu E, Bjursell M, Ljungberg A, Dickson SL, Kopchick JJ, Bergstrom G, Svensson L, Oscarsson J, Tornell J, Bohlooly YM (2006) Growth hormone receptor deficiency results in blunted ghrelin feeding response, obesity, and hypolipidemia in mice. Am J Physiol Endocrinol Metab 290(2):E317-325. https://doi. org/10.1152/ajpendo.00181.2005

207. Lubbers ER, List EO, Jara A, Sackman-Sala L, Cordoba-Chacon J, Gahete MD, Kineman RD, Boparai R, Bartke A, Kopchick JJ, Berryman DE (2013) Adiponectin in mice with altered GH action: links to insulin sensitivity and longevity? J Endocrinol 216(3):363-374. https://doi.org/10.1530/JOE-12-0505

208. Bartke A, Peluso MR, Moretz N, Wright C, Bonkowski M, Winters TA, Shanahan MF, Kopchick JJ, Banz WJ (2004) Effects of Soy-derived diets on plasma and liver lipids, glucose tolerance, and longevity in normal, long-lived and short-lived mice. Horm Metab Res 36(8):550-558. https://doi.org/10. 1055/s-2004-825796

209. Hauck SJ, Hunter WS, Danilovich N, Kopchick JJ, Bartke A (2001) Reduced levels of thyroid hormones, insulin, and glucose, and lower body core temperature in the growth hormone receptor/binding protein knockout mouse. Exp Biol Med (Maywood) 226(6):552-558. https://doi.org/10.1177/153537020122600607

210. Longo KA, Berryman DE, Kelder B, Charoenthongtrakul S, Distefano PS, Geddes BJ, Kopchick JJ (2010) Daily energy balance in growth hormone receptor/binding protein (GHR -/-) genedisrupted mice is achieved through an increase in dark-phase energy efficiency. Growth Horm IGF Res 20(1):73-79. https:// doi.org/10.1016/j.ghir.2009.08.002

211. Westbrook R, Bonkowski MS, Strader AD, Bartke A (2009) Alterations in oxygen consumption, respiratory quotient, and heat production in long-lived GHRKO and Ames dwarf mice, and short-lived bGH transgenic mice. J Gerontol A Biol Sci Med Sci 64(4):443-451. https://doi.org/10.1093/gerona/gln075

212. Kinney BA, Coschigano KT, Kopchick JJ, Steger RW, Bartke A (2001) Evidence that age-induced decline in memory retention is delayed in growth hormone resistant GH-R-KO (Laron) mice. Physiol Behav 72(5):653-660. https://doi.org/10.1016/s00319384(01)00423-1

213. Bellush LL, Doublier S, Holland AN, Striker LJ, Striker GE, Kopchick JJ (2000) Protection against diabetes-induced nephropathy in growth hormone receptor/binding protein gene-disrupted mice. Endocrinology 141(1):163-168. https://doi.org/10.1210/ endo.141.1.7284

214. Arum O, Rickman DJ, Kopchick JJ, Bartke A (2014) The slowaging growth hormone receptor/binding protein gene-disrupted (GHR-KO) mouse is protected from aging-resultant neuromusculoskeletal frailty. Age (Dordr) 36(1):117-127. https://doi.org/ 10.1007/s11357-013-9551-x

215. Coschigano KT, Clemmons D, Bellush LL, Kopchick JJ (2000) Assessment of growth parameters and life span of GHR/BP genedisrupted mice. Endocrinology 141(7):2608-2613. https://doi. org/10.1210/endo.141.7.7586

216. Liu JL, Yakar S, LeRoith D (2000) Mice deficient in liver production of insulin-like growth factor I display sexual dimorphism in growth hormone-stimulated postnatal growth. Endocrinology 141(12):4436-4441. https://doi.org/10.1210/endo.141.12.7825

217. Caplan AI, Fiszman MY, Eppenberger HM (1983) Molecular and cell isoforms during development. Science 221(4614):921-927. https://doi.org/10.1126/science.6348946
218. Agarwal P, Verzi MP, Nguyen T, Hu J, Ehlers ML, McCulley DJ, Xu SM, Dodou E, Anderson JP, Wei ML, Black BL (2011) The MADS box transcription factor MEF2C regulates melanocyte development and is a direct transcriptional target and partner of SOX10. Development 138(12):2555-2565. https://doi.org/10. 1242/dev.056804

219. Potthoff MJ, Olson EN (2007) MEF2: a central regulator of diverse developmental programs. Development 134(23):41314140. https://doi.org/10.1242/dev.008367

220. List EO, Berryman DE, Buchman M, Parker C, Funk K, Bell S, Duran-Ortiz S, Qian Y, Young JA, Wilson C, Slyby J, McKenna S, Jensen EA, Kopchick JJ (2019) Adipocyte-specific GH receptor-null (AdGHRKO) mice have enhanced insulin sensitivity with reduced liver triglycerides. Endocrinology 160(1):68-80. https://doi.org/10.1210/en.2018-00850

221. Herrera PL (2000) Adult insulin- and glucagon-producing cells differentiate from two independent cell lineages. Development 127(11):2317-2322

222. Brouwers B, de Faudeur G, Osipovich AB, Goyvaerts L, Lemaire K, Boesmans L, Cauwelier EJ, Granvik M, Pruniau VP, Van Lommel L, Van Schoors J, Stancill JS, Smolders I, Goffin V, Binart N, in't Veld P, Declercq J, Magnuson MA, Creemers JW, Schuit F, Schraenen A (2014) Impaired islet function in commonly used transgenic mouse lines due to human growth hormone minigene expression. Cell Metab 20(6): 979-990. https:// doi.org/10.1016/j.cmet.2014.11.004

223. Baan M, Kibbe CR, Bushkofsky JR, Harris TW, Sherman DS, Davis DB (2015) Transgenic expression of the human growth hormone minigene promotes pancreatic beta-cell proliferation. Am J Physiol Regul Integr Comp Physiol 309(7):R788-794. https://doi.org/10.1152/ajpregu.00244.2015

224. Liu Z, Kennedy OD, Cardoso L, Basta-Pljakic J, Partridge NC, Schaffler MB, Rosen CJ, Yakar S (2016) DMP-1-mediated Ghr gene recombination compromises skeletal development and impairs skeletal response to intermittent PTH. Faseb J 30(2):635-652. https://doi.org/10.1096/fj.15-275859

225. Rodig SJ, Meraz MA, White JM, Lampe PA, Riley JK, Arthur CD, King KL, Sheehan KC, Yin L, Pennica D, Johnson EM Jr, Schreiber RD (1998) Disruption of the Jak1 gene demonstrates obligatory and nonredundant roles of the Jaks in cytokineinduced biologic responses. Cell 93(3):373-383. https://doi.org/ 10.1016/s0092-8674(00)81166-6

226. Parganas E, Wang D, Stravopodis D, Topham DJ, Marine JC, Teglund S, Vanin EF, Bodner S, Colamonici OR, van Deursen JM, Grosveld G, Ihle JN (1998) Jak2 is essential for signaling through a variety of cytokine receptors. Cell 93(3):385-395. https://doi.org/10.1016/s0092-8674(00)81167-8

227. Neubauer H, Cumano A, Muller M, Wu H, Huffstadt U, Pfeffer K (1998) Jak2 deficiency defines an essential developmental checkpoint in definitive hematopoiesis. Cell 93(3):397-409. https:// doi.org/10.1016/s0092-8674(00)81168-х

228. Park SY, Saijo K, Takahashi T, Osawa M, Arase H, Hirayama N, Miyake K, Nakauchi H, Shirasawa T, Saito T (1995) Developmental defects of lymphoid cells in Jak3 kinase-deficient mice. Immunity 3(6):771-782. https://doi.org/10.1016/1074-7613(95) 90066-7

229. Shimoda K, Kato K, Aoki K, Matsuda T, Miyamoto A, Shibamori M, Yamashita M, Numata A, Takase K, Kobayashi S, Shibata S, Asano Y, Gondo H, Sekiguchi K, Nakayama K, Nakayama T, Okamura T, Okamura S, Niho Y (2000) Tyk2 plays a restricted role in IFN alpha signaling, although it is required for IL-12-mediated T cell function. Immunity 13(4):561-571. https://doi.org/10.1016/s1074-7613(00)00055-8

230. Derecka M, Gornicka A, Koralov SB, Szczepanek K, Morgan M, Raje V, Sisler J, Zhang Q, Otero D, Cichy J, Rajewsky K, Shimoda K, Poli V, Strobl B, Pellegrini S, Harris TE, Seale P, 
Russell AP, McAinch AJ, O'Brien PE, Keller SR, Croniger CM, Kordula T, Larner AC (2012) Tyk2 and Stat 3 regulate brown adipose tissue differentiation and obesity. Cell Metab 16(6):814824. https://doi.org/10.1016/j.cmet.2012.11.005

231. Sos BC, Harris C, Nordstrom SM, Tran JL, Balazs M, Caplazi P, Febbraio M, Applegate MA, Wagner KU, Weiss EJ (2011) Abrogation of growth hormone secretion rescues fatty liver in mice with hepatocyte-specific deletion of JAK2. J Clin Invest 121(4):1412-1423. https://doi.org/10.1172/JCI42894

232. Nordstrom SM, Tran JL, Sos BC, Wagner KU, Weiss EJ (2013) Disruption of JAK2 in adipocytes impairs lipolysis and improves fatty liver in mice with elevated GH. Mol Endocrinol 27(8):1333-1342. https://doi.org/10.1210/me.2013-1110

233. Meraz MA, White JM, Sheehan KC, Bach EA, Rodig SJ, Dighe AS, Kaplan DH, Riley JK, Greenlund AC, Campbell D, CarverMoore K, DuBois RN, Clark R, Aguet M, Schreiber RD (1996) Targeted disruption of the Stat 1 gene in mice reveals unexpected physiologic specificity in the JAK-STAT signaling pathway. Cell 84(3):431-442. https://doi.org/10.1016/s0092-8674(00)81288-x

234. Durbin JE, Hackenmiller R, Simon MC, Levy DE (1996) Targeted disruption of the mouse Stat 1 gene results in compromised innate immunity to viral disease. Cell 84(3):443-450. https://doi. org/10.1016/s0092-8674(00)81289-1

235. Park C, Li S, Cha E, Schindler C (2000) Immune response in Stat2 knockout mice. Immunity 13(6):795-804. https://doi.org/ 10.1016/s1074-7613(00)00077-7

236. Takeda K, Noguchi K, Shi W, Tanaka T, Matsumoto M, Yoshida N, Kishimoto T, Akira S (1997) Targeted disruption of the mouse Stat3 gene leads to early embryonic lethality. Proc Natl Acad Sci USA 94(8):3801-3804. https://doi.org/10.1073/pnas.94.8.3801

237. Wirtz S, Finotto S, Kanzler S, Lohse AW, Blessing M, Lehr HA, Galle PR, Neurath MF (1999) Cutting edge: chronic intestinal inflammation in STAT-4 transgenic mice: characterization of disease and adoptive transfer by TNF- plus IFN-gamma-producing $\mathrm{CD} 4+\mathrm{T}$ cells that respond to bacterial antigens. J Immunol 162(4):1884-1888

238. Thierfelder WE, van Deursen JM, Yamamoto K, Tripp RA, Sarawar SR, Carson RT, Sangster MY, Vignali DA, Doherty PC, Grosveld GC, Ihle JN (1996) Requirement for Stat4 in interleukin-12-mediated responses of natural killer and T cells. Nature 382(6587):171-174. https://doi.org/10.1038/382171a0

239. Kaplan MH, Sun YL, Hoey T, Grusby MJ (1996) Impaired IL-12 responses and enhanced development of Th2 cells in Stat4-deficient mice. Nature 382(6587):174-177. https://doi.org/10.1038/ $382174 \mathrm{a} 0$

240. Liu X, Robinson GW, Wagner KU, Garrett L, Wynshaw-Boris A, Hennighausen L (1997) Stat5a is mandatory for adult mammary gland development and lactogenesis. Genes Dev 11(2):179-186. https://doi.org/10.1101/gad.11.2.179

241. Udy GB, Towers RP, Snell RG, Wilkins RJ, Park SH, Ram PA, Waxman DJ, Davey HW (1997) Requirement of STAT5b for sexual dimorphism of body growth rates and liver gene expression. Proc Natl Acad Sci USA 94(14):7239-7244. https://doi.org/ 10.1073/pnas.94.14.7239

242. Teglund S, McKay C, Schuetz E, van Deursen JM, Stravopodis D, Wang D, Brown M, Bodner S, Grosveld G, Ihle JN (1998) Stat5a and Stat5b proteins have essential and nonessential, or redundant, roles in cytokine responses. Cell 93(5):841-850. https://doi.org/10.1016/s0092-8674(00)81444-0

243. Takeda K, Tanaka T, Shi W, Matsumoto M, Minami M, Kashiwamura S, Nakanishi K, Yoshida N, Kishimoto T, Akira S (1996) Essential role of Stat6 in IL-4 signalling. Nature 380(6575):627630. https://doi.org/10.1038/380627a0

244. Trengove MC, Ward AC (2013) SOCS proteins in development and disease. Am J Clin Exp Immunol 2(1):1-29
245. Ram PA, Waxman DJ (1999) SOCS/CIS protein inhibition of growth hormone-stimulated STAT5 signaling by multiple mechanisms. J Biol Chem 274(50):35553-35561. https://doi.org/10. $1074 /$ jbc. 274.50 .35553

246. Starr R, Metcalf D, Elefanty AG, Brysha M, Willson TA, Nicola NA, Hilton DJ, Alexander WS (1998) Liver degeneration and lymphoid deficiencies in mice lacking suppressor of cytokine signaling-1. Proc Natl Acad Sci U S A 95(24):14395-14399. https://doi.org/10.1073/pnas.95.24.14395

247. Fujimoto M, Naka T, Nakagawa R, Kawazoe Y, Morita Y, Tateishi A, Okumura K, Narazaki M, Kishimoto T (2000) Defective thymocyte development and perturbed homeostasis of $\mathrm{T}$ cells in STAT-induced STAT inhibitor-1/suppressors of cytokine signaling-1 transgenic mice. J Immunol 165(4):1799-1806. https://doi. org/10.4049/jimmunol.165.4.1799

248. Kaplan DH, Shankaran V, Dighe AS, Stockert E, Aguet M, Old LJ, Schreiber RD (1998) Demonstration of an interferon gammadependent tumor surveillance system in immunocompetent mice. Proc Natl Acad Sci USA 95(13):7556-7561. https://doi.org/10. 1073/pnas.95.13.7556

249. Greenhalgh CJ, Metcalf D, Thaus AL, Corbin JE, Uren R, Morgan PO, Fabri LJ, Zhang JG, Martin HM, Willson TA, Billestrup N, Nicola NA, Baca M, Alexander WS, Hilton DJ (2002) Biological evidence that SOCS-2 can act either as an enhancer or suppressor of growth hormone signaling. J Biol Chem 277(43):40181-40184. https://doi.org/10.1074/jbc.C200450200

250. Marine JC, McKay C, Wang D, Topham DJ, Parganas E, Nakajima H, Pendeville H, Yasukawa H, Sasaki A, Yoshimura A, Ihle JN (1999) SOCS3 is essential in the regulation of fetal liver erythropoiesis. Cell 98(5):617-627. https://doi.org/10.1016/ s0092-8674(00)80049-5

251. Seki Y, Hayashi K, Matsumoto A, Seki N, Tsukada J, Ransom J, Naka T, Kishimoto T, Yoshimura A, Kubo M (2002) Expression of the suppressor of cytokine signaling-5 (SOCS5) negatively regulates IL-4-dependent STAT6 activation and Th2 differentiation. Proc Natl Acad Sci USA 99(20):13003-13008. https://doi. org/10.1073/pnas.202477099

252. Brender C, Columbus R, Metcalf D, Handman E, Starr R, Huntington N, Tarlinton D, Odum N, Nicholson SE, Nicola NA, Hilton DJ, Alexander WS (2004) SOCS5 is expressed in primary B and $\mathrm{T}$ lymphoid cells but is dispensable for lymphocyte production and function. Mol Cell Biol 24(13):6094-6103. https://doi. org/10.1128/mcb.24.13.6094-6103.2004

253. Li L, Gronning LM, Anderson PO, Li S, Edvardsen K, Johnston J, Kioussis D, Shepherd PR, Wang P (2004) Insulin induces SOCS-6 expression and its binding to the $\mathrm{p} 85$ monomer of phosphoinositide 3-kinase, resulting in improvement in glucose metabolism. J Biol Chem 279(33):34107-34114. https://doi.org/ 10.1074/jbc.M312672200

254. Matsumoto A, Seki Y, Kubo M, Ohtsuka S, Suzuki A, Hayashi I, Tsuji K, Nakahata T, Okabe M, Yamada S, Yoshimura A (1999) Suppression of STAT5 functions in liver, mammary glands, and $\mathrm{T}$ cells in cytokine-inducible $\mathrm{SH}$-containing protein 1 transgenic mice. Mol Cell Biol 19(9):6396-6407. https://doi.org/10.1128/ mcb.19.9.6396

255. Krebs DL, Uren RT, Metcalf D, Rakar S, Zhang JG, Starr R, De Souza DP, Hanzinikolas K, Eyles J, Connolly LM, Simpson RJ, Nicola NA, Nicholson SE, Baca M, Hilton DJ, Alexander WS (2002) SOCS-6 binds to insulin receptor substrate 4, and mice lacking the SOCS-6 gene exhibit mild growth retardation. Mol Cell Biol 22(13):4567-4578. https://doi.org/10.1128/mcb.22.13. 4567-4578.2002

256. Banks AS, Li J, McKeag L, Hribal ML, Kashiwada M, Accili D, Rothman PB (2005) Deletion of SOCS7 leads to enhanced insulin action and enlarged islets of Langerhans. J Clin Invest 115(9):2462-2471. https://doi.org/10.1172/jci23853 
257. Mathews LS, Hammer RE, Behringer RR, D'Ercole AJ, Bell GI, Brinster RL, Palmiter RD (1988) Growth enhancement of transgenic mice expressing human insulin-like growth factor I. Endocrinology 123(6):2827-2833. https://doi.org/10.1210/ endo-123-6-2827

258. Doi T, Striker LJ, Gibson CC, Agodoa LY, Brinster RL, Striker GE (1990) Glomerular lesions in mice transgenic for growth hormone and insulinlike growth factor-I. I. Relationship between increased glomerular size and mesangial sclerosis. Am J Pathol 137(3):541-552

259. DeChiara TM, Efstratiadis A, Robertson EJ (1990) A growthdeficiency phenotype in heterozygous mice carrying an insulin-like growth factor II gene disrupted by targeting. Nature 345(6270):78-80. https://doi.org/10.1038/345078a0

260. Liu JP, Baker J, Perkins AS, Robertson EJ, Efstratiadis A (1993) Mice carrying null mutations of the genes encoding insulin-like growth factor I (Igf-1) and type 1 IGF receptor (Igf1r). Cell 75(1):59-72

261. Baker J, Liu JP, Robertson EJ, Efstratiadis A (1993) Role of insulin-like growth factors in embryonic and postnatal growth. Cell 75(1):73-82

262. Lupu F, Terwilliger JD, Lee K, Segre GV, Efstratiadis A (2001) Roles of growth hormone and insulin-like growth factor 1 in mouse postnatal growth. Dev Biol 229(1):141-162. https://doi. org/10.1006/dbio.2000.9975

263. Liao L, Dearth RK, Zhou S, Britton OL, Lee AV, Xu J (2006) Liver-specific overexpression of the insulin-like growth factor-I enhances somatic growth and partially prevents the effects of growth hormone deficiency. Endocrinology 147(8):3877-3888. https://doi.org/10.1210/en.2005-1537

264. Dearth RK, Kuiatse I, Wang YF, Liao L, Hilsenbeck SG, Brown PH, Xu J, Lee AV (2011) A moderate elevation of circulating levels of IGF-I does not alter ErbB2 induced mammary tumorigenesis. BMC Cancer 11:377. https://doi.org/10.1186/ 1471-2407-11-377

265. Wu Y, Sun H, Yakar S, LeRoith D (2009) Elevated levels of insulin-like growth factor (IGF)-I in serum rescue the severe growth retardation of IGF-I null mice. Endocrinology 150(9):43954403. https://doi.org/10.1210/en.2009-0272

266. Elis S, Courtland HW, Wu Y, Rosen CJ, Sun H, Jepsen KJ, Majeska RJ, Yakar S (2010) Elevated serum levels of IGF-1 are sufficient to establish normal body size and skeletal properties even in the absence of tissue IGF-1. J Bone Miner Res 25(6):1257-1266. https://doi.org/10.1002/jbmr.20

267. Wu Y, Sun H, Basta-Pljakic J, Cardoso L, Kennedy OD, Jasper H, Domene H, Karabatas L, Guida C, Schaffler MB, Rosen CJ, Yakar S (2013) Serum IGF-1 is insufficient to restore skeletal size in the total absence of the growth hormone receptor. J Bone Miner Res 28(7):1575-1586. https://doi.org/10.1002/jbmr.1920

268. Yakar S, Liu JL, Stannard B, Butler A, Accili D, Sauer B, LeRoith D (1999) Normal growth and development in the absence of hepatic insulin-like growth factor I. Proc Natl Acad Sci USA 96(13):7324-7329. https://doi.org/10.1073/pnas.96.13. 7324

269. Novosyadlyy R, Leroith D (2012) Insulin-like growth factors and insulin: at the crossroad between tumor development and longevity. J Gerontol A 67(6):640-651. https://doi.org/10.1093/ gerona/gls065

270. Sjogren K, Liu JL, Blad K, Skrtic S, Vidal O, Wallenius V, LeRoith D, Tornell J, Isaksson OG, Jansson JO, Ohlsson C (1999) Liver-derived insulin-like growth factor I (IGF-I) is the principal source of IGF-I in blood but is not required for postnatal body growth in mice. Proc Natl Acad Sci U S A 96(12):70887092. https://doi.org/10.1073/pnas.96.12.7088

271. Sjogren K, Wallenius K, Liu JL, Bohlooly YM, Pacini G, Svensson L, Tornell J, Isaksson OG, Ahren B, Jansson JO, Ohlsson C
(2001) Liver-derived IGF-I is of importance for normal carbohydrate and lipid metabolism. Diabetes 50(7):1539-1545. https:// doi.org/10.2337/diabetes.50.7.1539

272. Svensson J, Sjogren K, Faldt J, Andersson N, Isaksson O, Jansson JO, Ohlsson C (2011) Liver-derived IGF-I regulates mean life span in mice. PLoS ONE 6(7):e22640. https://doi.org/10.1371/ journal.pone. 0022640

273. Kloting N, Koch L, Wunderlich T, Kern M, Ruschke K, Krone W, Bruning JC, Bluher M (2008) Autocrine IGF-1 action in adipocytes controls systemic IGF-1 concentrations and growth. Diabetes 57(8):2074-2082. https://doi.org/10.2337/db07-1538

274. Lee KY, Russell SJ, Ussar S, Boucher J, Vernochet C, Mori MA, Smyth G, Rourk M, Cederquist C, Rosen ED, Kahn BB, Kahn CR (2013) Lessons on conditional gene targeting in mouse adipose tissue. Diabetes 62(3):864-874. https://doi.org/10.2337/ db12-1089

275. Krueger KC, Costa MJ, Du H, Feldman BJ (2014) Characterization of Cre recombinase activity for in vivo targeting of adipocyte precursor cells. Stem Cell Reports 3(6):1147-1158. https://doi. org/10.1016/j.stemcr.2014.10.009

276. Martens K, Bottelbergs A, Baes M (2010) Ectopic recombination in the central and peripheral nervous system by aP2/FABP4Cre mice: implications for metabolism research. FEBS Lett 584(5):1054-1058. https://doi.org/10.1016/j.febslet.2010.01.061

277. Boucher J, Softic S, El Ouaamari A, Krumpoch MT, Kleinridders A, Kulkarni RN, O’Neill BT, Kahn CR (2016) Differential roles of insulin and IGF-1 receptors in adipose tissue development and function. Diabetes 65(8):2201-2213. https://doi.org/10.2337/ db16-0212

278. Kappeler L, De Magalhaes Filho C, Dupont J, Leneuve P, Cervera P, Perin L, Loudes C, Blaise A, Klein R, Epelbaum J, Le Bouc Y, Holzenberger M (2008) Brain IGF-1 receptors control mammalian growth and lifespan through a neuroendocrine mechanism. PLoS Biol 6(10):e254. https://doi.org/10.1371/journal. pbio. 0060254

279. Coleman ME, DeMayo F, Yin KC, Lee HM, Geske R, Montgomery C, Schwartz RJ (1995) Myogenic vector expression of insulin-like growth factor I stimulates muscle cell differentiation and myofiber hypertrophy in transgenic mice. J Biol Chem 270(20):12109-12116. https://doi.org/10.1074/jbc.270.20.12109

280. Fernandez AM, Kim JK, Yakar S, Dupont J, Hernandez-Sanchez C, Castle AL, Filmore J, Shulman GI, Le Roith D (2001) Functional inactivation of the IGF-I and insulin receptors in skeletal muscle causes type 2 diabetes. Genes Dev 15(15):1926-1934. https://doi.org/10.1101/gad.908001

281. O'Neill BT, Lauritzen HP, Hirshman MF, Smyth G, Goodyear LJ, Kahn CR (2015) Differential role of insulin/IGF-1 receptor signaling in muscle growth and glucose homeostasis. Cell Rep 11(8):1220-1235. https://doi.org/10.1016/j.celrep.2015.04.037

282. O’Neill BT, Lee KY, Klaus K, Softic S, Krumpoch MT, Fentz J, Stanford KI, Robinson MM, Cai W, Kleinridders A, Pereira RO, Hirshman MF, Abel ED, Accili D, Goodyear LJ, Nair KS, Kahn CR (2016) Insulin and IGF-1 receptors regulate FoxO-mediated signaling in muscle proteostasis. J Clin Invest 126(9):3433-3446. https://doi.org/10.1172/jci86522

283. Reiss K, Cheng W, Ferber A, Kajstura J, Li P, Li B, Olivetti G, Homcy CJ, Baserga R, Anversa P (1996) Overexpression of insulin-like growth factor-1 in the heart is coupled with myocyte proliferation in transgenic mice. Proc Natl Acad Sci U S A 93(16):8630-8635. https://doi.org/10.1073/pnas.93.16.8630

284. Santini MP, Tsao L, Monassier L, Theodoropoulos C, Carter J, Lara-Pezzi E, Slonimsky E, Salimova E, Delafontaine P, Song YH, Bergmann M, Freund C, Suzuki K, Rosenthal N (2007) Enhancing repair of the mammalian heart. Circ Res 100(12):1732-1740. https://doi.org/10.1161/circresaha.107. 148791 
285. Kim J, Wende AR, Sena S, Theobald HA, Soto J, Sloan C, Wayment BE, Litwin SE, Holzenberger M, LeRoith D, Abel ED (2008) Insulin-like growth factor I receptor signaling is required for exercise-induced cardiac hypertrophy. Mol Endocrinol 22(11):2531-2543. https://doi.org/10.1210/me.2008-0265

286. Moellendorf S, Kessels C, Peiseler L, Raupach A, Jacoby C, Vogt N, Lindecke A, Koch L, Bruning J, Heger J, Kohrer K, Godecke A (2012) IGF-IR signaling attenuates the age-related decline of diastolic cardiac function. Am J Physiol Endocrinol Metab 303(2):E213-222. https://doi.org/10.1152/ajpendo.00538. 2011

287. Imrie H, Viswambharan $\mathrm{H}$, Sukumar $\mathrm{P}$, Abbas A, Cubbon RM, Yuldasheva N, Gage M, Smith J, Galloway S, Skromna A, Rashid ST, Futers TS, Xuan S, Gatenby VK, Grant PJ, Channon KM, Beech DJ, Wheatcroft SB, Kearney MT (2012) Novel role of the IGF-1 receptor in endothelial function and repair: studies in endothelium-targeted IGF-1 receptor transgenic mice. Diabetes 61(9):2359-2368. https://doi.org/10.2337/db11-1494

288. Abbas A, Imrie H, Viswambharan H, Sukumar P, Rajwani A, Cubbon RM, Gage M, Smith J, Galloway S, Yuldeshava N, Kahn M, Xuan S, Grant PJ, Channon KM, Beech DJ, Wheatcroft SB, Kearney MT (2011) The insulin-like growth factor-1 receptor is a negative regulator of nitric oxide bioavailability and insulin sensitivity in the endothelium. Diabetes 60(8):2169-2178. https:// doi.org/10.2337/db11-0197

289. Liang M, Woodard LE, Liang A, Luo J, Wilson MH, Mitch WE, Cheng J (2015) Protective role of insulin-like growth factor-1 receptor in endothelial cells against unilateral ureteral obstruction-induced renal fibrosis. Am J Pathol 185(5):1234-1250. https://doi.org/10.1016/j.ajpath.2015.01.027

290. Spadaro O, Goldberg EL, Camell CD, Youm YH, Kopchick JJ, Nguyen KY, Bartke A, Sun LY, Dixit VD (2016) Growth hormone receptor deficiency protects against age-related NLRP3 inflammasome activation and immune senescence. Cell Rep 14(7):1571-1580. https://doi.org/10.1016/j.celrep.2016.01.044

291. Spadaro O, Camell CD, Bosurgi L, Nguyen KY, Youm YH, Rothlin CV, Dixit VD (2017) IGF1 shapes macrophage activation in response to immunometabolic challenge. Cell Rep 19(2):225234. https://doi.org/10.1016/j.celrep.2017.03.046

292. Higashi Y, Sukhanov S, Shai SY, Danchuk S, Tang R, Snarski P, Li Z, Lobelle-Rich P, Wang M, Wang D, Yu H, Korthuis R, Delafontaine $P$ (2016) Insulin-like growth factor-1 receptor deficiency in macrophages accelerates atherosclerosis and induces an unstable plaque phenotype in apolipoprotein E-deficient mice. Circulation 133(23):2263-2278. https://doi.org/10.1161/circu lationaha.116.021805

293. Zhao G, Monier-Faugere MC, Langub MC, Geng Z, Nakayama T, Pike JW, Chernausek SD, Rosen CJ, Donahue LR, Malluche HH, Fagin JA, Clemens TL (2000) Targeted overexpression of insulin-like growth factor I to osteoblasts of transgenic mice: increased trabecular bone volume without increased osteoblast proliferation. Endocrinology 141(7):2674-2682. https://doi.org/ 10.1210/endo.141.7.7585

294. Jiang J, Lichtler AC, Gronowicz GA, Adams DJ, Clark SH, Rosen CJ, Kream BE (2006) Transgenic mice with osteoblasttargeted insulin-like growth factor-I show increased bone remodeling. Bone 39(3):494-504. https://doi.org/10.1016/j.bone.2006. 02.068

295. Rutter MM, Markoff E, Clayton L, Akeno N, Zhao G, Clemens TL, Chernausek SD (2005) Osteoblast-specific expression of insulin-like growth factor-1 in bone of transgenic mice induces insulin-like growth factor binding protein-5. Bone 36(2):224 231. https://doi.org/10.1016/j.bone.2004.10.005

296. Zhang M, Xuan S, Bouxsein ML, von Stechow D, Akeno N, Faugere MC, Malluche H, Zhao G, Rosen CJ, Efstratiadis A, Clemens TL (2002) Osteoblast-specific knockout of the insulin-like growth factor (IGF) receptor gene reveals an essential role of IGF signaling in bone matrix mineralization. J Biol Chem 277(46):44005-44012. https://doi.org/10.1074/jbc.M208265200

297. Kubota T, Elalieh HZ, Saless N, Fong C, Wang Y, Babey M, Cheng Z, Bikle DD (2013) Insulin-like growth factor-1 receptor in mature osteoblasts is required for periosteal bone formation induced by reloading. Acta Astronaut 92(1):73-78. https://doi. org/10.1016/j.actaastro.2012.08.007

298. Wang T, Wang Y, Menendez A, Fong C, Babey M, Tahimic CG, Cheng Z, Li A, Chang W, Bikle DD (2015) Osteoblast-Specific Loss of IGF1R Signaling Results in Impaired Endochondral Bone Formation During Fracture Healing. J Bone Miner Res 30(9):1572-1584. https://doi.org/10.1002/jbmr.2510

299. Govoni KE, Lee SK, Chung YS, Behringer RR, Wergedal JE, Baylink DJ, Mohan S (2007) Disruption of insulin-like growth factor-I expression in type IIalphaI collagen-expressing cells reduces bone length and width in mice. Physiol Genomics 30(3):354-362. https://doi.org/10.1152/physiolgenomics.00022. 2007

300. Govoni KE, Wergedal JE, Florin L, Angel P, Baylink DJ, Mohan $S$ (2007) Conditional deletion of insulin-like growth factor-I in collagen type 1alpha2-expressing cells results in postnatal lethality and a dramatic reduction in bone accretion. Endocrinology 148(12):5706-5715. https://doi.org/10.1210/en.2007-0608

301. Sheng MH, Zhou XD, Bonewald LF, Baylink DJ, Lau KH (2013) Disruption of the insulin-like growth factor-1 gene in osteocytes impairs developmental bone growth in mice. Bone 52(1):133144. https://doi.org/10.1016/j.bone.2012.09.027

302. Yakar S, Werner H, Rosen CJ (2018) Insulin-like growth factors: actions on the skeleton. J Mol Endocrinol 61(1):T115-T137. https://doi.org/10.1530/jme-17-0298

303. Baumgarten SC, Armouti M, Ko C, Stocco C (2017) IGF1R expression in ovarian granulosa cells is essential for steroidogenesis, follicle survival, and fertility in female mice. Endocrinology 158(7):2309-2318. https://doi.org/10.1210/en.2017-00146

304. Xuan S, Kitamura T, Nakae J, Politi K, Kido Y, Fisher PE, Morroni M, Cinti S, White MF, Herrera PL, Accili D, Efstratiadis A (2002) Defective insulin secretion in pancreatic beta cells lacking type 1 IGF receptor. J Clin Invest 110(7):1011-1019. https://doi. org/10.1172/jci15276

305. Kulkarni RN, Holzenberger M, Shih DQ, Ozcan U, Stoffel M, Magnuson MA, Kahn CR (2002) beta-cell-specific deletion of the Igf1 receptor leads to hyperinsulinemia and glucose intolerance but does not alter beta-cell mass. Nat Genet 31(1):111-115. https://doi.org/10.1038/ng872

306. Ueki K, Okada T, Hu J, Liew CW, Assmann A, Dahlgren GM, Peters JL, Shackman JG, Zhang M, Artner I, Satin LS, Stein R, Holzenberger M, Kennedy RT, Kahn CR, Kulkarni RN (2006) Total insulin and IGF-I resistance in pancreatic beta cells causes overt diabetes. Nat Genet 38(5):583-588. https://doi.org/10. 1038/ng 1787

307. Neirijnck Y, Calvel P, Kilcoyne KR, Kuhne F, Stevant I, Griffeth RJ, Pitetti JL, Andric SA, Hu MC, Pralong F, Smith LB, Nef S (2018) Insulin and IGF1 receptors are essential for the development and steroidogenic function of adult Leydig cells. Faseb J 32(6):3321-3335. https://doi.org/10.1096/fj.201700769RR

308. Romero CJ, Ng Y, Luque RM, Kineman RD, Koch L, Bruning JC, Radovick S (2010) Targeted deletion of somatotroph insulinlike growth factor-I signaling in a cell-specific knockout mouse model. Mol Endocrinol 24(5):1077-1089. https://doi.org/10. 1210/me.2009-0393

309. Gahete MD, Cordoba-Chacon J, Anadumaka CV, Lin Q, Bruning JC, Kahn CR, Luque RM, Kineman RD (2011) Elevated GH/ IGF-I, due to somatotrope-specific loss of both IGF-I and insulin receptors, alters glucose homeostasis and insulin sensitivity in 
a diet-dependent manner. Endocrinology 152(12):4825-4837. https://doi.org/10.1210/en.2011-1447

310. Muller K, Fuhrer D, Mittag J, Kloting N, Bluher M, Weiss RE, Many MC, Schmid KW, Krohn K (2011) TSH compensates thyroid-specific IGF-I receptor knockout and causes papillary thyroid hyperplasia. Mol Endocrinol 25(11):1867-1879. https:// doi.org/10.1210/me.2011-0065

311. Bach LA (2018) IGF-binding proteins. J Mol Endocrinol 61(1):T11-T28. https://doi.org/10.1530/JME-17-0254

312. D'Ercole AJ, Ye P, Dai Z (1995) Human insulin-like growth factor binding protein-1 (hIGFBP-1) transgenic mice: insights into hIGFBP-1 regulation and actions. Prog Growth Factor Res 6(2-4):417-423. https://doi.org/10.1016/0955-2235(95)00010-0

313. Schneider MR, Lahm H, Wu M, Hoeflich A, Wolf E (2000) Transgenic mouse models for studying the functions of insulinlike growth factor-binding proteins. Faseb J 14(5):629-640. https://doi.org/10.1096/fasebj.14.5.629

314. Ben Lagha N, Seurin D, Le Bouc Y, Binoux M, Berdal A, Menuelle $P$, Babajko $S$ (2006) Insulin-like growth factor binding protein (IGFBP-1) involvement in intrauterine growth retardation: study on IGFBP-1 overexpressing transgenic mice. Endocrinology 147(10):4730-4737. https://doi.org/10.1210/en.2006-0171

315. Rajkumar K, Krsek M, Dheen ST, Murphy LJ (1996) Impaired glucose homeostasis in insulin-like growth factor binding protein-1 transgenic mice. J Clin Invest 98(8):1818-1825. https:// doi.org/10.1172/jci118982

316. Froment P, Seurin D, Hembert S, Levine JE, Pisselet C, Monniaux D, Binoux M, Monget P (2002) Reproductive abnormalities in human IGF binding protein-1 transgenic female mice. Endocrinology 143(5):1801-1808. https://doi.org/10.1210/endo. 143.5.8815

317. Doublier S, Seurin D, Fouqueray B, Verpont MC, Callard P, Striker LJ, Striker GE, Binoux M, Baud L (2000) Glomerulosclerosis in mice transgenic for human insulin-like growth factorbinding protein-1. Kidney Int 57(6):2299-2307. https://doi.org/ 10.1046/j.1523-1755.2000.00090.x

318. Leu JI, Crissey MA, Craig LE, Taub R (2003) Impaired hepatocyte DNA synthetic response posthepatectomy in insulin-like growth factor binding protein 1-deficient mice with defects in $\mathrm{C} /$ EBP beta and mitogen-activated protein kinase/extracellular signal-regulated kinase regulation. Mol Cell Biol 23(4):1251-1259. https://doi.org/10.1128/mcb.23.4.1251-1259.2003

319. Gray A, Aronson WJ, Barnard RJ, Mehta H, Wan J, Said J, Cohen P, Galet C (2011) Global Igfbp1 deletion does not affect prostate cancer development in a c-Myc transgenic mouse model. J Endocrinol 211(3):297-304. https://doi.org/10.1530/JOE-11-0240

320. Hoeflich A, Wu M, Mohan S, Foll J, Wanke R, Froehlich T, Arnold GJ, Lahm H, Kolb HJ, Wolf E (1999) Overexpression of insulin-like growth factor-binding protein-2 in transgenic mice reduces postnatal body weight gain. Endocrinology 140(12):5488-5496. https://doi.org/10.1210/endo.140.12.7169

321. Wheatcroft SB, Kearney MT, Shah AM, Ezzat VA, Miell JR, Modo M, Williams SC, Cawthorn WP, Medina-Gomez G, VidalPuig A, Sethi JK, Crossey PA (2007) IGF-binding protein-2 protects against the development of obesity and insulin resistance. Diabetes 56(2):285-294. https://doi.org/10.2337/db06-0436

322. Diehl D, Hessel E, Oesterle D, Renner-Muller I, Elmlinger M, Langhammer M, Gottlicher M, Wolf E, Lahm H, Hoeflich A (2009) IGFBP-2 overexpression reduces the appearance of dysplastic aberrant crypt foci and inhibits growth of adenomas in chemically induced colorectal carcinogenesis. Int J Cancer 124(9):2220-2225. https://doi.org/10.1002/ijc.24193

323. Wood TL, Rogler LE, Czick ME, Schuller AG, Pintar JE (2000) Selective alterations in organ sizes in mice with a targeted disruption of the insulin-like growth factor binding protein-2 gene. Mol
Endocrinol 14(9):1472-1482. https://doi.org/10.1210/mend.14.9. 0517

324. Liu Y, Song C, Shen F, Zhang J, Song SW (2019) IGFBP2 promotes immunosuppression associated with its mesenchymal induction and FcgammaRIIB phosphorylation in glioblastoma. PLoS ONE 14(9):e0222999. https://doi.org/10.1371/journal. pone.0222999

325. Murphy LJ, Rajkumar K, Molnar P (1995) Phenotypic manifestations of insulin-like growth factor binding protein-1 (IGFBP-1) and IGFBP-3 overexpression in transgenic mice. Prog Growth Factor Res 6(2-4):425-432. https://doi.org/10.1016/09552235(95)00026-7

326. Modric T, Silha JV, Shi Z, Gui Y, Suwanichkul A, Durham SK, Powell DR, Murphy LJ (2001) Phenotypic manifestations of insulin-like growth factor-binding protein-3 overexpression in transgenic mice. Endocrinology 142(5):1958-1967. https://doi. org/10.1210/endo.142.5.8165

327. Nguyen KH, Yao XH, Erickson AG, Mishra S, Nyomba BL (2015) Glucose intolerance in aging male IGFBP-3 transgenic mice: differential effects of human IGFBP-3 and its mutant IGFBP-3 devoid of IGF binding ability. Endocrinology 156(2):462-474. https://doi.org/10.1210/en.2014-1271

328. Ning Y, Schuller AG, Bradshaw S, Rotwein P, Ludwig T, Frystyk J, Pintar JE (2006) Diminished growth and enhanced glucose metabolism in triple knockout mice containing mutations of insulin-like growth factor binding protein-3, -4 , and -5 . Mol Endocrinol 20(9):2173-2186. https://doi.org/10.1210/me.2005-0196

329. Yamada PM, Mehta HH, Hwang D, Roos KP, Hevener AL, Lee KW (2010) Evidence of a role for insulin-like growth factor binding protein (IGFBP)-3 in metabolic regulation. Endocrinology 151(12):5741-5750. https://doi.org/10.1210/en.2010-0672

330. Wang YA, Sun Y, Palmer J, Solomides C, Huang LC, Shyr Y, Dicker AP, Lu B (2017) IGFBP3 modulates lung tumorigenesis and cell growth through IGF1 signaling. Mol Cancer Res 15(7):896-904. https://doi.org/10.1158/1541-7786.mcr-16-0390

331. Wang J, Niu W, Witte DP, Chernausek SD, Nikiforov YE, Clemens TL, Sharifi B, Strauch AR, Fagin JA (1998) Overexpression of insulin-like growth factor-binding protein-4 (IGFBP-4) in smooth muscle cells of transgenic mice through a smooth muscle alpha-actin-IGFBP-4 fusion gene induces smooth muscle hypoplasia. Endocrinology 139(5):2605-2614. https://doi.org/10. 1210/endo.139.5.5986

332. Ning Y, Schuller AG, Conover CA, Pintar JE (2008) Insulinlike growth factor (IGF) binding protein-4 is both a positive and negative regulator of IGF activity in vivo. Mol Endocrinol 22(5):1213-1225. https://doi.org/10.1210/me.2007-0536

333. Maridas DE, DeMambro VE, Le PT, Mohan S, Rosen CJ (2017) IGFBP4 is required for adipogenesis and influences the distribution of adipose depots. Endocrinology 158(10):3488-3500. https://doi.org/10.1210/en.2017-00248

334. Maridas DE, DeMambro VE, Le PT, Nagano K, Baron R, Mohan S, Rosen CJ (2017) IGFBP-4 regulates adult skeletal growth in a sex-specific manner. J Endocrinol 233(1):131-144. https://doi. org/10.1530/joe-16-0673

335. Tonner E, Barber MC, Allan GJ, Beattie J, Webster J, Whitelaw CB, Flint DJ (2002) Insulin-like growth factor binding protein-5 (IGFBP-5) induces premature cell death in the mammary glands of transgenic mice. Development 129(19):4547-4557

336. Salih DA, Tripathi G, Holding C, Szestak TA, Gonzalez MI, Carter EJ, Cobb LJ, Eisemann JE, Pell JM (2004) Insulin-like growth factor-binding protein 5 (Igfbp5) compromises survival, growth, muscle development, and fertility in mice. Proc Natl Acad Sci U S A 101(12):4314-4319. https://doi.org/10.1073/ pnas.0400230101

337. Devlin RD, Du Z, Buccilli V, Jorgetti V, Canalis E (2002) Transgenic mice overexpressing insulin-like growth factor binding 
protein-5 display transiently decreased osteoblastic function and osteopenia. Endocrinology 143(10):3955-3962. https://doi.org/ 10.1210/en.2002-220129

338. Ning Y, Hoang B, Schuller AG, Cominski TP, Hsu MS, Wood TL, Pintar JE (2007) Delayed mammary gland involution in mice with mutation of the insulin-like growth factor binding protein 5 gene. Endocrinology 148(5):2138-2147. https://doi.org/10.1210/ en.2006-0041

339. Gleason CE, Ning Y, Cominski TP, Gupta R, Kaestner KH, Pintar JE, Birnbaum MJ (2010) Role of insulin-like growth factorbinding protein 5 (IGFBP5) in organismal and pancreatic betacell growth. Mol Endocrinol 24(1):178-192. https://doi.org/10. 1210/me.2009-0167

340. Bienvenu G, Seurin D, Grellier P, Froment P, Baudrimont M, Monget P, Le Bouc Y, Babajko S (2004) Insulin-like growth factor binding protein- 6 transgenic mice: postnatal growth, brain development, and reproduction abnormalities. Endocrinology 145(5):2412-2420. https://doi.org/10.1210/en.2003-1196

341. Bienvenu G, Seurin D, Le Bouc Y, Even P, Babajko S, Magnan C (2005) Dysregulation of energy homeostasis in mice overexpressing insulin-like growth factor-binding protein 6 in the brain. Diabetologia 48(6):1189-1197. https://doi.org/10.1007/ s00125-005-1767-6

342. Silha JV, Gui Y, Modric T, Suwanichkul A, Durham SK, Powell DR, Murphy LJ (2001) Overexpression of the acid-labile subunit of the IGF ternary complex in transgenic mice. Endocrinology 142(10):4305-4313. https://doi.org/10.1210/endo.142.10.8427

343. Ueki I, Ooi GT, Tremblay ML, Hurst KR, Bach LA, Boisclair YR (2000) Inactivation of the acid labile subunit gene in mice results in mild retardation of postnatal growth despite profound disruptions in the circulating insulin-like growth factor system. Proc Natl Acad Sci U S A 97(12):6868-6873. https://doi.org/10. 1073/pnas.120172697

344. Courtland HW, DeMambro V, Maynard J, Sun H, Elis S, Rosen C, Yakar S (2010) Sex-specific regulation of body size and bone slenderness by the acid labile subunit. J Bone Miner Res 25(9):2059-2068. https://doi.org/10.1002/jbmr.94

345. Oxvig C (2015) The role of PAPP-A in the IGF system: location, location, location. J Cell Commun Signal 9(2):177-187. https:// doi.org/10.1007/s12079-015-0259-9

346. Conover CA, Bale LK, Overgaard MT, Johnstone EW, Laursen UH, Fuchtbauer EM, Oxvig C, van Deursen J (2004) Metalloproteinase pregnancy-associated plasma protein $\mathrm{A}$ is a critical growth regulatory factor during fetal development. Development 131(5):1187-1194. https://doi.org/10.1242/dev.00997

347. Nyegaard M, Overgaard MT, Su YQ, Hamilton AE, Kwintkiewicz J, Hsieh M, Nayak NR, Conti M, Conover CA, Giudice LC (2010) Lack of functional pregnancy-associated plasma proteinA (PAPPA) compromises mouse ovarian steroidogenesis and female fertility. Biol Reprod 82(6):1129-1138. https://doi.org/ 10.1095/biolreprod.109.079517

348. Conover CA, Bale LK (2007) Loss of pregnancy-associated plasma protein A extends lifespan in mice. Aging Cell 6(5):727729. https://doi.org/10.1111/j.1474-9726.2007.00328.x

349. Conover CA, Mason MA, Levine JA, Novak CM (2008) Metabolic consequences of pregnancy-associated plasma protein-A deficiency in mice: exploring possible relationship to the longevity phenotype. J Endocrinol 198(3):599-605. https://doi.org/10. 1677/joe-08-0179

350. Conover CA, Bale LK, Oxvig C (2016) Targeted inhibition of pregnancy-associated plasma protein-a activity reduces atherosclerotic plaque burden in mice. J Cardiovasc Transl Res 9(1):77-79. https://doi.org/10.1007/s12265-015-9666-9

351. Conover CA, Oxvig C (2017) PAPP-A: a promising therapeutic target for healthy longevity. Aging Cell 16(2):205-209. https:// doi.org/10.1111/acel.12564

352. Conover CA, Bale LK, Nair KS (2016) Comparative gene expression and phenotype analyses of skeletal muscle from aged wildtype and PAPP-A-deficient mice. Exp Gerontol 80:36-42. https:// doi.org/10.1016/j.exger.2016.04.005

353. Bale LK, West SA, Conover CA (2017) Inducible knockdown of pregnancy-associated plasma protein-A gene expression in adult female mice extends life span. Aging Cell 16(4):895-897. https:// doi.org/10.1111/acel.12624

354. Hjortebjerg R, Berryman DE, Comisford R, List EO, Oxvig C, Bjerre M, Frystyk J, Kopchick JJ (2018) Depot-specific and GH-dependent regulation of IGF binding protein-4, pregnancyassociated plasma protein-A, and stanniocalcin-2 in murine adipose tissue. Growth Horm IGF Res 39:54-61. https://doi.org/10. 1016/j.ghir.2018.01.001

Publisher's Note Springer Nature remains neutral with regard to jurisdictional claims in published maps and institutional affiliations. 